


\section{Parametric Kinetics}

Allan Clayton

PROJECT SUBMITTED IN PARTIAL FULFILLMENT OF THE REQUIREMENTS FOR THE DEGREE OF

Master of Architecture (Professional)

At the

SCHOOL OF ARCHITECTURE AND DESIGN

VICTORIA UNIVERSITY OF WELLINGTON

2014 


\section{Acknowledgments}

I would like to thank Tane Moleta and Professor Jules Moloney for their guidance throughout the course of this thesis.

I would also like to thank my family and friends; Lyn Peter, Kelsi, Tom, Jamie and Geoff. You guys have

provided invaluable support and guidance, without

which this thesis would not have been the same. 


\section{Abstract}

This thesis examines how parametric modelling can be used in

the design process to aid in the development of a kinetic architec-

tural skin. A parametric scripting process has been used to contro

morphological change in architectural models. This has enabled the

description of responsive kinetic form, and has facilitated a process

of iterative design development. At the conceptual stage, weather

data has been used to generate responsive form, enabling explora-

tion into a range of potential designs. At the developmental stage,

static and dynamic iterative modelling has been used to inform the

development of a final skin system. The process of iterative mode-

ling has introduced a high level of feedback to the design process,

allowing for a thoroughly developed architectural system that per-

forms well against established design criteria. This thesis proposes

that parametric modelling is a credible tool for the development of

dynamic architectural systems. 


\section{Contents}

\section{Abstract}

Introduction

Section One: Scope and process

1.0 Kinetic and responsive architecture

1.1 Digital design in architecture

$1.2 \quad$ Position

10

11

1.3 Methodology

Section Two: Parametric modelling in the design process

Parametric modelling at the conceptual design stage

Client and programme

14

Parametric modelling in design development

Section Three: Developed design

3.0 Kinetic skin system

$3.1 \quad$ Kumototo

3.2 Te Aro

Section Four: Reflection

Works Cited

Appendix 


\section{Introduction}

Tristan d'Estrée Sterk states that an emerging generation of architects are embracing digital design methodologies in order to engage with increasingly complex architectural problems (18). 17) through to manufacturing (Anderson and Tang, 91), the use of digital methodologies in the design process offers an intriguing field for research. Adding to the work of Sterk's 'digital design design an kinetic skin.

Utilising parametric modelling processes for the devent of deve of architectural focus into align several arare: environmentally responsive architecture, netic skin systens and digital parameric design.

The term responsive architecture was first used is used to classify architecture which is able to is used to clachify architecture which is able to connding environmental conditions (Sterk, 86).

Kinetic skin systems can be responsive and are often used as mechanisms for environmental control (Fox, 3); they can also take the form of media facades (Molon 201). media facades (Moloney, 201).

Parametric modelling is a digital design procedure which gives programmable control to the digital modelling process.
This design exegesis is comprised of four sections:

Section one outlines a history of kinetic architec ture, responsive architecture and digital design in architecture. This background acts to provide a contextual foundation, from which the scope and intent of this thesis is expanded upon.

Section two will document the process of the development of a responsive skin system, forming the core design research of this work.

Section three presents this design research as a series of developed designs.

Section four concludes this thesis with design reflection and discussion. 


\subsection{Kinetic and responsive architecture}

The contemporary history of kinetic architecture can be traced back to the Futurist movement of the early $20^{\text {th }}$ Century. The works of Umberto Boccioni (Unique Forms of Continuity in Space, 1913), Marcel Duchamp (Bicycle Wheel, 1913) and Giamcomo Balla (Abstract Speed + Sound, 1913-1914) represents a selection of creative practices that engaged critically with kinetics (Hansen, 4) Subsequently, Richard Buckminster Fuller explor d architecture with kinetic and responsive qualities in both his 4D House (1927) and Dymaxion qualltes in bich his 40 House (1927) and Dymaxion House (1933). The two houses examined notions of mobity through the utilisation of light-weight and prefabricated building elements. At another scale, Ron Herron proposed city wide architectural mobility in his essay Walking City (1964). While the ideas of Buckminster Fuller and Herron share common ground in their experimental approach toward new technologies, their chosen modes of practice were in contrast. Walking City was an entirely paper based exercise which comprised of ideas intended to challenge contemporary discourse, whereas Buckminster Fuller's work comprised of a research and development oriented approach to practice.

Tomasz Jaskiewicz writes that in the 1960's, the science of cybernetics allowed for a systems oriented understanding of the emerging relationships between digital technologies and responsive architecture (34). Sterk explains how cybernetics provided a novel prospect for the future of architecture (1):

As a mechanism, architects discovered that feedback could be incorporated directly into buildings via the use of responsive systems, and that these systems would enable spaces and people to enter into a dynamic relationship.

The cybernetician Gordon Pask developed an under- standing of how "interactions lead to the creation of knowledge" in his work on Conversation Theory [Jaskiewicz, 34]. Sterk writes that Pask's contemporary, Nicholas Negroponte, was the first to use the term responsive architecture (86). Negroponte stated that responsive architecture is " .. (the) product of into built spaces (St) performing, more rational buildings are the result" (Sterk, 86).

In Using Actuated Tensegrity Structures to produce a Responsive Architecture, Sterk examines three built examples of responsive architecture in order to develop a classification that is relevant to current reseach (86)(See figures 1.2-1.4). Sterk proposes that the underlying features of these works are: “. their dependence upon computing their connecting digtandents and their desire to make contin the real world, and their desire to make continuously altering forms of architecture (86). From these propositions, he de velops 3 categories in which responsive architecture can operate (86):

1. responsive architecture must be able to cope with the dynamic loading conditions that result from environmental changes

2. the adjustments made in response to these changes must be controlled

3. all responsive buildings must provide shelter from changing environmental conditions

By not addressing the subject of shelter, traditional notions 1 or 2 which gives a broad scope to what respon sive archich gives a broad scope to what responScofidio's Blur building. Whis is evident in Diler and tural elements do not provide environmental shelter and form is predominantly defined by water vapour. Provision for shelter is also not evident in the Aegis Hyposurface; however, the potential for this work to provide shelter with further development is high compared to the Blur building, given its more traditional building fabric. NOX's Preshwater Pavilion does not provide shelter or physically controllablion does not prave sherts, opting instead for audio visual responses to environment which operate within a static envelope.

It is evident from the 3 categories of responsive architecture outlined by Sterk, that there is scope within the field of digitally controlled responsive wrchitecture to develop work which actively responds to

In his seminal publication Sustainable Applications of in selligent Systems, Michael A. Fox breaks kinetic of Intellignt Systems, Michael A. Fx breaks kic architectural facades (4):

1. Embedded-Kinetics are confined to the movement of individual parts, but do not affect greater structure.

2. Dynamic-Architecture which can move as a whole. Described by Fox as being "Transformable and Incremental kinetic" systems.

3. Deployable- Kinetic structures which operate at the whole structure level.

This thesis will explore a design solution using embedded kinetics. Embedded kinetics were selected over dynamic and deployable systems, due to the context of the design as an environmentally responsive skin. Embedded kinetics provides an adequate

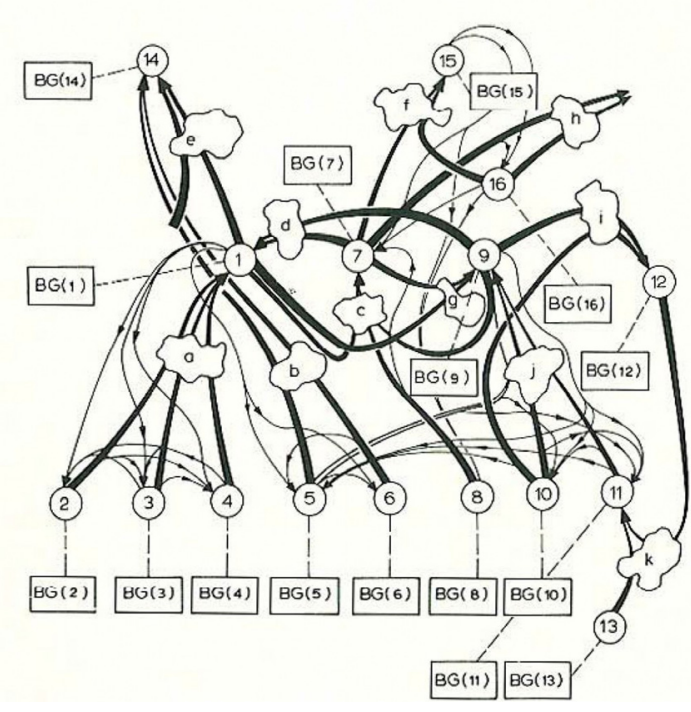

Fig. 1.1 Pask, Gordon. Con
gram. Web. 8 July 2013 . 
scope, without overcomplicating the design brief with the need to integrate dynamic or deployable functionalities into the skin.

Fox, in Sustainable Applications of Intelligent Systems, defines 6 types of kinetic motion in architecture. These categories are (5):

1. Internal control - Implies an ability to move constructional elements, however no direct control system is present.

2. Direct control - Movement is induced by an energy source, for the purpose of environmental control.

3. Indirect control - Kinetic instruction is transmitted to a direct control device via sensor or input device. Fox explains this as being "... a singular self-controlled response to a singular stimulus."

4. Responsive indirect control - Uses the same principal as indirect control, however data from multiple sensor devices are aggregated and processed by a computer before being transmitted as kinetic instruction to a control device. This sees computationaly a control devision making introduced to the

5. Ubiquitous responsive indirect control This uses the same principal as responsive indirect control, however movement data is sent to multiple kinetic elements.

6. Heuristic responsive indirect control - Uses the same principal as singular or biquitous indirect control, but the feedback system and computationally enabled learning capabilities allow for

These modes of control are all applicable to the creation of a kinetic skin, and provide a wide range of options for further design work. However, the lack of digital control associated with the internal control category rules it out as an remain applicable.

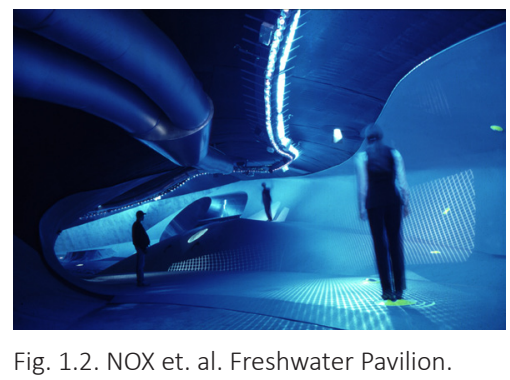

Fig. 1.2. NoX et.a.
Web. 9 June 2013 .

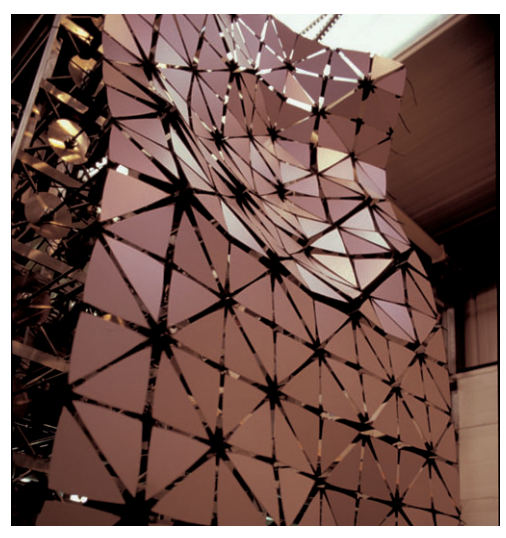
2013.

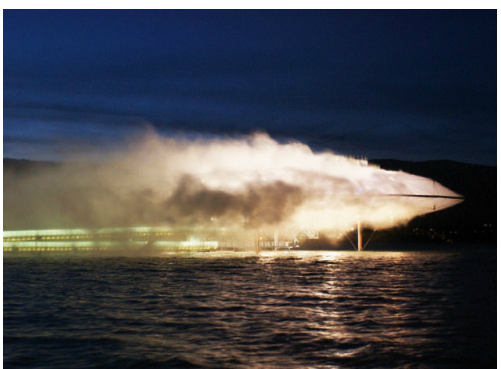

Fig. 1.4. Diller \& Scofidio. Blur. Web. 9 June 


\subsection{Digital design in architecture}

In a 2009 article for Architectural Digest, Patrick Schumacher writes that academics and avant-garde practitioners have been expanding the scope of computer aided design in architecture by leveraging the potential of scripting within the design process (15). These approaches can be traced back to the 1980 s, where animation software native to the entertainment industry was used in universities to generate form for design (Ottchen, 23). From this point onward, practitioners such as Gro Lynn (se his semiward, practition nal publication, Animate Form, 199 ) have set in motion a digital uprising, forming what Sterk describes as a "generation $X$ " of architects (18). Despite the plurality of approaches that higher level digital design enables, the common and fundamental element of this work is its reliance on scripting (Burry, 8).

Sterk (2009) describes this new work as a redefinition of the role of measurement in architecture. He explains that while the Modernists used rigid measurement protocols to produce form, digital practitioners produce form "fluidly and intuitively" and view measurement as an analytical design tool which, at the cutting edge of this field, is able to loop back in to the form finding process (20). This 'fluid and intuitive' design process is described by Sterk as being a product of digitally enabled parametric techniques (20).

In digital design, parametric modification refers to the capacity to alter the digital description of design information (often three dimensional CAD data) in a dynamic and hierarchical manner through scripting. This is enabled by either altering the description of a model directly via coding (apparent in older and complex parametric modelling approaches) or more commonly through software which simplifies the process. Such software includes visual programming interfaces like Grasshopper or heavily developed proprietary software such as Revit or ArchiCad, which allow users to enter values into a user interface to alter 'parametric' elements of a building information model (BIM)

Bohnacker et. Al, refer to the process of using code to create form as 'generative design' (460). Design input occurs through the process of defining the rule algorithm and/ or the source code. After an initial output, the designer can make changes to the source code, rule alsorithm, and associated parameters; in order to achieve a desirable design outcome (See figure 17). This understanding of the parametric desig process risforces Sterk's assentationametric desig process rein urces Sterk's assentation thet parametric processes enable a fluid and intuitive' process of
design (20):

“...in the work of Gen X... form is produced intuitively and with great fluidity. It is cast, pulled, stretch, and twisted by parametric processes

The term "Parametric Architecture" is gaining frequency of use as a means to classify the work of new quency Schulpractioners. While seminal writers such as Burry acher advocate the use of this classification, Bury argues that he label is too narrow inits scope an architectural tool (15). Burry asks: ". what is non parturic tool (15). Burry asks. "...What exactly is non-parametric design?" (15). Despite this revealing question, it is generally accepted that parametric processes play an integral role in the field of digital design. The stance in this thesis is to avoid the use of parametric architecture as a name or classification of a resulting architectural product, but does acknowledge the importance of parametric modelling as a part of the design process.
In Designing Kinetics for Architectural Facades, Jules Moloney states that parametric processes enable design optimisation through the manipulation of input parameters (201). However he extends the scope of parametric modelling beyond the production of a single design outcome by stating that the kinetics can be achieved if focus is given to the parametric system, as opposed to a static singur parametric This understanding of parametric modelling is critical to this thesis, as it widens the scope of parametric to this thesis, as the wesign of stapic construmetric modelling from the design of static construction eleties.

Sterk's view of the future of parametric design aligns with Moloney's interest in using pasametric aligns with Moloney's interest in using parametric processes to generate non static design outcomes. Sterk writes that the evolutionary path of parametric design will soon see it operating in a mode of continuous measurement, in order to enable intelligent and dynamic architecture (21). Notions of non-static parametric processes are apparent in the thinking of both Moloney and Sterk, and demonstrate a strong link between the fields of kinetic and responsive architecture (explored in Section 1.0), and digital parametric design methodologies (which are explored in this section).

Architectural manufacturing is currently in a state of transition from mass standardisation to mass cus tomisation, caused by rapidly evolving material and manufacturing technologies. The Modern Movement developed notions of modularity and standardisation in architecture as a reaction to emerging material and construction technologies developed in the $20^{\text {th }}$ Century. More recent developments in computer science and mechatronic engineering have produced machines capable of exceeding the ridged construc-

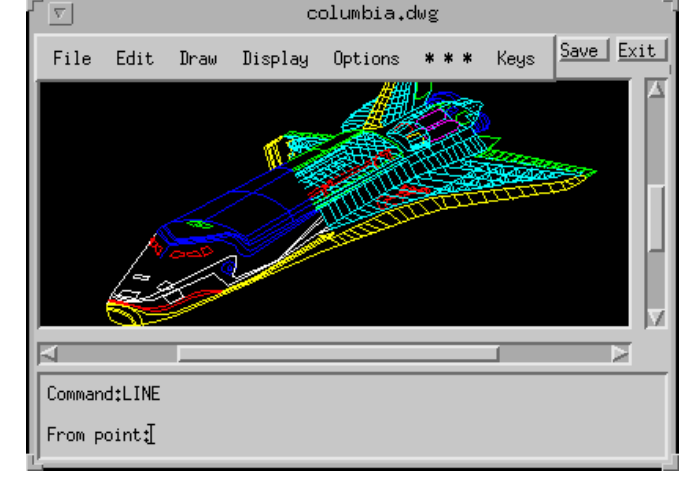

Fig. 1.5. Autocad in 1985. Web. 10 June 2013.

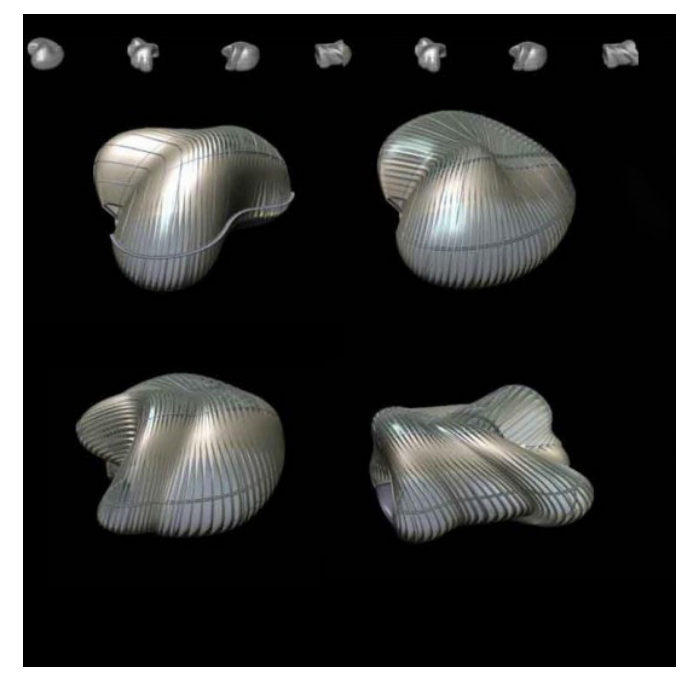

Fig. 1.6. Lynn, Greg. Images from the design process of the
Embryological House. 1998-9. Film Still. Web. 3 August, 2013 


\subsection{Position}

tional confines which conditioned the Modern Movement. Computer Numerically Controlled manufac-

turing tools including routers, benders, welders and

cutters, along with emerging tools such as 3D print-

ers, allow for the efficient manufacturing of custom-

ised and complex construction elements.

While it is apparent through the work of Moloney

and Sterk that parametric design is emerging as a

tool for kinetic and responsive architecture, Ander-

son and Tang believe there is scope for its role in the

manufacturing process as well (1). When the in the

bilities of digital masufacturing tools are coupled

with the new digtal methods of form creation and

with the new distans

ics inherited from Modensism can be extinguished

ics inherited from Mod construction and aeshet-

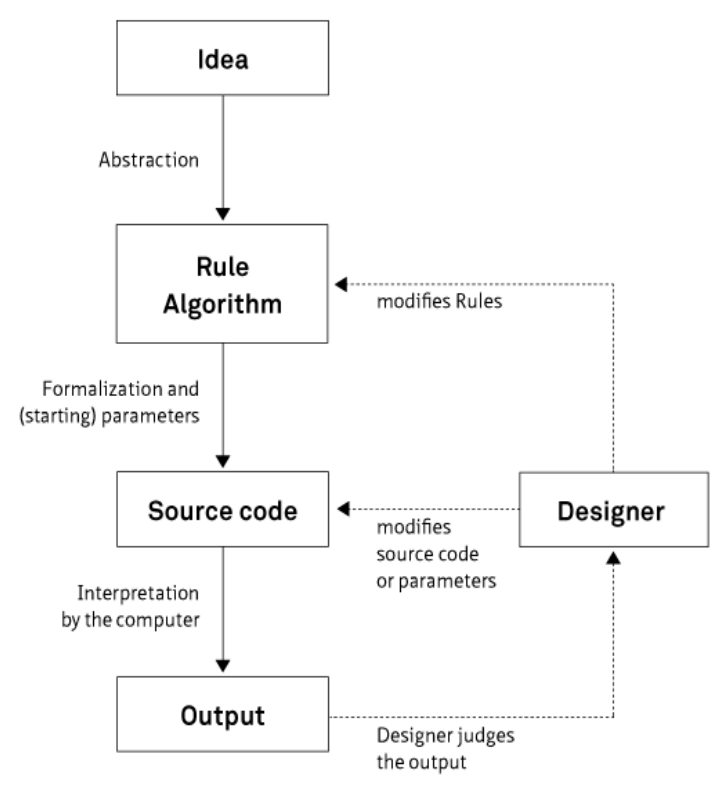

Fig. 1.7. Bohnacker, hartmut et. al.Parametric process
In this design exegesis, parametric scripting methods will be used to aid the design development of a kinetic skin system. The purpose of this will be to explore and evaluate the potential for this design approach within the scope of kinetic and environmentally responsive skins.

As explored in Section 1.1, parametric design methodologies enable fluid and iterative design action. Alterations to the structure of the script and associated input parameters control morphological change in architectural models. This process can be used to enable design optimisation through an iterative modelling approach, or control the movement of architectural elements in a 3D model. This thesis will use both of these approaches to aid in the design process of a kinetic skin. The design process will involve the ongoing development of potentia kinetic skin applications, and this 


\subsection{Methodology}

Section 2.0 will use on-site environmental data as a parametric input to control morphological change in responsive skin designs. This will be undertaken in order to aid the conceptual development of a responsive skin. Some designs in Section 2.0 propose augmented reality systems as a means to produce responsive architecture. The nature of the rela-

tionship between digital models and architecture using an augmented reality system will be explored, and it is proposed that novel kinetic form may result.

Section 2.2 uses both iterative parametric modelling and parametrically enabled dynamics to develop a kinetic skin system. Development will occur through a cyclic process of design, evaluation and modification. Evaluation will take place directly in the 3D modelling software, and also via animation software where it can be undertaken in simulated lighting conditions. Establishing design criteria will ensure a feasible and wellperforming developed design will result.

Section 3 will evaluate the developed kinetic skin system as it has been applied to two buildings designed for a hypothetical client. This will provide an understanding of the skin system as applied in an architectural context.

\section{RESPONSIVE
KINETIC}

ARCHITECTURE 
2.0 Parametric modelling at the conceptual design stage

The scope for digitally enabled responsive architecture developed in Section 1 does not specify a particular programme or any functional requirements for design output. Rather, it defines principles addressing the essence of this area of work. The scope has been articulated in this way to ensure that the conceptual development of a kinetic skin is not stifled at early stages of design.

In order to evaluate and subsequently narrow the potential design outcomes possible within the scope of parametrically enabled responsive architecture, a series of tests were undertaken to ex plore a range of design solutions. These tests were undertaken in Rhinoceros 3D and its parametric design plugin Grasshopper. Local weather data was sampled from the internet to inform a range of parametric definitions, which were able to produce a range of kinetic and responsive design outcomes.

To evaluate the quality of the resulting architecture, and determine its potential for further use in this thesis, a series of questions were considered against test designs:

- How well would users engage with the design?

- How do parameters affect architectural kinetics?

- What benefit does the responsive kinetic action provide?

- What is the aesthetic and/ or spatial quality of the design? 
Test 1 uses humidity data as a parametric input to control the translation of an augmented reality mesh, which is suspended over a large area of terrain on Wellington's south coast. As onsite humidity levels increase, the mesh moves toward the ground. At 100 percent humidity, the web would be positioned $1900 \mathrm{~mm}$ above the ground. It was intended that the mesh would establish a notion of enclosure, which would become more defined as the weather became worse In a later development the parametric model was altered to project the responsive mesh only above the existing trails on the hillside. In this instance the mesh also acts as a navigational aid, as a response to the potential for poor visibility at the site when weather conditions are poor. User engagement with presented in an architectural context, the novelty ofthe cal architecture has to exist.

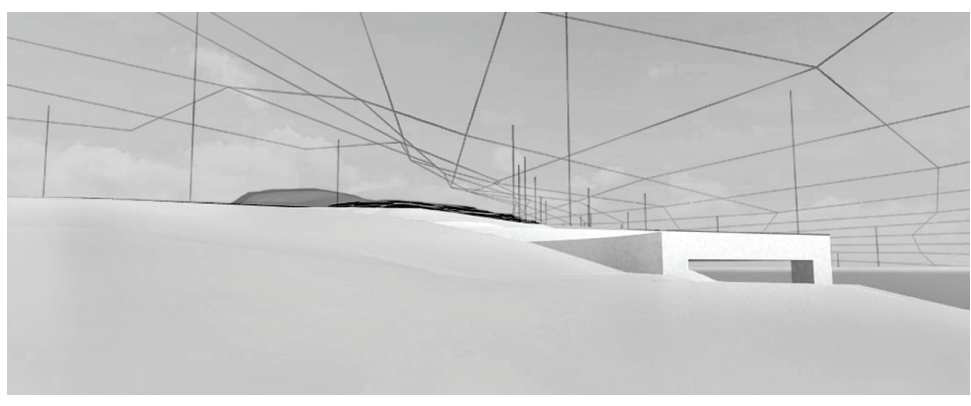

Fig. 1.9. Augmented reality mesh.

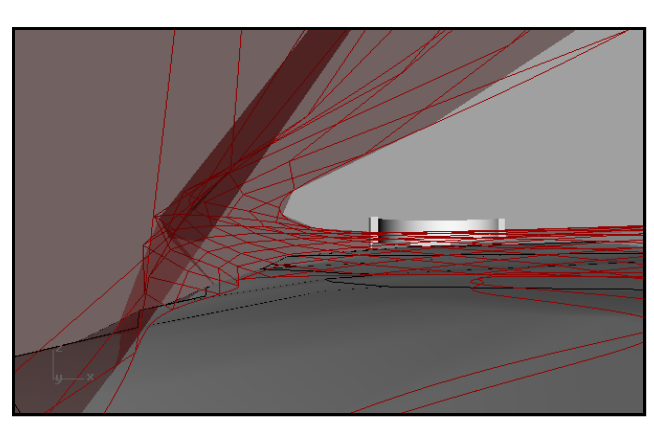

Fig. 1.11. Animation of mesh pathway.
http://youtu.be/NNyUjHZITkk

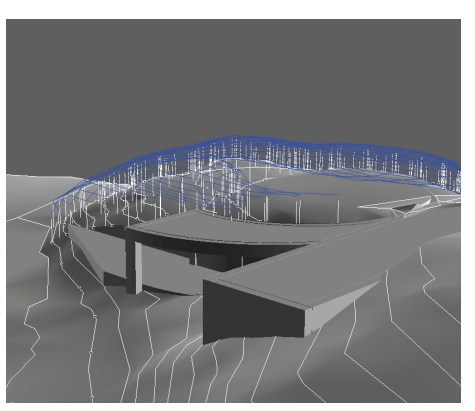

Fig. 1.10. Augmented reality mesh and
lookout structure.

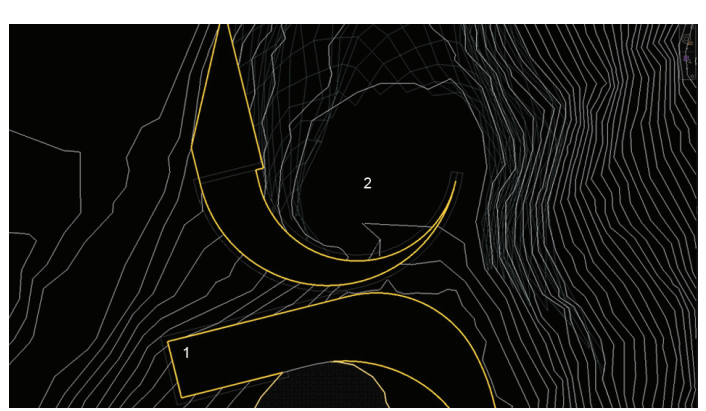

Fig. 1.12. Plan of lookout and mesh composition.
Test 2 is a series of augmented reality fin structures, which grow in size and spread in direct relation to wind speeds measured on site. The fins grow from contour lines defined in Grasshopper, and are able to dramatically alter the sites topography. In extreme wind events, the fins become smaller in their distribution around the peak, events, the fins take up a large portion of the peak, but are comparatively low in stature. Wind speed data has been sampled in Grasshopper, and a parametric definition has been developed which defines the kinetic nature of the fins. The fins cause users to alter the way in which they engage with the site, opting to explore parts of the landscape covered in fins which they may otherwise ignore. The installation provides a visual and spatial experience, where weather events are inexplicably related to new topographical formations.

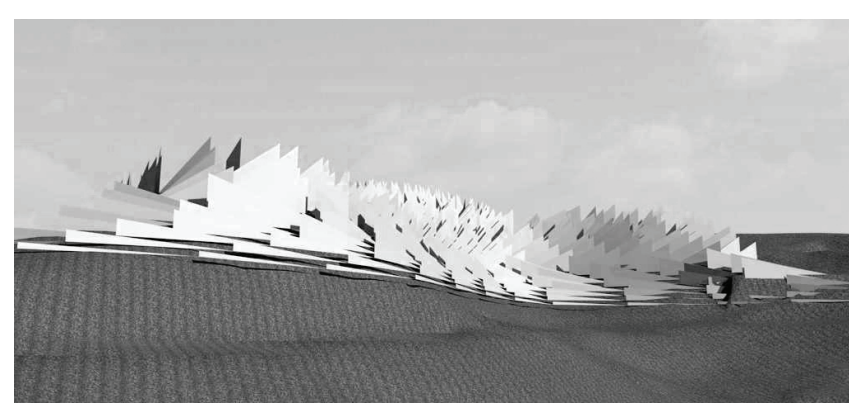

Fig. 1.13. Augmented reality fins, $8 \mathrm{~m} / \mathrm{s}$ wind.

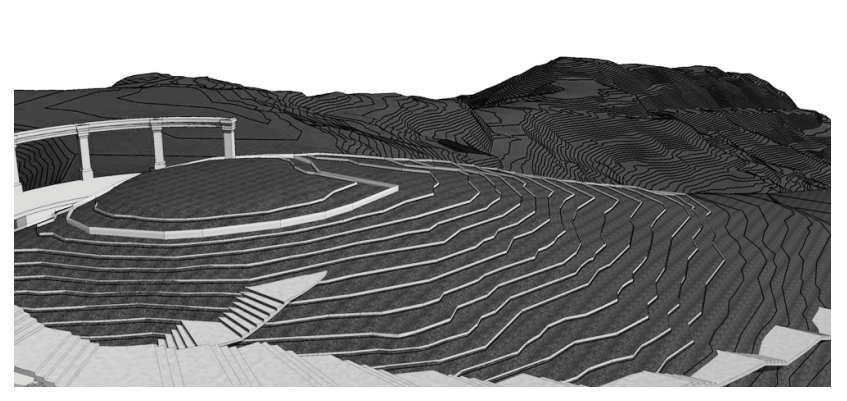

Fig. 1.15. Augmented reality fins and lookout structure

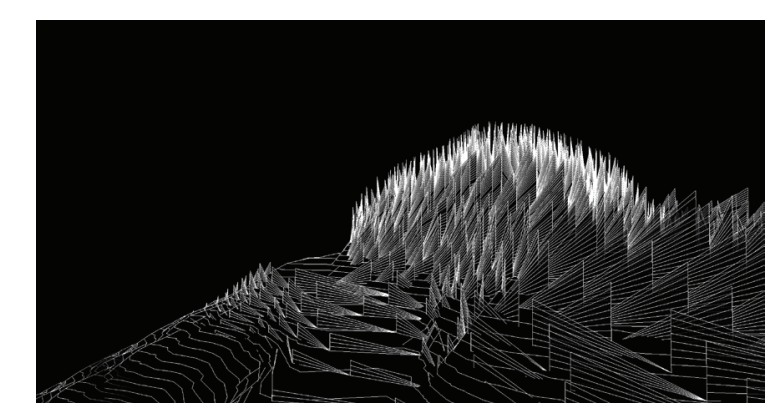

Fig. 1.14. Augmented reality fins, $18 \mathrm{~m} / \mathrm{s}$ wind.

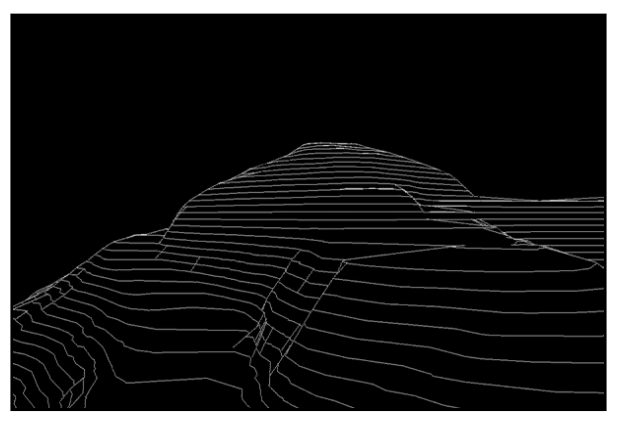

Fig. 1.16. Animation of fin growth. 
Test 3 is an augmented reality skin that uses sampled weather data as a parametric variable, to generate random geometric configurations in its surface. While tests 1 and 2 provide a relatively direct relationship between parametric values and the resulting form (translation and growth), the relationship is difficult to define. The performative, continuously changing nature of the skin would encourage user engagement with the design, and the complex surface geometries are aesthetically pleasing.
Test 4 is a lookout structure comprised of panels which rotate outward in response to changing wind speeds. With no wind, the surface of the skin is relatively flat. In high wind the panels open, exposing the building to the elements. This responsive action is intended to highlight the presence of wind acting on the structure, by disrupting internal air currents and altering internal light qualities. The presence of wind is also communicated at a distance, by changes in the surface appearance of the skin. The purpose of the design is to make users aware of changing wind speeds in a performative architectural context.

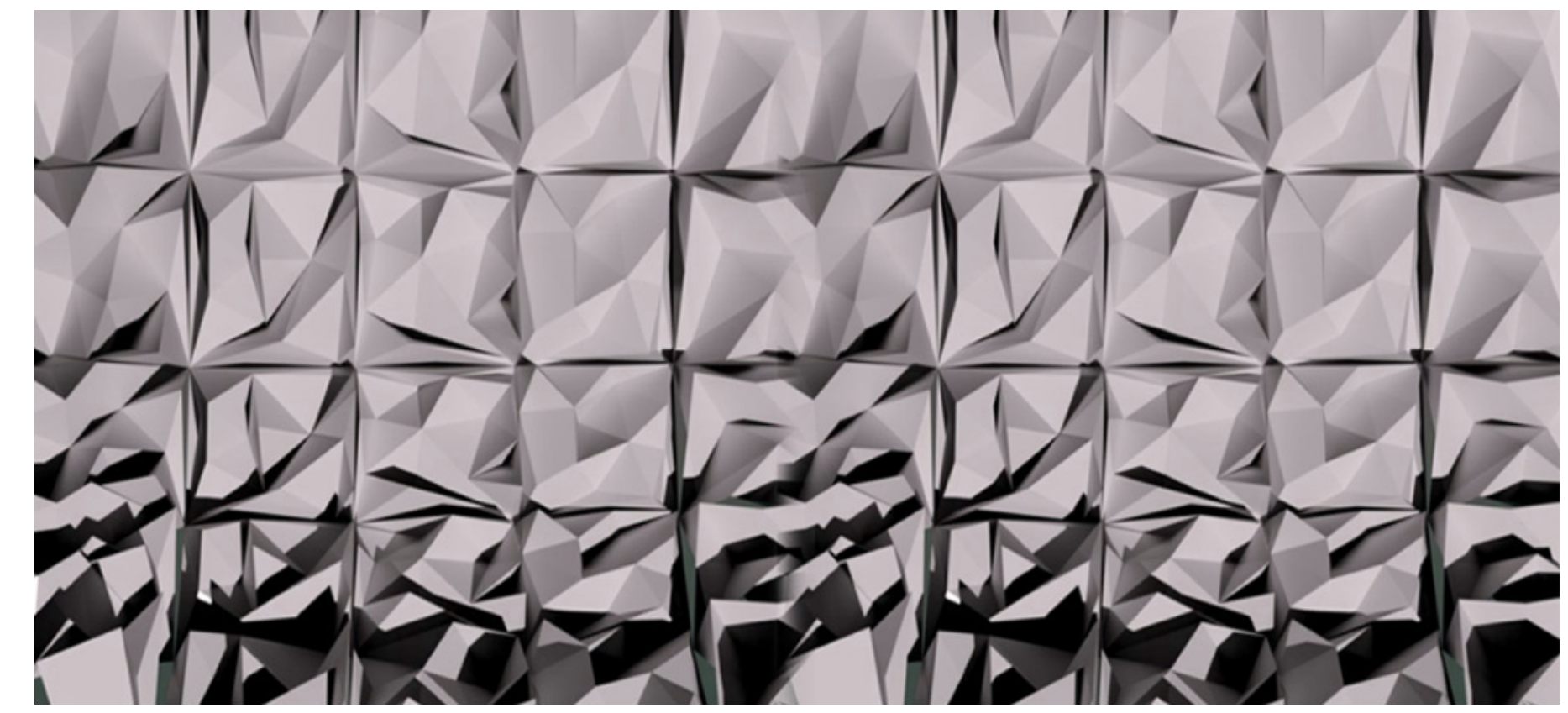

Fig. 1.17. Responsive augmented reality skin system.

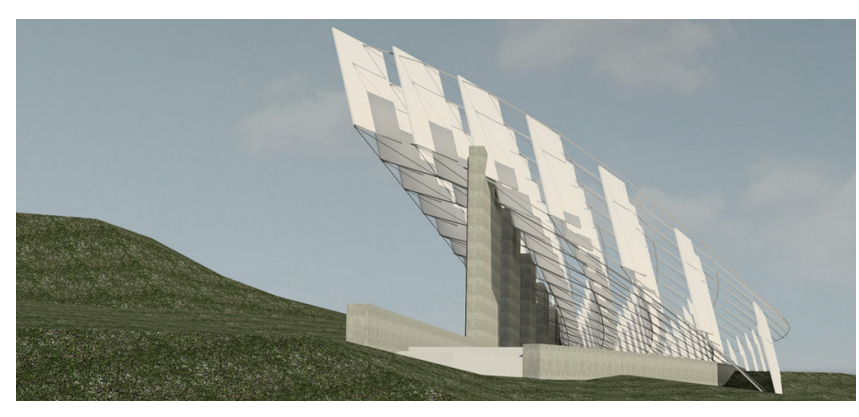

Fig. 1.18. Responsive lookout.
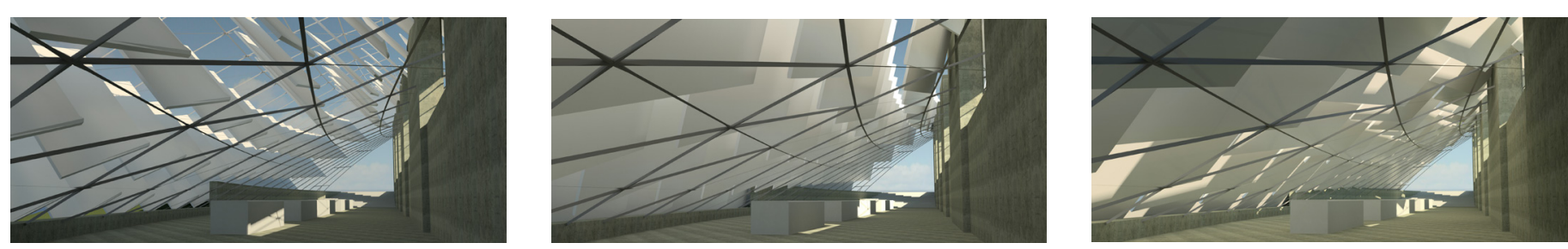

Fig. 1.20-1.22 Changing interior qualities. 


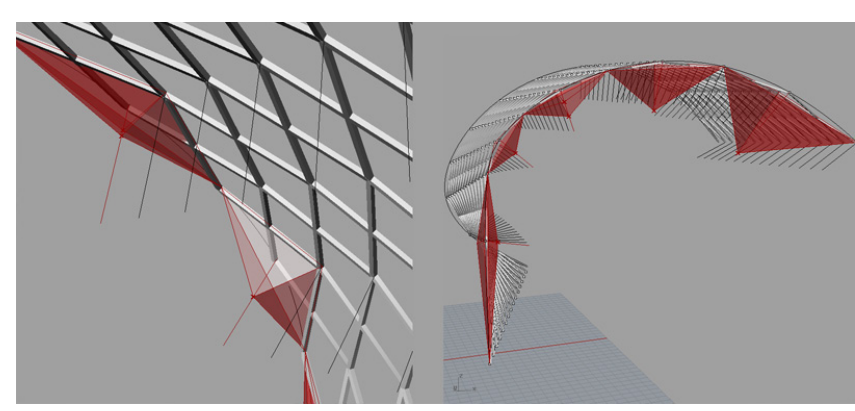

Fig. 1.23 Hybrid digital skin system.

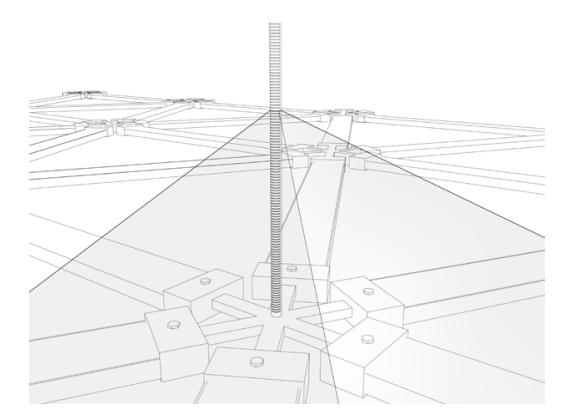

Fig. 1.24 Hybrid digital skin system.

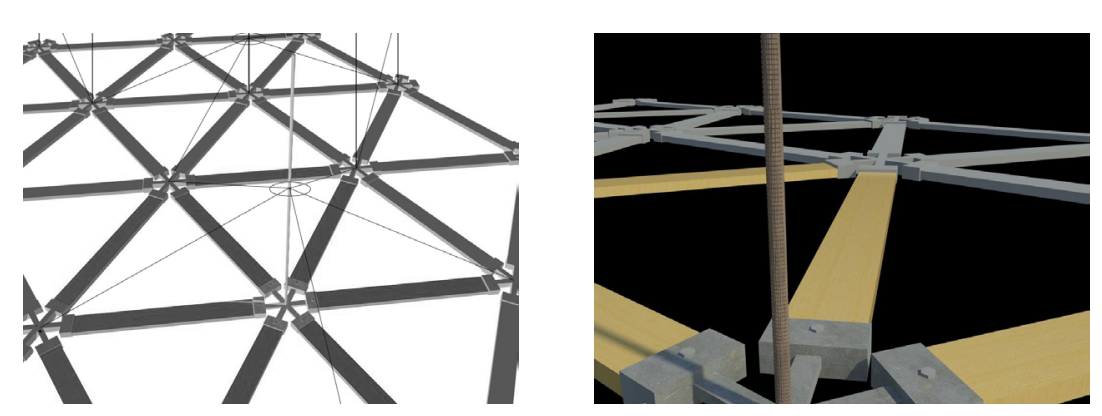

Fig. 1.25 Hybrid digital skin system __ Fig. 1.26 Hybrid digital skin system.
Three general characteristics are evident in all test designs:

- Architecture which alters its spatial, environmental or landscape qualities in response to environmental change

- Architecture which communicates qualitative or abstracted weather information through changes in form

- Architecture which uses kinetic elements to alter the behaviour of its surrounding environment

A fourth related quality is evident in test 5 :

- Architecture which communicates quantitative weather information through changes in form

Tests 1, 2 and 3 propose responsive kinetic systems which are achieved wholly through the use of augmented reality systems. The responsive kinetic action produced by these designs is visually intriguing with strong aesthetic and spatial qualities resulting. However, the potential for user engagement with these designs tends to be limited, as a clear func tion is not evident. It is apparent through these tests that augmented reality systems allow parametric architectural designs to achieve extremely novel and dynamic form, but the lack of physical elements in these systems give them too narrow a scope to prove useful for further use in this thesis.

Although test 4 cannot achieve the same levels of dynamic form evident in the previous tests, its ability to physically alter its surrounding environment has a significant effect on the user experience. Although the responsive action in this design is intended to highlight the event of wind acting on the structure, which is limited and conceptual, the system could be used in reverse to provide shelter to its occupants.

Test 5 attempts to use kinetic and responsive action to provide user engagement, by encouraging direct interaction with the surface of the skin system. This has been an attempt to improve on the shortcomings evident in tests 1,2 and 3 , where the relationship evident in tests 1,2 and 3 , where the relationship relatively arbitrary.

From this initial testing, it is clear that parametric modelling can be used to create a range of responsive architectural design outcomes. Test 4 has provided the strongest platform for further deve ment. The physical panel system proposed by this design can modulate light and air as well as commudesign can modulate light and air as well as communicate environmental information through its kinetic from this test will be used as a base for fur system sign deves wil be used as a base for further design development in this thesis, to achieve a responsive skin. It is possible that the panel system could be used to achieve kinetic outcomes not yet revealed, and a process of continued conceptual development will be undertaken alongside further developments to the panel system. 


\subsection{Client and programme}

The National Institute of Water and Atmospheric Research (NIWA) is the hypothetical client for the design of a responsive skin. NIWA's primary function iesign of a responsive skin. NiwA's primary function involves the collection and distribution of information about New Zealand's climate, to both public and private interests. The collation and processing of environmental data by NIWA is inherently digital. The relationship between weather, data processing, and the dissemination of information is central to NIWA's operations, but elements of this relationship are evident in responsive and kinetic skin systems, and this relationship will be explored further throughout development.

A new building for NIWA's High Performance Computing Facility (HPCF) will provide a hypothetical design context for this thesis. The NIWA HPCF currently houses an IBM p575 POWER6 supercompute This is used to compute weather simulations for the purpose of forecasting and environmental analysis, and is available to scientists for a variety of other ap plications.

Within the brief, space is required for the computer and its associated mechanical services. In addition to this, the only other vital designation in the brief is for laboratory space, which may only require a minimum of five additional computers or interfaces. However, there is scope for the provision of more office space. Extra space could be used by NIWA as new office space, or could be leased.

The HPCF is currently located at NIWA's Greta Point Campus. In order for the HPCF to maximise the potential of a responsive skin, it is proposed that a new location for the facility is in a central urban area, in order to foster greater levels of public engagement. On-site public interaction should be considered as a way to extend NIWA's public image. Potential strategies include:

- Designing a skin which can provide responsive environmental control to benefit building users.

- Designing the skin to operate as a media façade, from which advertising revenue could be made.

- Providing extra leasable space within the development to enhance the economic feasibility of the proposal.

- Providing public education, information or art space.

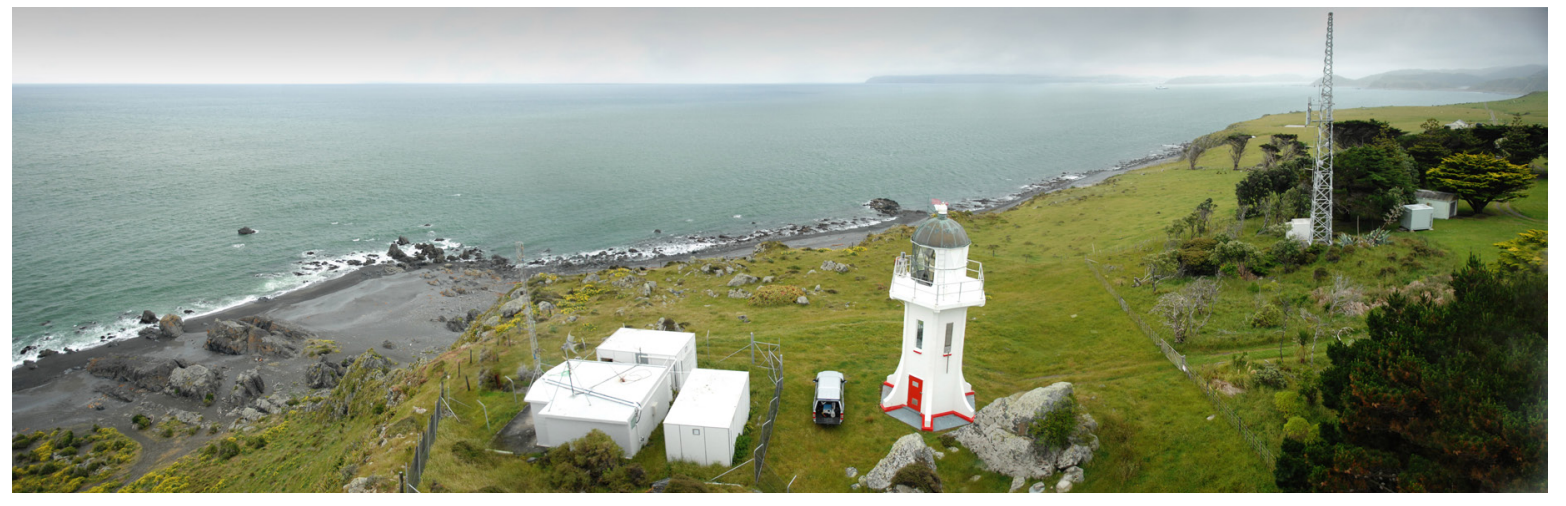

Fig. 2.1 NIWA's Baring Head Clean Air Monotoring Station. Web. 15 June, 2013.

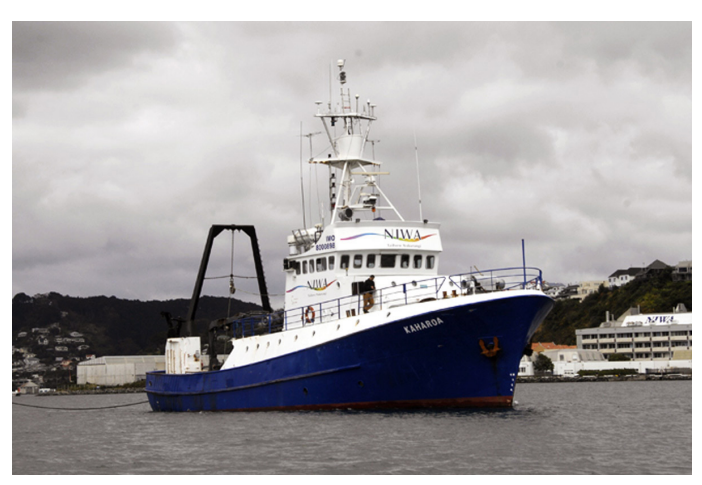

Fig. 2.2 NIWA research vessel Kaharoa. Web. 12 Dec, 2013.

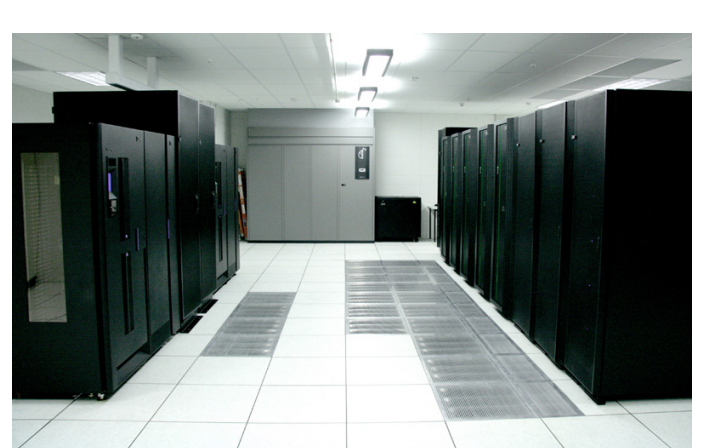

Fig. 2.3. p575 POWER6 supercomputer. Web. 12 Dec, 2013. 


\subsection{Parametric modelling in design development}

Testing in Section 2.0 identified a responsive system involving rotatable panels as an effective foundation for further design development. Design outcomes (identified in Section 2.0) included a rotatable panel system which is able to express environmental information and modulate its surrounding environment. This section will use parametric modelling to define and develop the shape and movement of the kinetic skin components. Components will be evaluated against design criteria, and relevant changes will be made to the parametric definition until a satisfactory result is achieved.

The criteria used to indicate successful panel iterations are as follows:

- Size of panel will result in a medium resolution image or surface pattern, identifiable at a minimum distance of $10 \mathrm{~m}$ from the skin

- Size and shape of panel will result in a feasible panel system in terms of cost and construction

- Size and shape of panel should result in a satisfactory aesthetic quality when skin is in motion or at rest

- Shape and rotation of panel should allow for adequate modulation of light and air

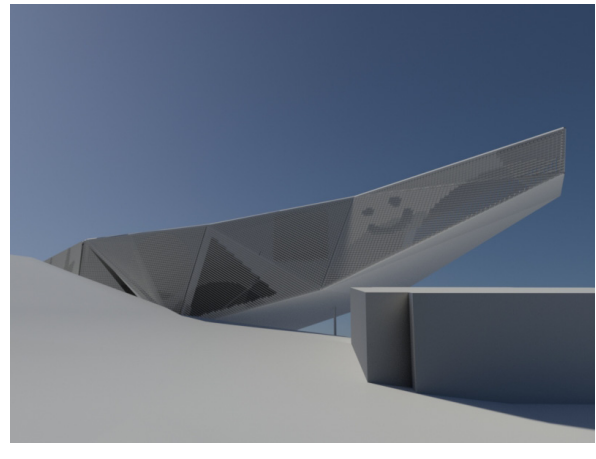

Fig. 2.4. 200mm panel test, exterior view.

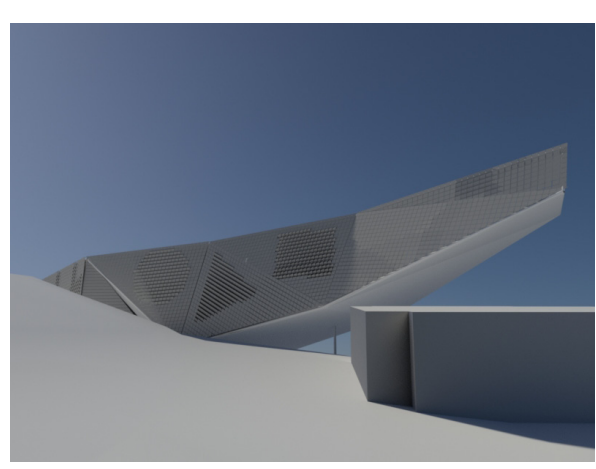

Fig. 2.6. $400 \mathrm{~mm}$ panel test, exterior view.

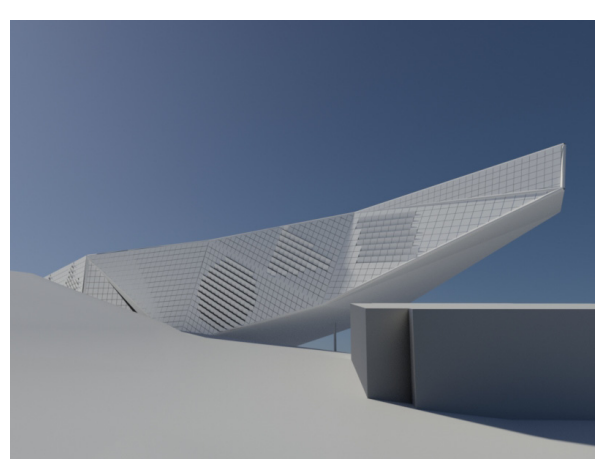

Fig. 2.8. 600mm panel test, exterior view.

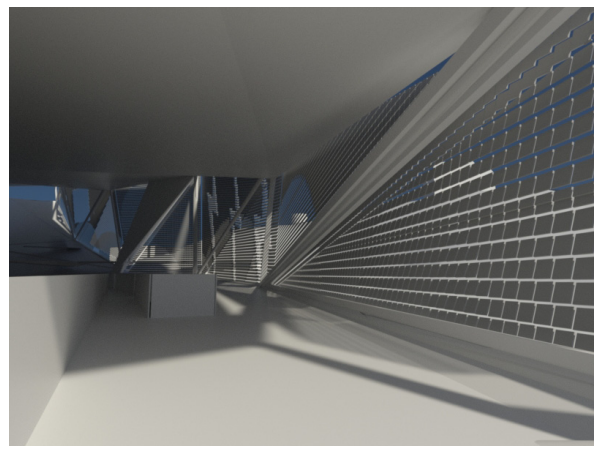

Fig. 2.5. $200 \mathrm{~mm}$ panel test, interior view.

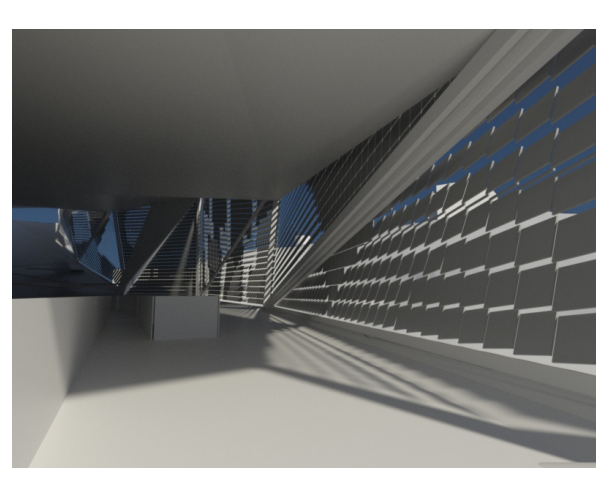

Fig. 2.7. 400mm panel test, interior view.

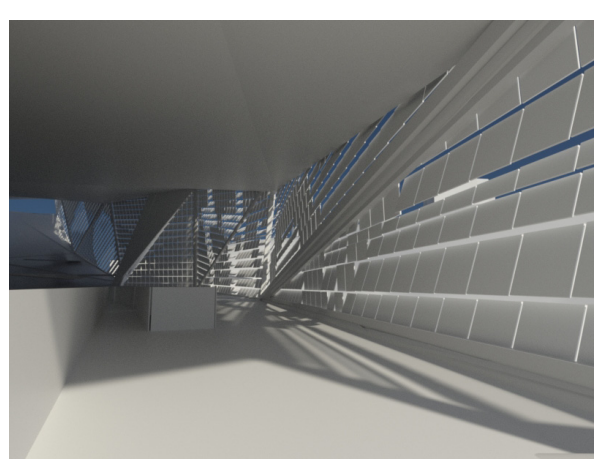

Fig. 2.9. $600 \mathrm{~mm}$ panel test, interior view.

\section{Visual acuity testing}

Trial and error based optimisation enabled by parametric modelling has been used to identify a preferable panel size for effective visual communication.

200, 400 and $600 \mathrm{~mm}$ square panels were modelled parametrically in Grasshopper. Geometries were then applied to a test structure and animated using 3Ds Max. Animations allow for an analysis of how effectively different sized panels display kinetic pattern.

$200 \mathrm{~mm}$ panels produced high resolution images and kinetic pattern at very close range. The size of the individual tiles reduced constructional feasibility, as each tile would require some form of individual mechanical actuation and related support structure. The panels produce a very fine aesthetic quality.

$400 \mathrm{~mm}$ panels produced images with slightly less resolution that the $200 \mathrm{~mm}$ panel. However, at $10 \mathrm{~m}$ from the surface of the skin, images and kinetic pattern were still easy to read. In terms of constructional feasibility, $400 \mathrm{~mm}$ panels would still require significant support structures and mechanisms. The panels also produce a fine aesthetic quality.

$600 \mathrm{~mm}$ panels produced medium resolution images and kinetic pattern at $10 \mathrm{~m}$. The larger size of the panel indicates a reduced level of construction cost and complexity, including less driver assemblies needed to move individual panels relative to the area of skin. The $600 \mathrm{~mm}$ panel size produces a fine aesthetic quality when all panels are flat, but a pixilation of images can occur when panels undergo rotation.

The $600 \mathrm{~mm}$ panel size returned the best results relative to the design criteria. This panel size would be easier to construct; however, this is at the cost of reduced resolution. The aesthetic effect of a $600 \mathrm{~mm}$ square panel may be less attractive than smaller panel sizes. 
To determine whether regular or irregular tiling arrangements would be more suitable for use in the skin system, hexagonal and voronoi panels were animated in grasshopper and analysed in real time in a first person view using 3Ds Max. This approach allowed for a more fluid way to view facade moveto view façade movecameras.

The hexagonal panel arrangement produced clearer images than the voronoi arrangement. Hexagonal image edges were more defined, whereas the voronoi geometry tended to fra ment at the edges.

Hexagonal geometries would be cheaper and simpler to construct than a panel system based on voronoi geometries. However, digital manufacturing processes significantly enhance the constructional feasibility of a vorono based panel system.

The voronoi panels were more aesthetically pleasing than the seen throughout architectural history, and in contrast the vorseen links to the digital movement, making them more relevant to this thesis. The voronoi panels may also produce move to this thesis. The voronoi panels may also proc

plex and aesthetically pleasing shadows.

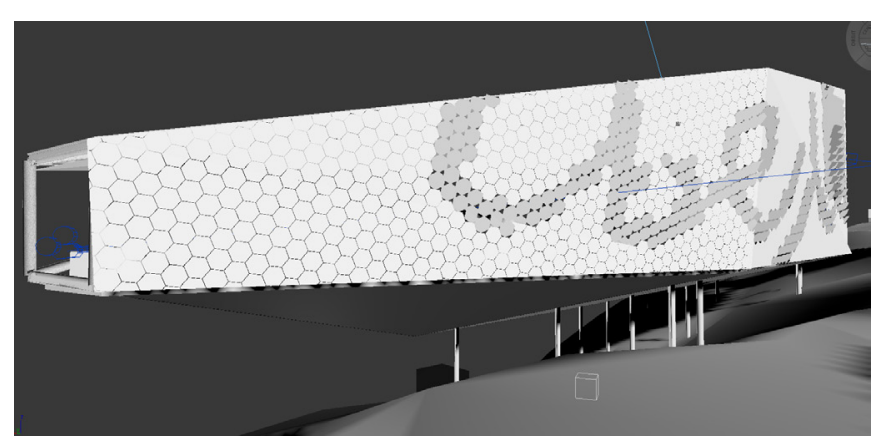

Fig. 2.10. Live simulation panel geometry tests,
showing hexagonal panels.

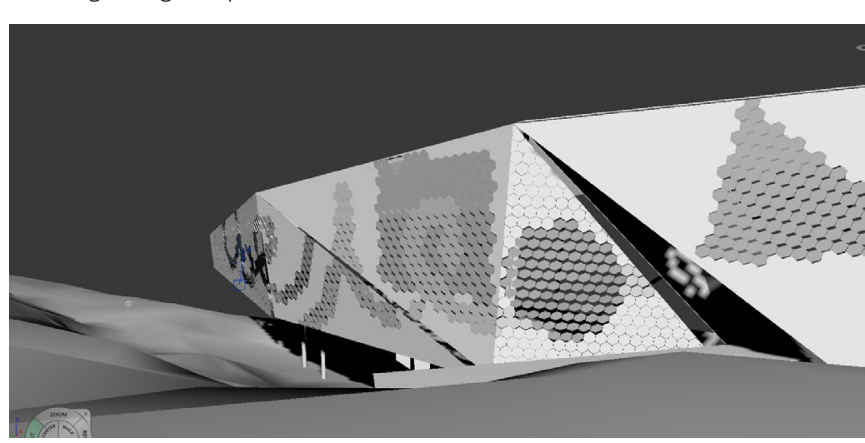

Fig. 2.12. Live simulation panel geometry tests,

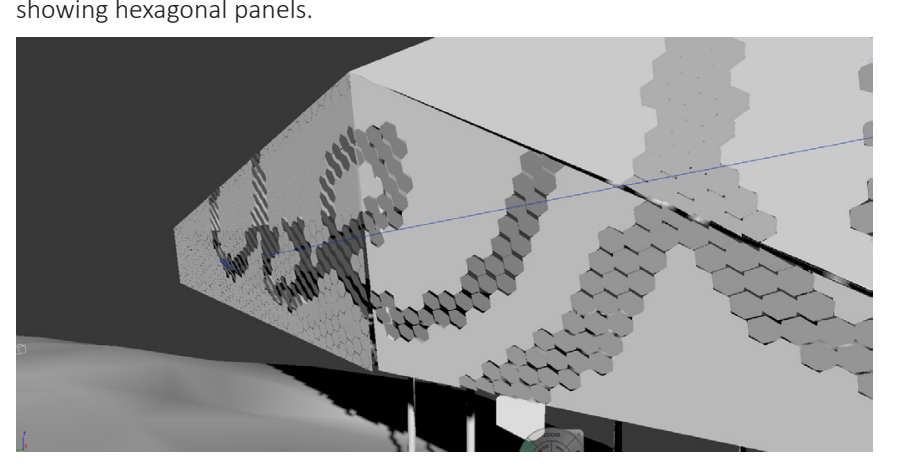

Fig. 2.14. Live simulation panel geometry tests,
showing hexagonal panels.

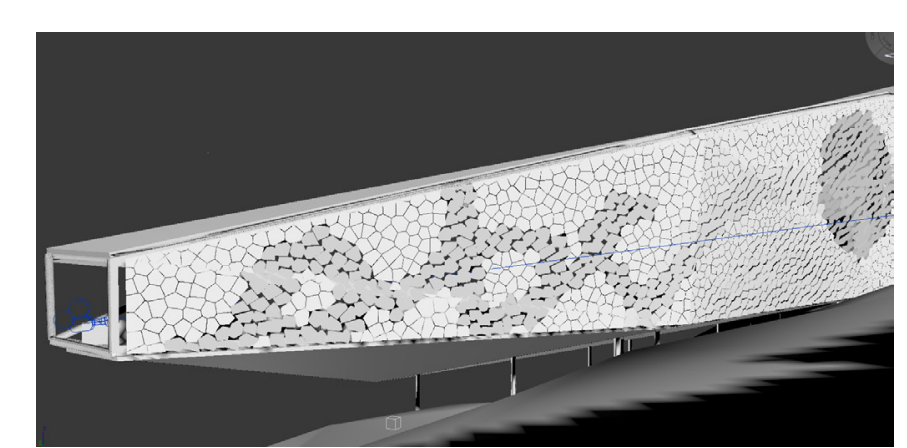

Fig. 2.11. Live simulation panel geometry tests,

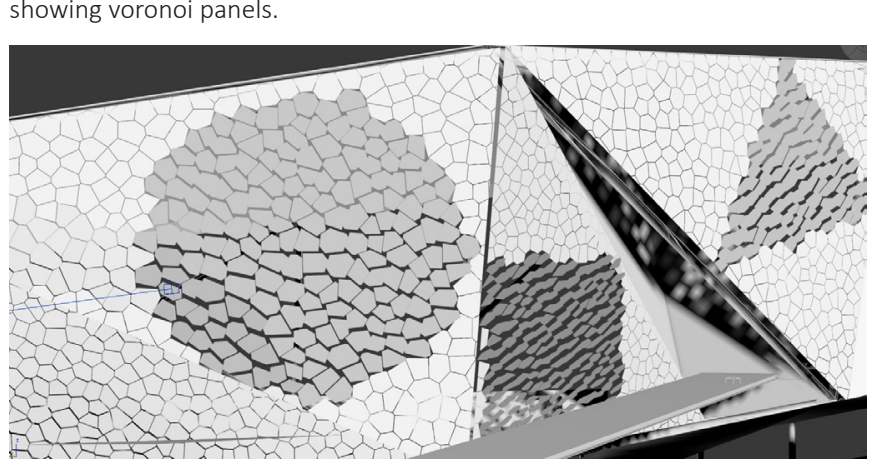

Fig. 2.13. Live simulation panel geometry tests,

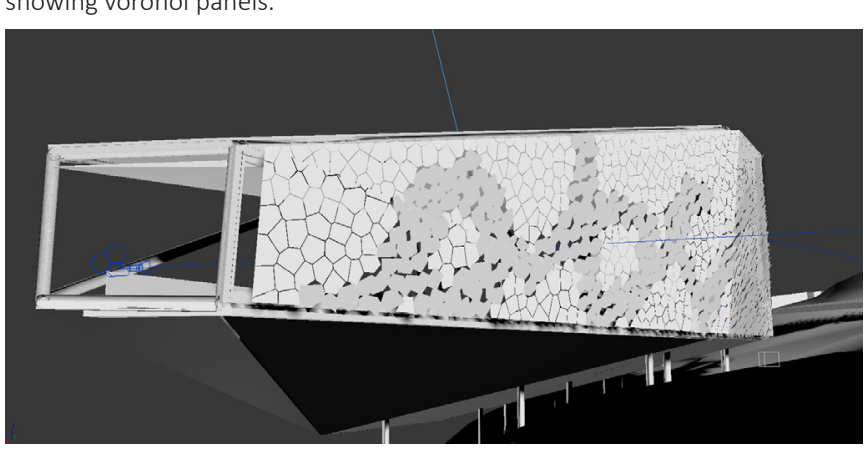

Fig. 2.15. Live simulation panel geometry tests,
showing voronoi panels. 
In order to develop the general panel form in greater detail, generations of 3Ds Max, and evaluated against the panel design criteria. This approach was used to help develop an understanding of panel performance in realistic lighting conditions. The ability for parametric modelling to efficiently generate a vast amount of model data, and reproduce these geometries with quantifiable

adjustments, made this process very efficient in comparison to non-parametric digital modelling methods. The images shown in this section are the first and last frames from test animations. The first frames show panels with no rotation; and the second, with a rotation of 30 degrees. The design analysis in this section focuses on panel aesthetics, and the clarity of embedded images relative to panel shape. Consideration of environmental performance and construction feasibility of the panel system are omitted in this section, because the changes to the skin are not significant chang to atter their influence on design.
doster their influence on the

Cameras were set up at fixed points around the model to effectively analyse the performance of the skin from a range of angles and distances.

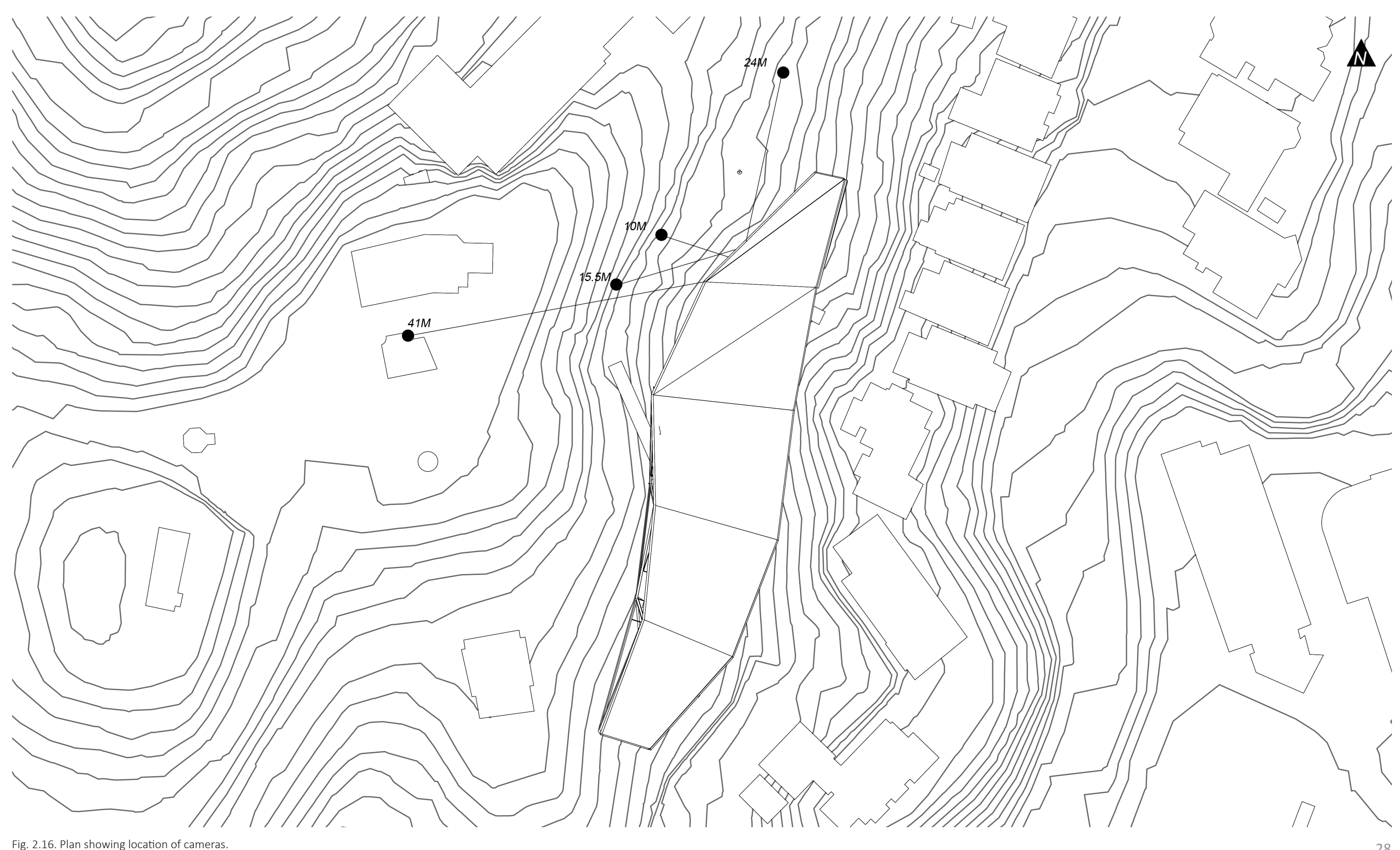


As hexagonal panels were deemed to have an unsatisfactory aesthetic in the previous test, triangular panels were trialled to determine their aesthetic and communicative strengths. In this series of tests,

the hexagonal panels were used as

a benchmark of bad design.

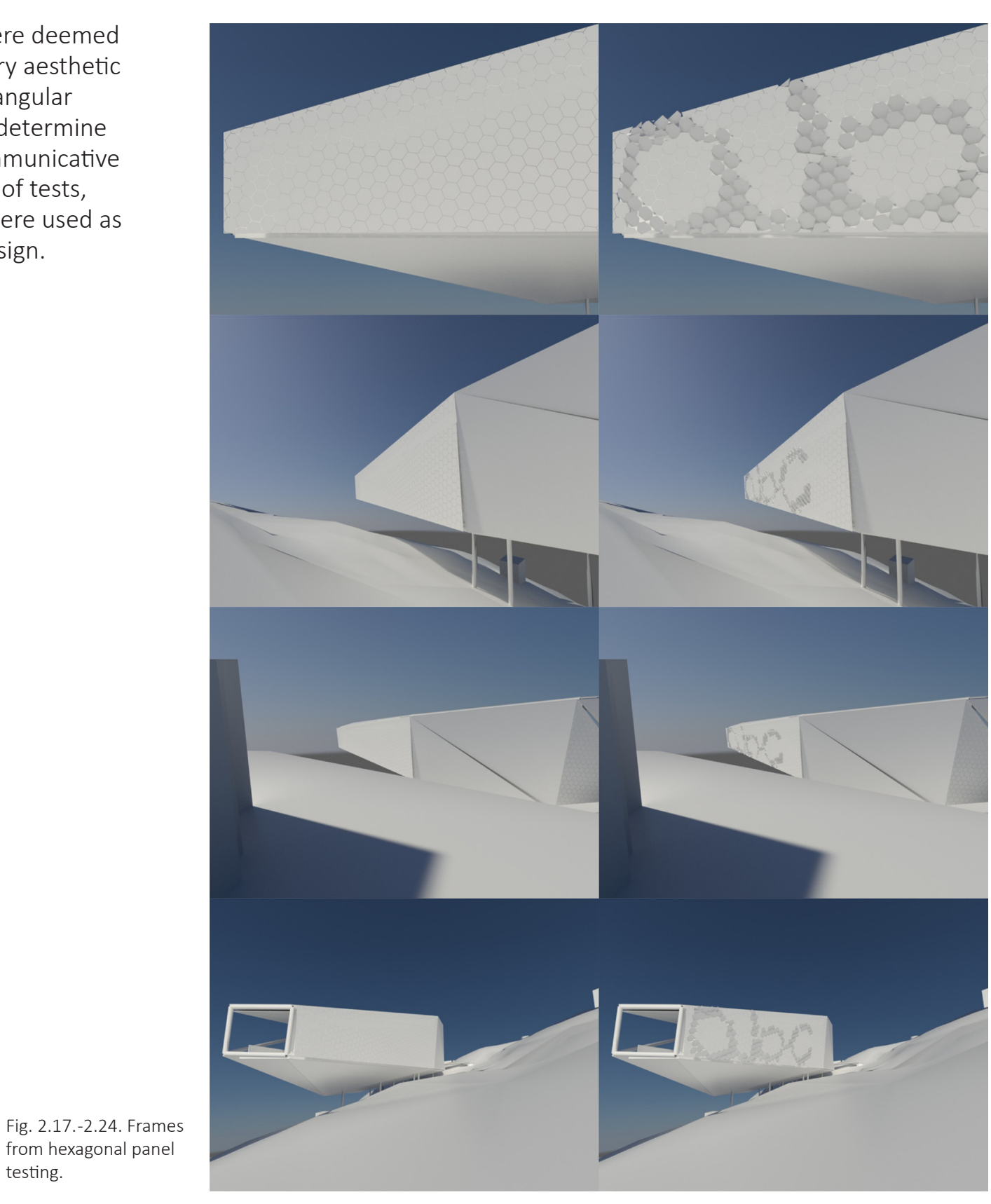

Pyramidal triangular geometries did not provide greater visual definition when displaying the same image under identical lighting conditions. However, the resulting aesthetic quality was stronger than the hexagonal panels.

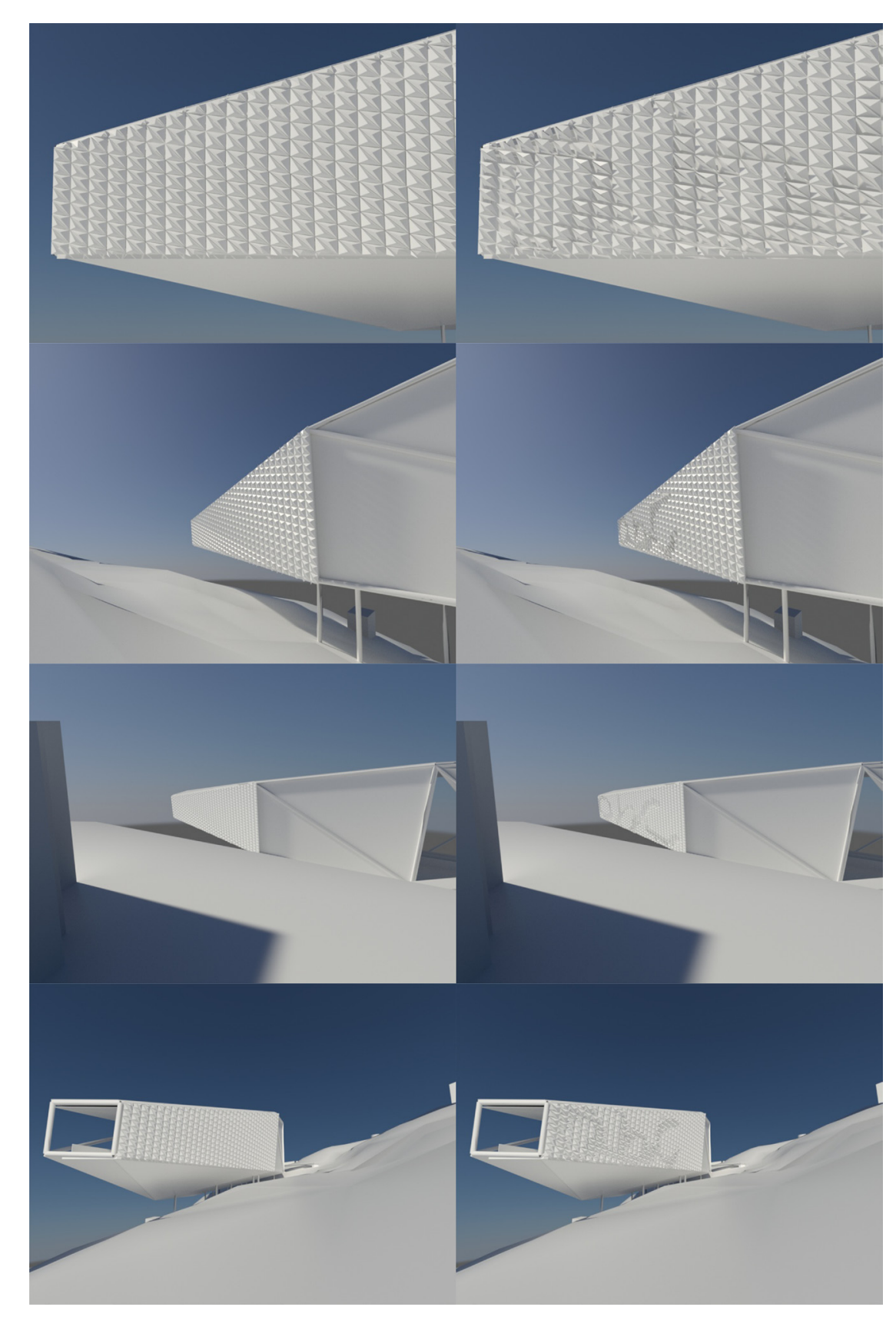

Fig. 2.25.- 2.32. Frames Fig. 2.17.-2.24. Frames testing.

testing. 
It was hypothesised that by increasing the tonal range of the individual panels, imbedded images would be clearer. An increased tonal range could be achieved by increasing the surface complexity of the panels, which could also provide a stronger panel aesthetic. The second triangular panel combined two pyramidal shapes within bined two pyramidal shapes within each panel. This resulted in slightly control animation.

Despite a drop in visual clarity from the hexagonal panel test,

triangular geometries were consid-

ered to provide an adequte middium resolution image from a 10 dium resovion istance, as per the 10 metre distance, as per the pane development criteria. In addition, their aesthetic qualty was stror gonal panel.

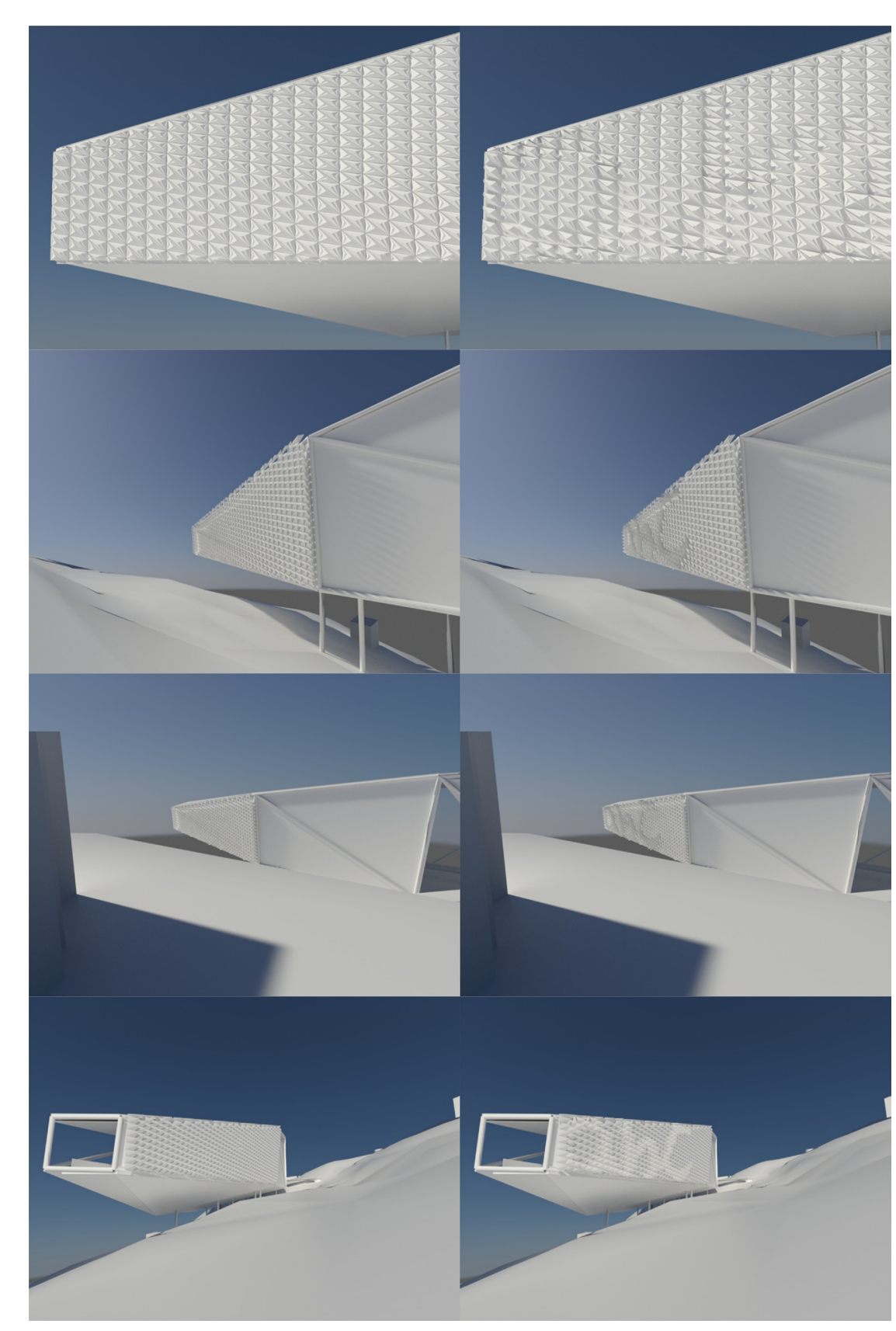

In order to develop a stronger response to the environmenta control criteria, a third triangle based panel iteration was trialled. This four sided panel is set out in an overlapping arrangement, so that only two edges of the pane are visible. The overlapping panels reduce light penetration when fully closed, and their configuration alows them to rotate 90 degrees to allow light through the skin capacity they are more efficient at controlling light and air than previous iterations. In addition the resulting aesthetic effect is the resulting aesthetic effect is stronger than both the hexagonal and triangular iterations, as a more faceted and complex aesthetic

has been achieved. The clarity of

imbedded images produced by this iteration is similar to the triangular panels; however, when rotated fully, a far stronger appearance is produced.

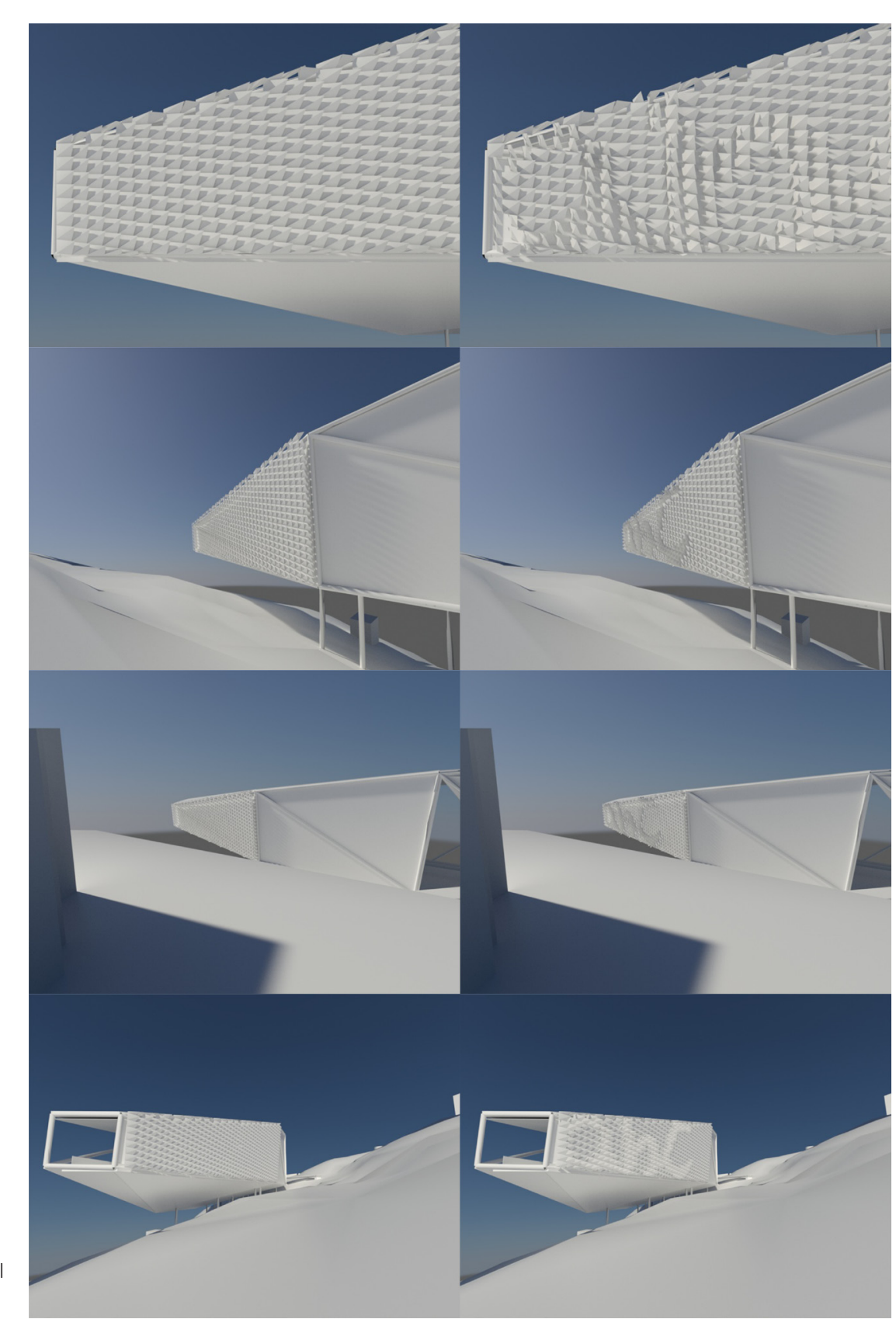


The following series of iterations develop the overlapping pane design more thoroughly. The first overlapping iteration brings the basic panel shape closer to square in elevation, and introduces two more angled faces to the surface of the panel. Bring-

ing the panel shape closer to

square results in a less interesting

aesthetic, however the two extra

angled faces improve the over-

all panel aesthetic and provide

greater definition to embedde

greater

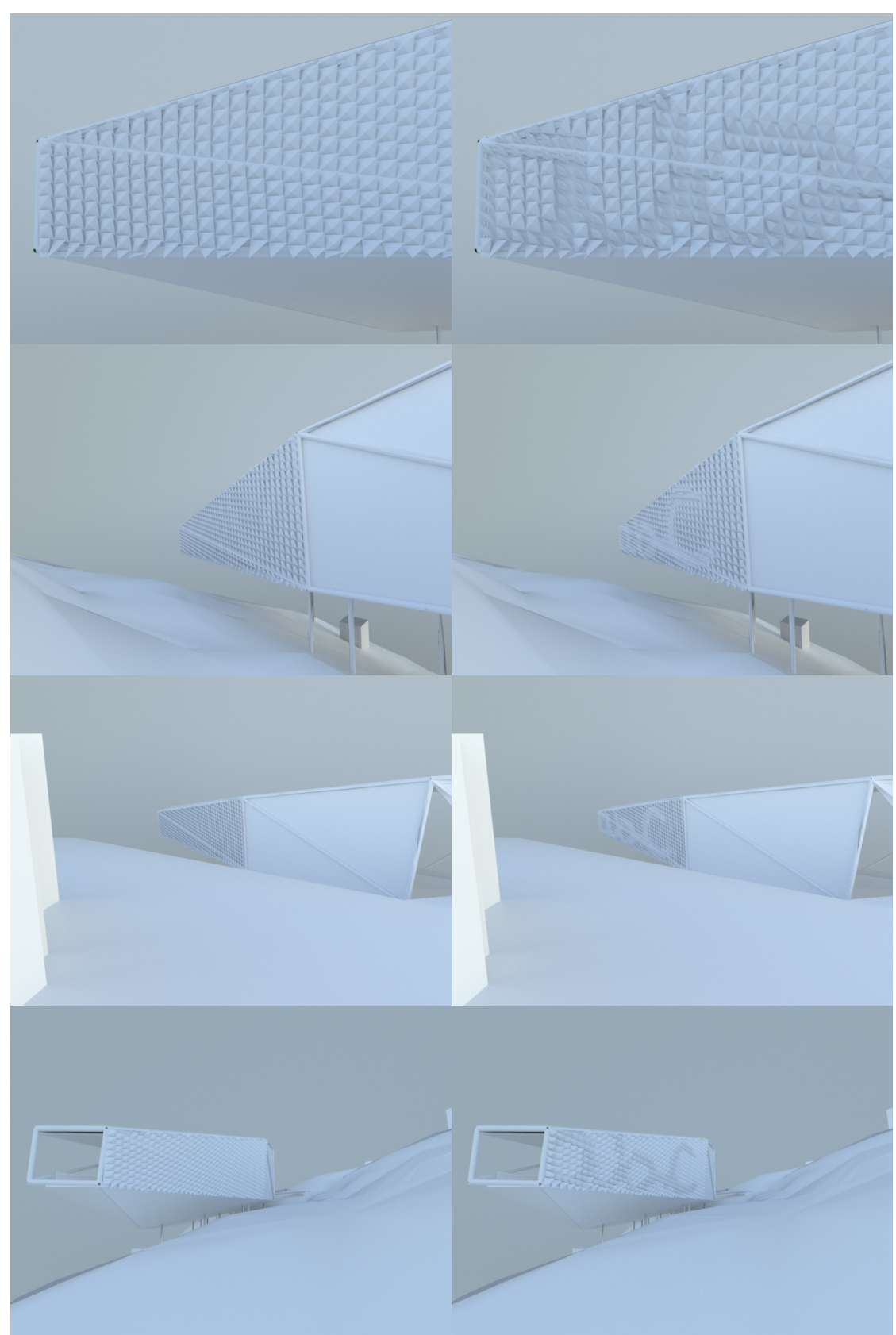

The panel design has also been rendered in a rubber material. The overall aesthetic effect is strong. Imbedded images are clear, and the material diffuses light in an aesthetically pleasing way.

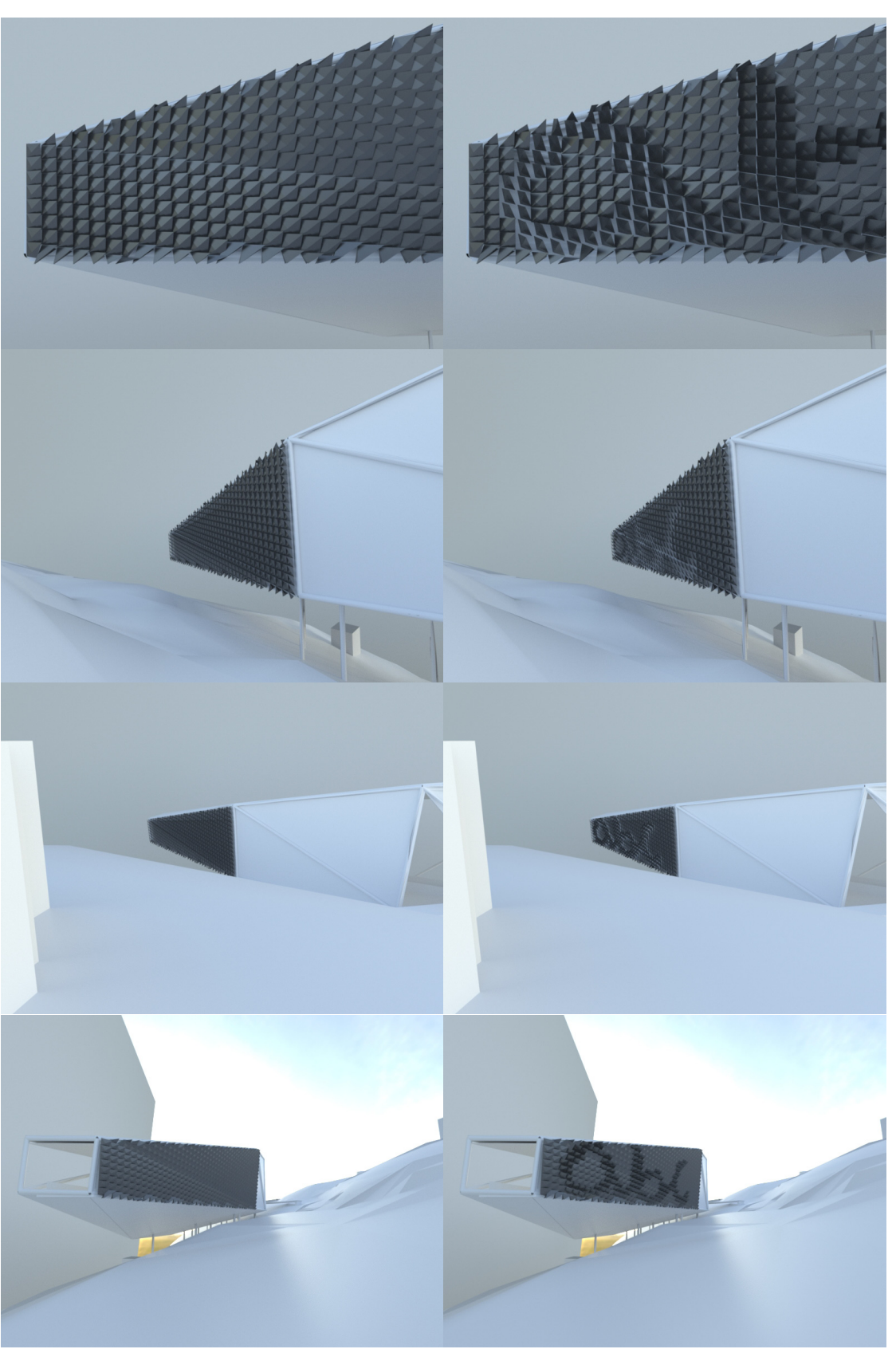


In response to the squared pane looking producing less satisfactory results, the top left point of this panel has been shifted

to produce a significantly more

angular look than previous itera-

tions. Like the previous itera-

tion, this panel has 4 faces. The

result is a strong aesthetic, and

both white and rubber materials

effectively communicate eterials

ded visual information fromb

range of distances.

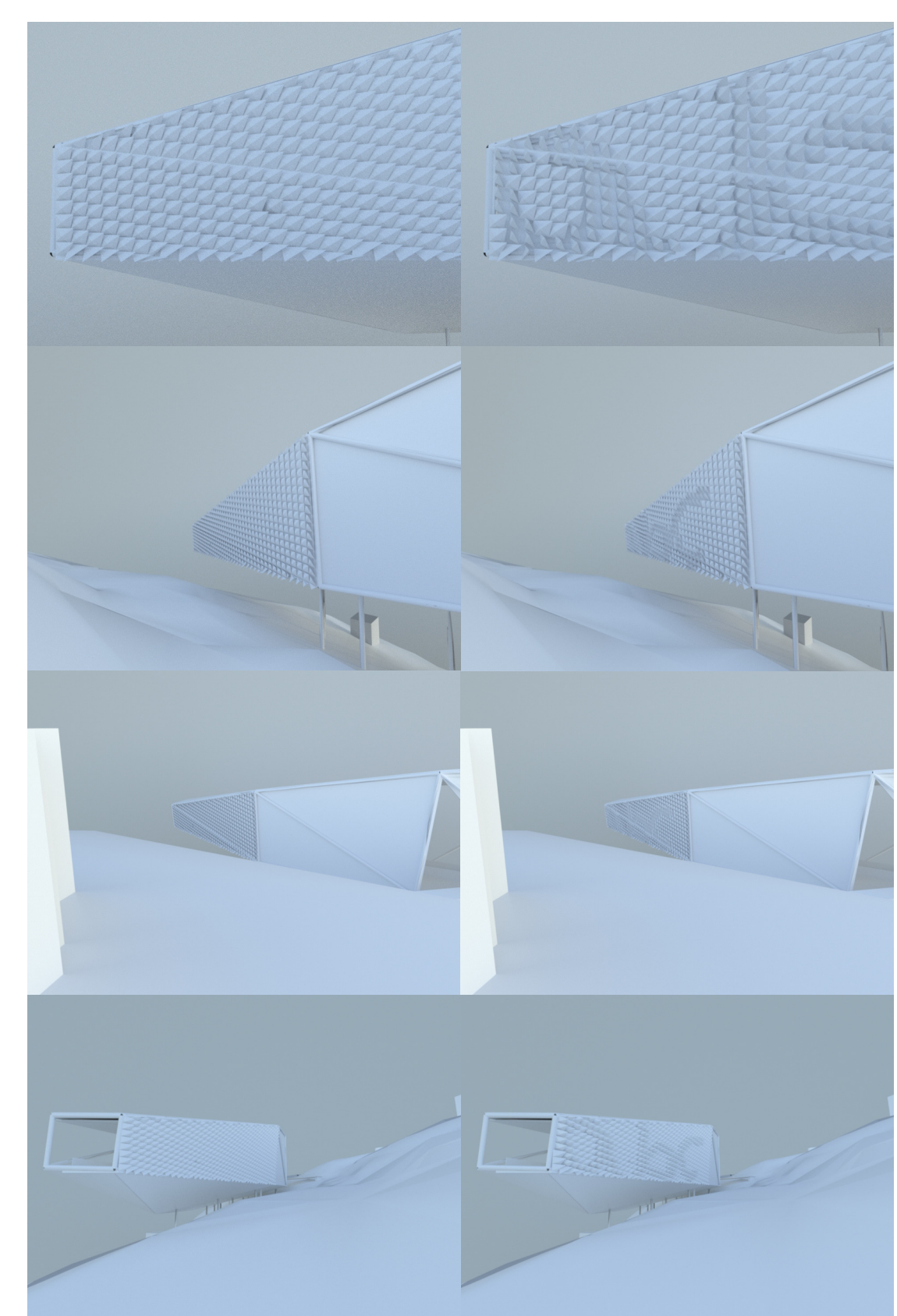

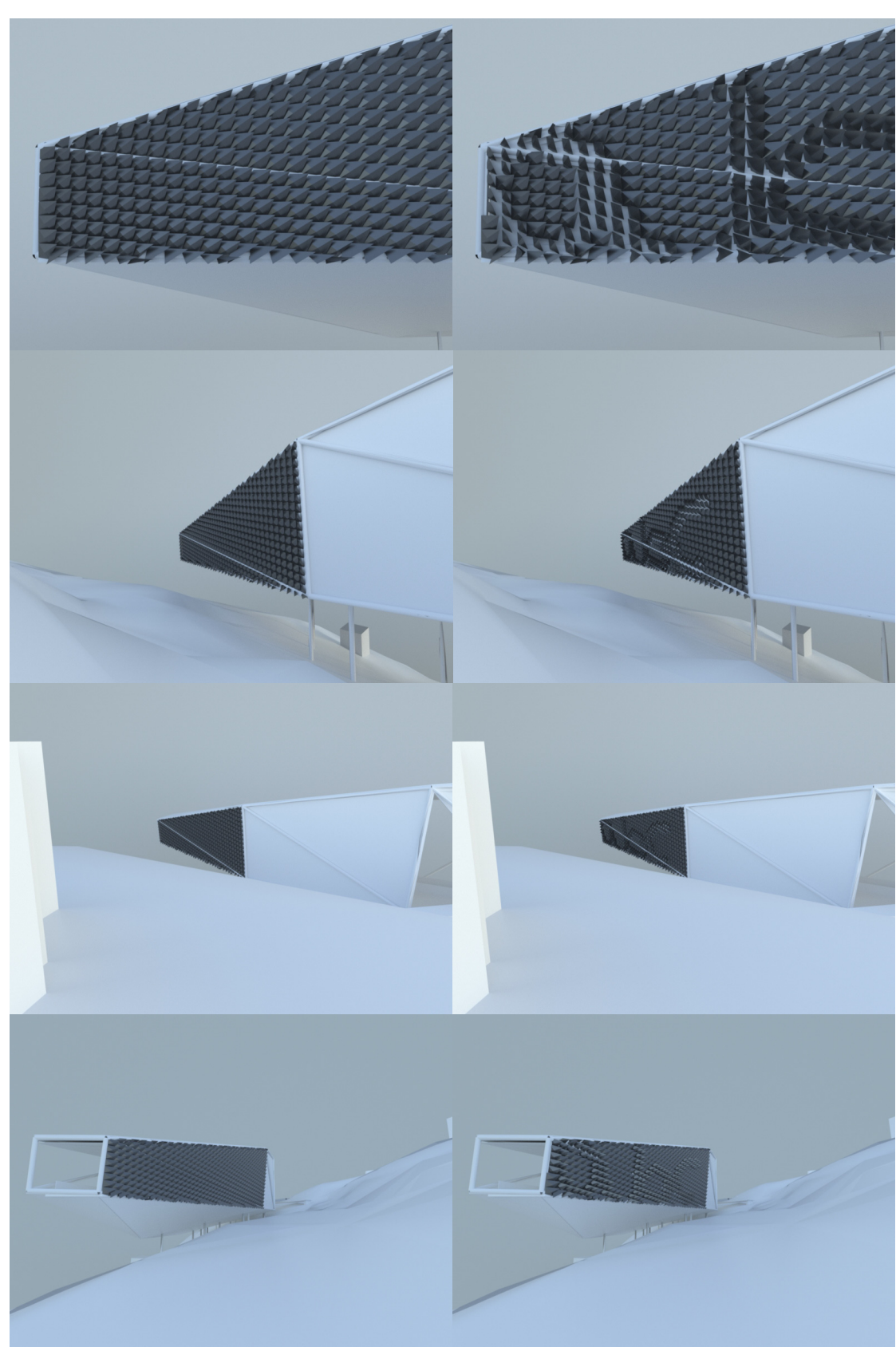
panel testing. lapping panel testing. 
This panel shape is based on the previous iteration, but the four front faces converge on a point set into the body of the panel, producing a dished outer

surface. The concave panel does

not look as good as previous

iterations- the panels appear

to be flatter and less dynamic

Imbedded images are not signifi-

cantly improved with this design

cantly improved with this design

to warrant further development.

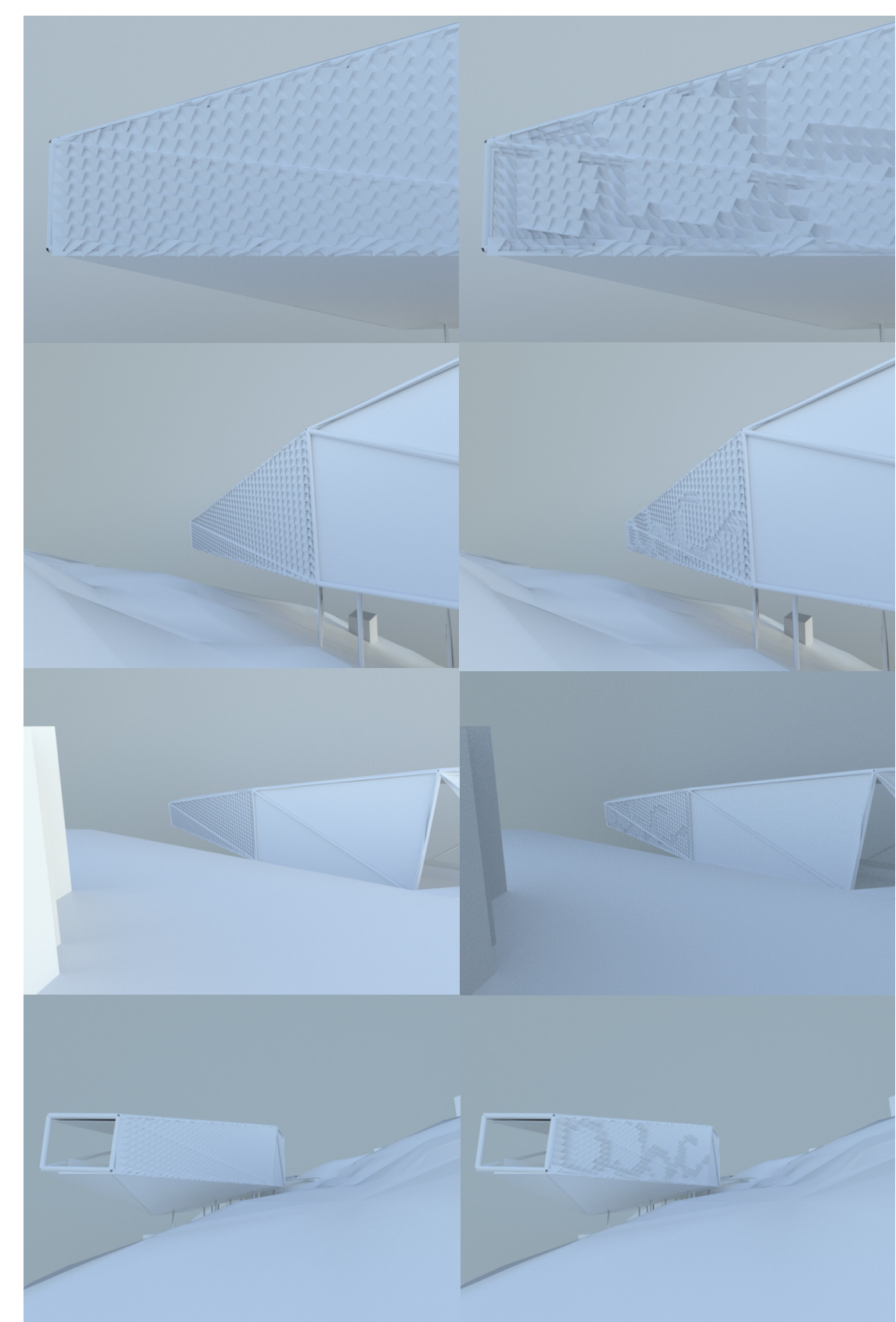

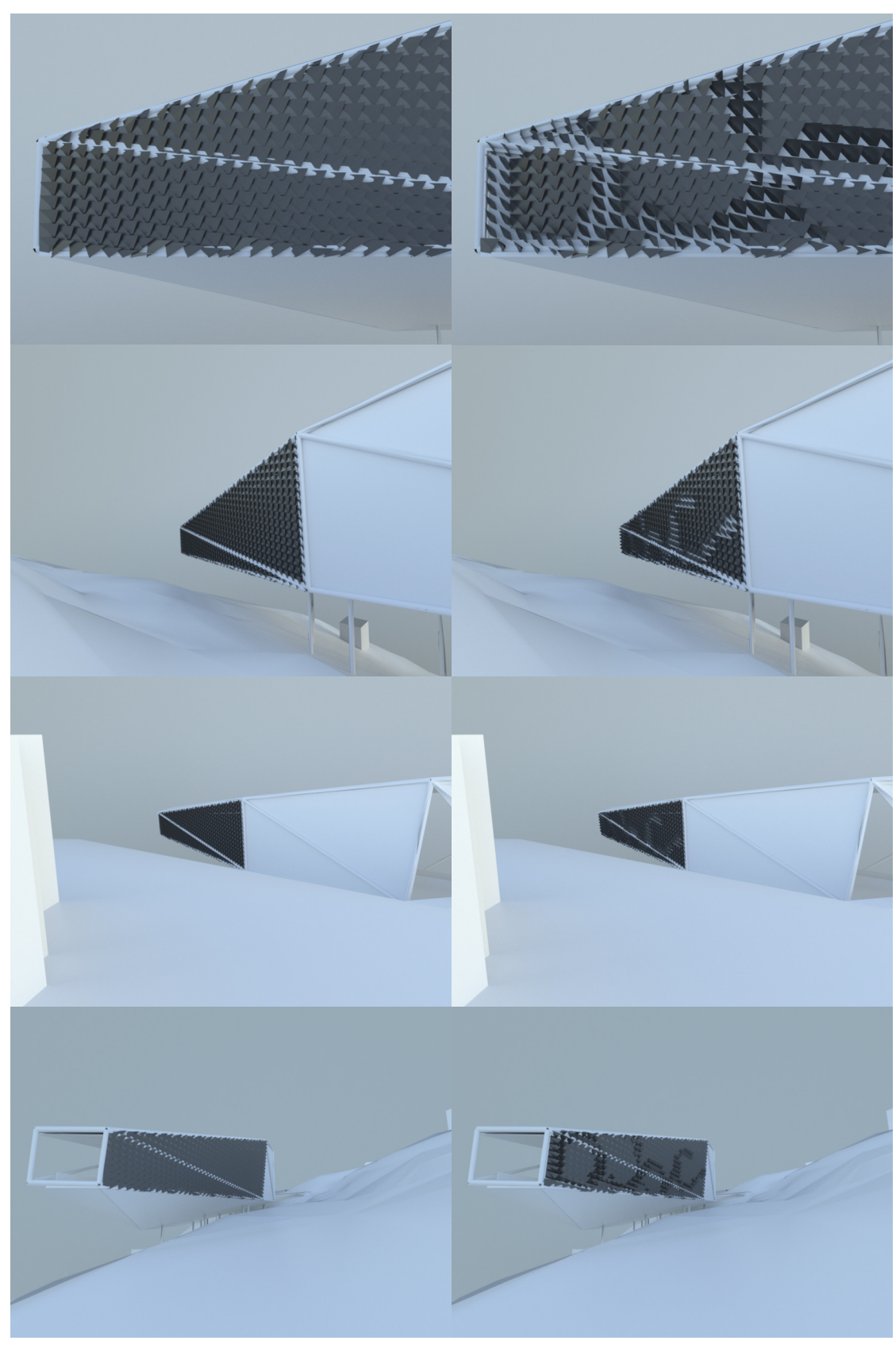
from concave r. 
The first panel iteration in this test was trialled again, in metallic and matte grey finishes. In comparison to the white finish, the metallic

finish did not clearly communicate

images, except from the cam-

era positioned 24 metres to the

north. The metallic finish however

looks good applied to the skin.

The matte grey finish has a similar

aesthetic effect to the white;

however embedded imite;

significantly clearer.

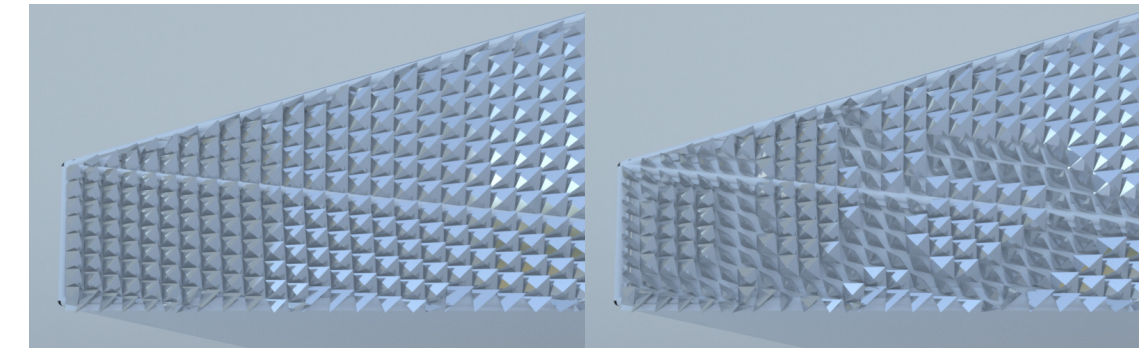

Fig. 2.111-2.119. Frames from 'square' grey over-
lapping panel testing.
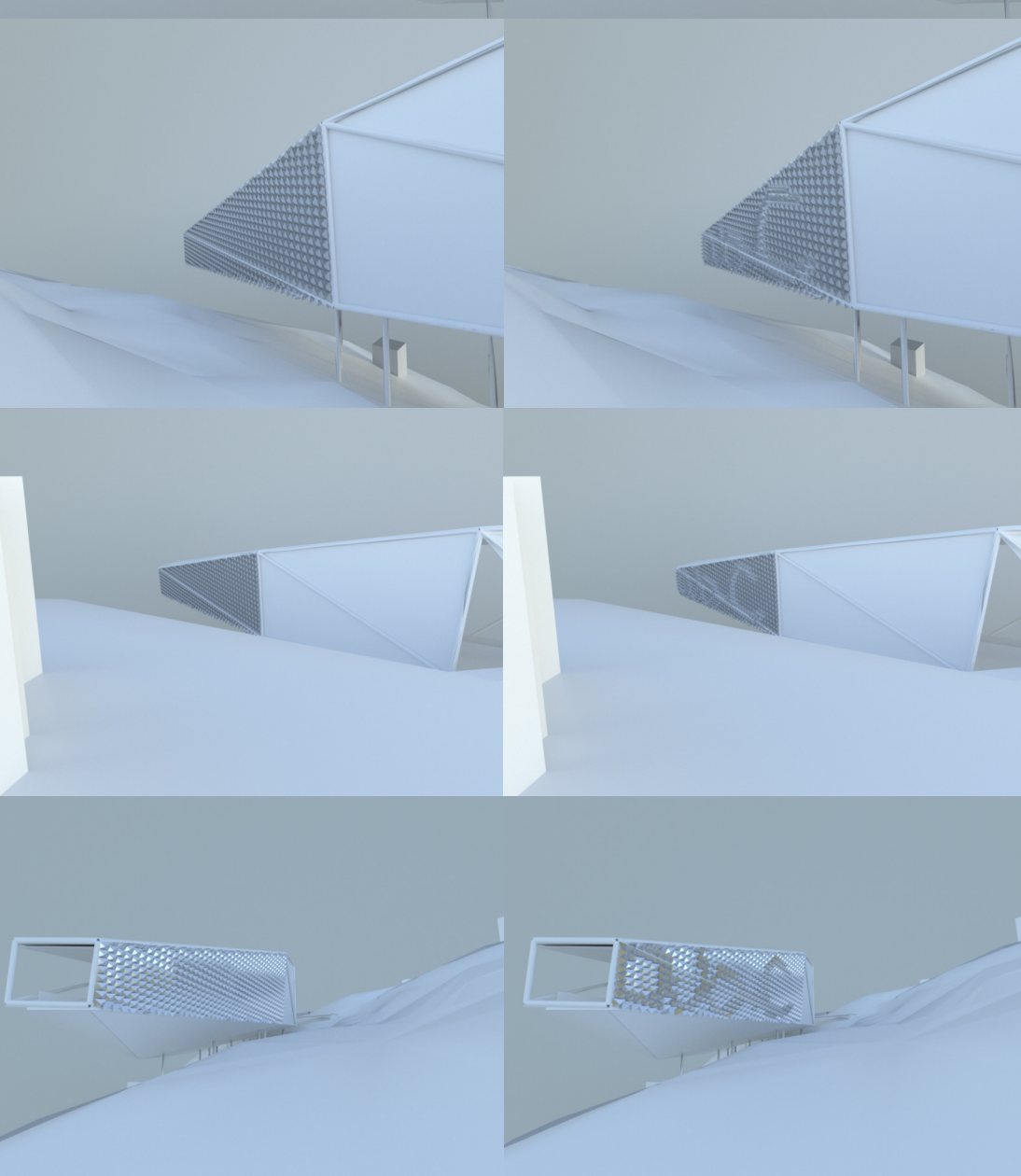

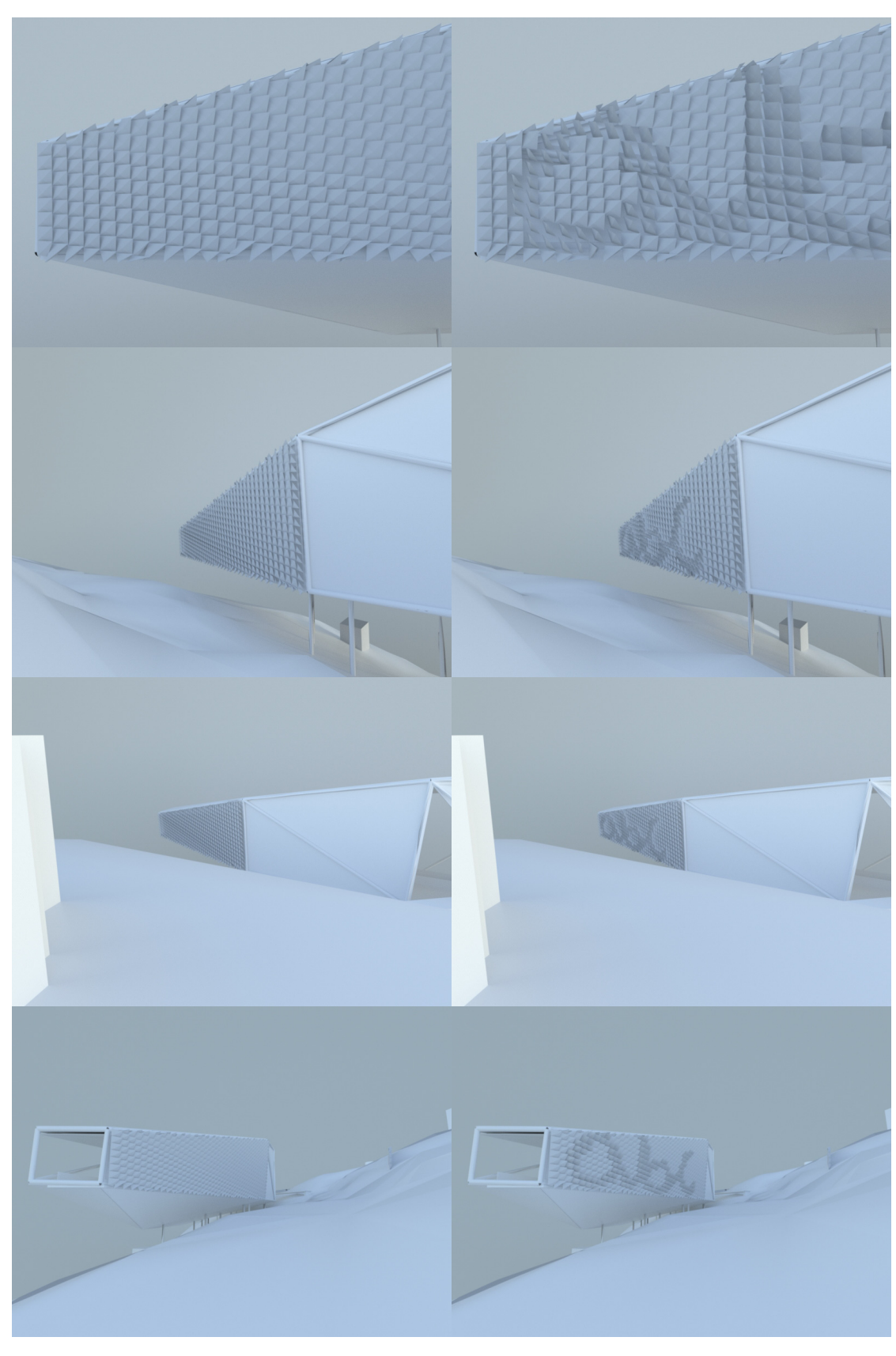


The final panel iteration is comprised of 8 surface segments, with 2 adjacent peaks and 1 valley. The increased surface complexity of this design improves the definition of embedded images, and creates a satisfactorily complex faceted

surface. A more complex surface

may be too difficult and costly to

feasibly construct, whereas a de-

sign with a simpler surface results

in less clear images and is not as

aesthetically pleasing.

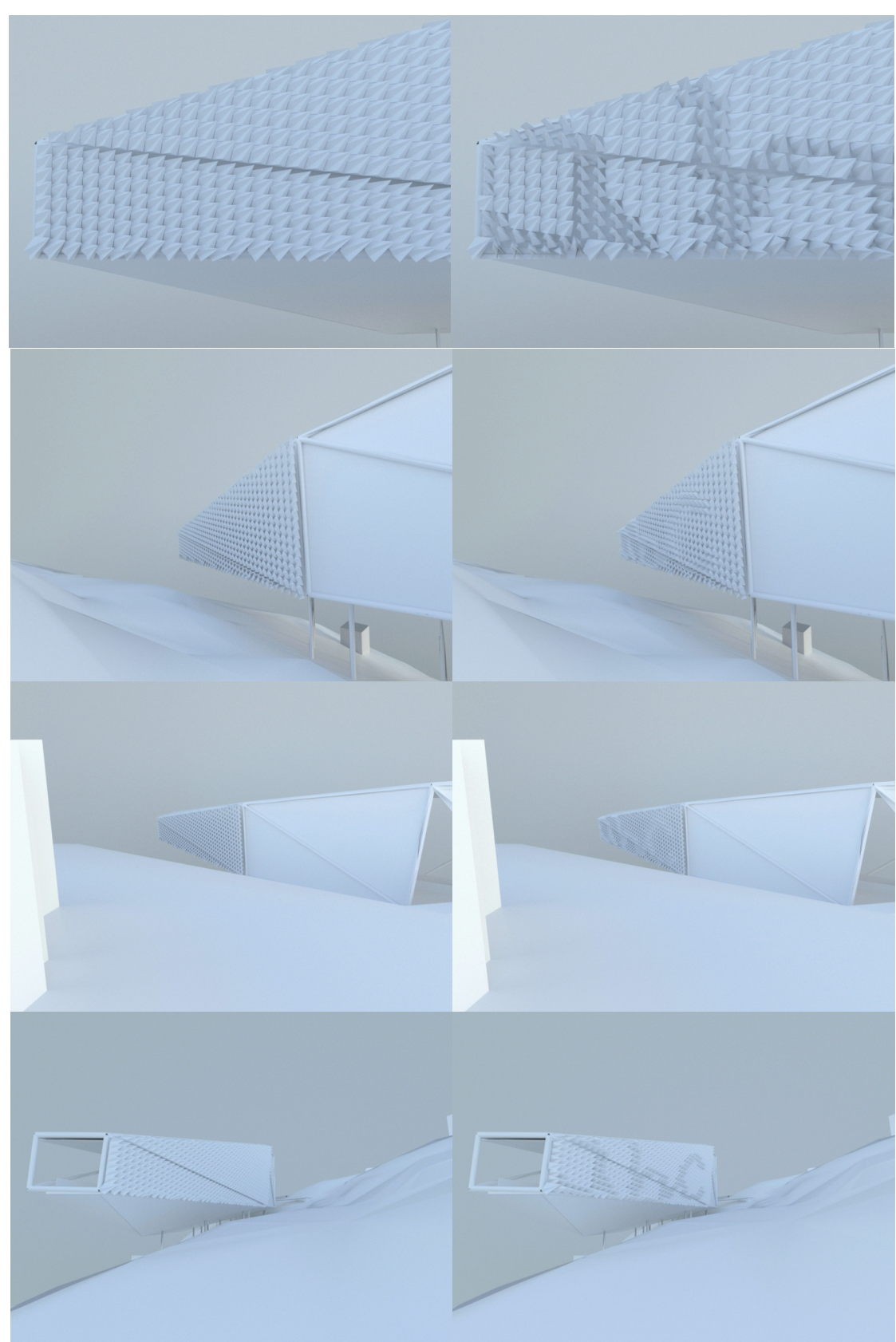

The final iteration has been rendered in a clear polycarbonate material. Imbedded images are difficult to see, however, extruded cellular polycarbonate would be an effec-

tive material to construct the panel

form. A net of the skin could be CNC

routed to produce the complex panel

geometries quickly and low cost.

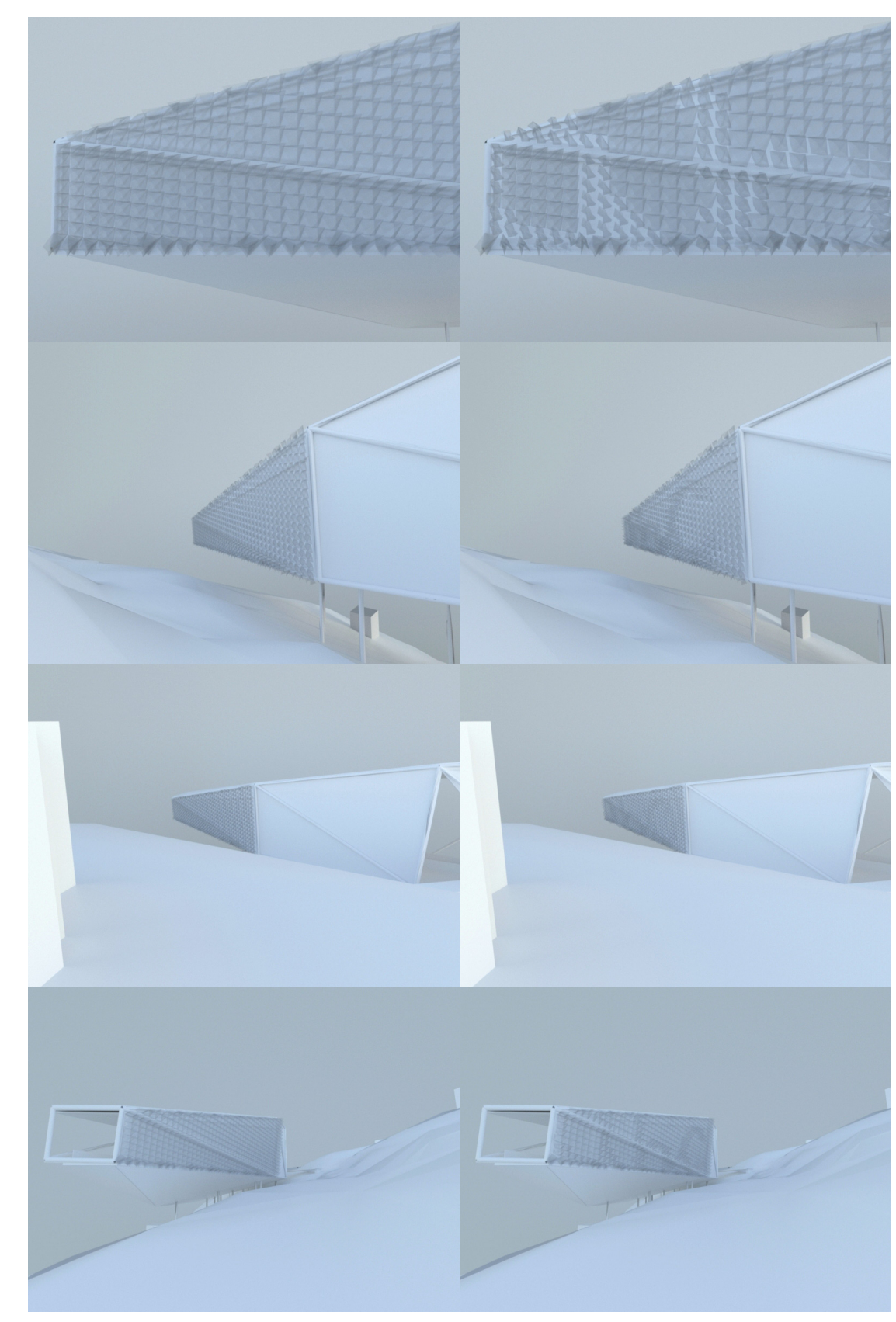



from the iterative testing were the 8 segment, 2 peak unit; and the elongated 4 panel and 1 peak unit. Most of the design decisions stemmed from a desire to develop an aesthetical pleasing panel form. The nam Kinetic Unit (KU) has been given to the final design.

Light grey, rubber and polycarbonate materials performed well for various reasons, and will be considered for use in further development.

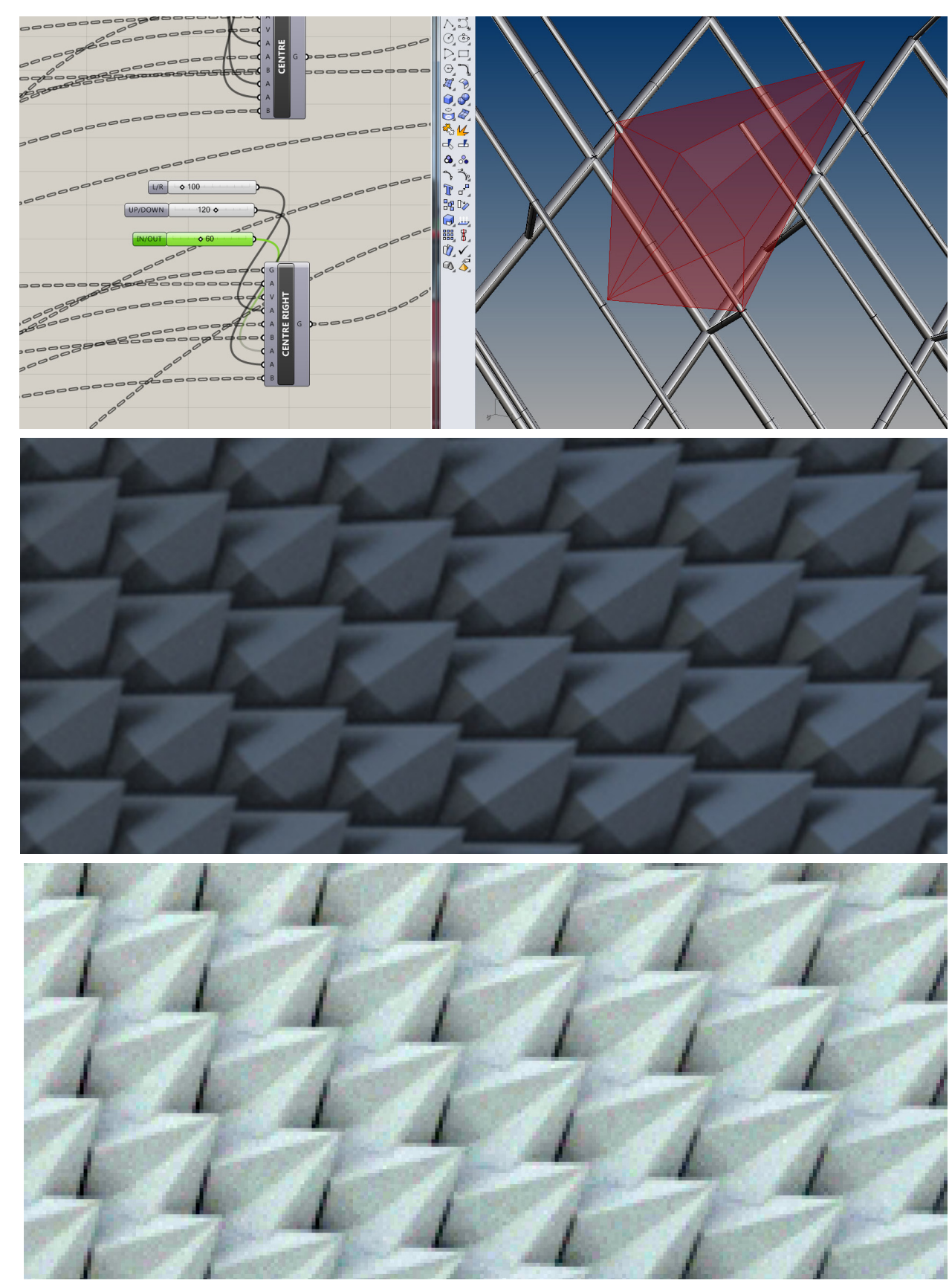

Fig. 2.129. (Top) ParametFig. 2.130-2.131. Details of test frames, showing
successful iterations
The most successful designs
Like the Kinetic Unit, the skin's structural support system was developed using an iterative parametric modelling approach. The parametric definition allowed adjustments to be made to the configuration of structural ele

ments, their spacing and size. This

allowed the structural design to

state, as can be seen in figure

2.132 and 2.133 , to a more con-

vincing final result, with gre con-

vincing final result, with gradual

definition based on feedback from

Fig. 2.132. Test render from iterative structur
develooment process

Fig. 2.133. Parame modelling interface fro iterative structural deveFig. 2.133. Image from iterative structural deve-
opment process develop from a rough and no

design professionals.
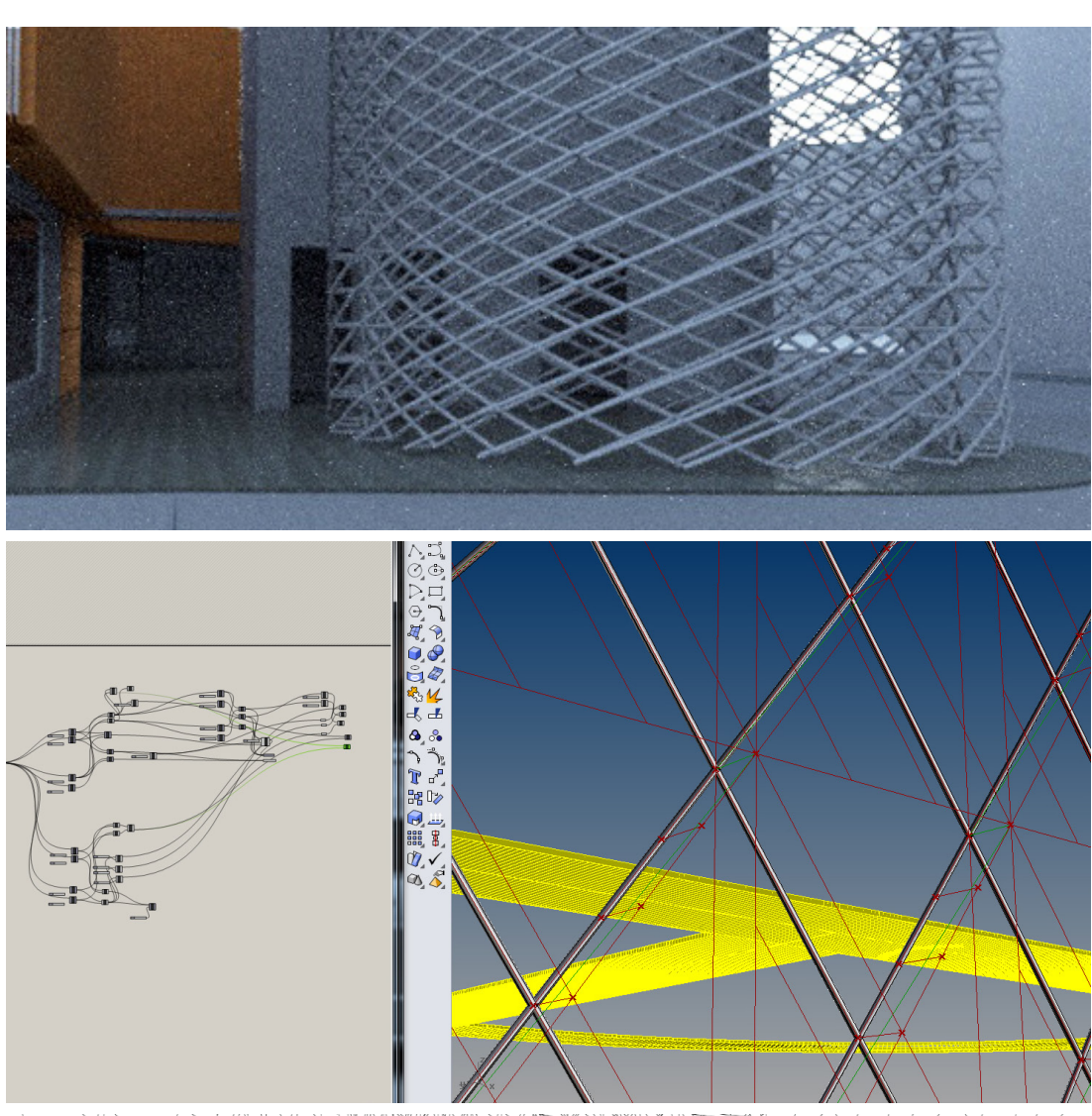
3. Developed design 


\subsection{Kinetic skin system}

The design process in Section 2.2 has resulted in a parametric model that is capable of producing the developed skin system on both planar and curved surfaces. One definition has been developed to

describe the resolved Kinetic Unit, and another to

describe the basic structural system and an internal

layer of glazing. The definition has been developed so

that panel rotation can be parametrically controlled

with environmental data sampled from the internet,

either directly by user input or via an image sampler

to enable the display of images. The definition also

allows for structural members to be rearranged and resized, which is useful for further engineering of the system, and for alterations to be made to the shape of the Kinetic Unit.

Section 3.0 introduces the developed panel system. This system is based on the design information and 3D model data produced by the developed parametric definition, however construction detail which is not present in the definition has been added. This detail has been digitally modelled, but is not parametric. The addition of construction information at this stage of the design process exposes a limitation in the parametric modelling methodology. Adding in the parametric modition model is possible; however it represents significant further developme ho the definition and would refurther development to the definition and would re-
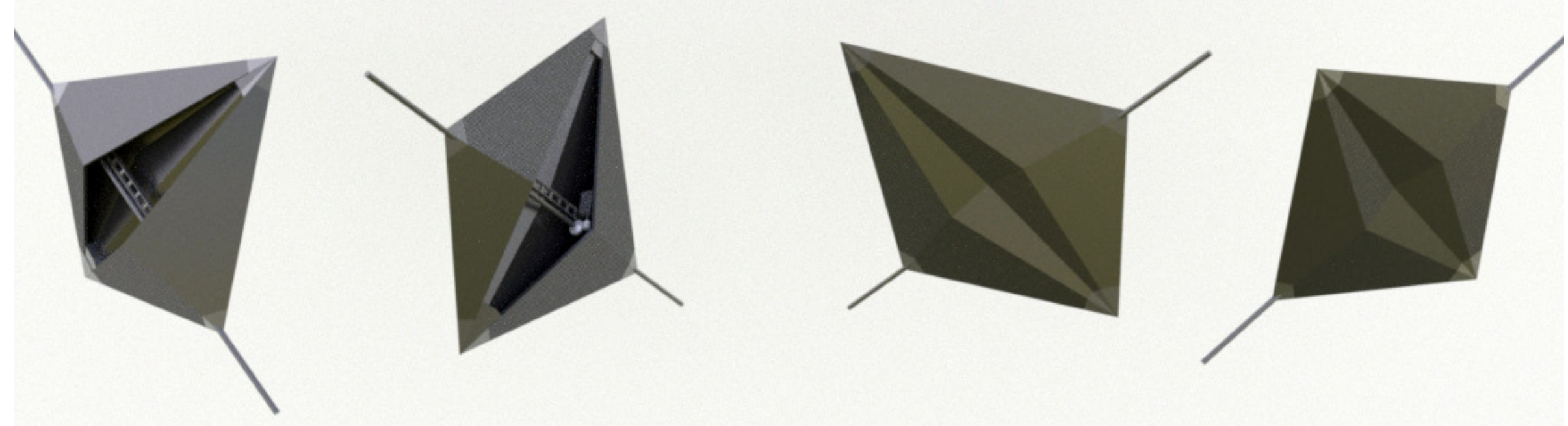

Fig. 3.1. Final Kinetic
Unit shown in a rubber

finish. 16D galvanized and

powdercoated steel rod 
CNC routed aluminium tips,

fixed with adhesive to polycar-

bonate skin

Electric motor and worm drive

mounted to CNC routed alu-

minium strut

$10 \mathrm{~mm}$ twin cell polycarbonate

net, $10 \mathrm{~mm}$ CNC routed channels

along folds to allow sharp outer

edges

Ball bearings housed in end tips

Powder coated and galvanized $16 \mathrm{D}$ mild steel support rod not shown in image

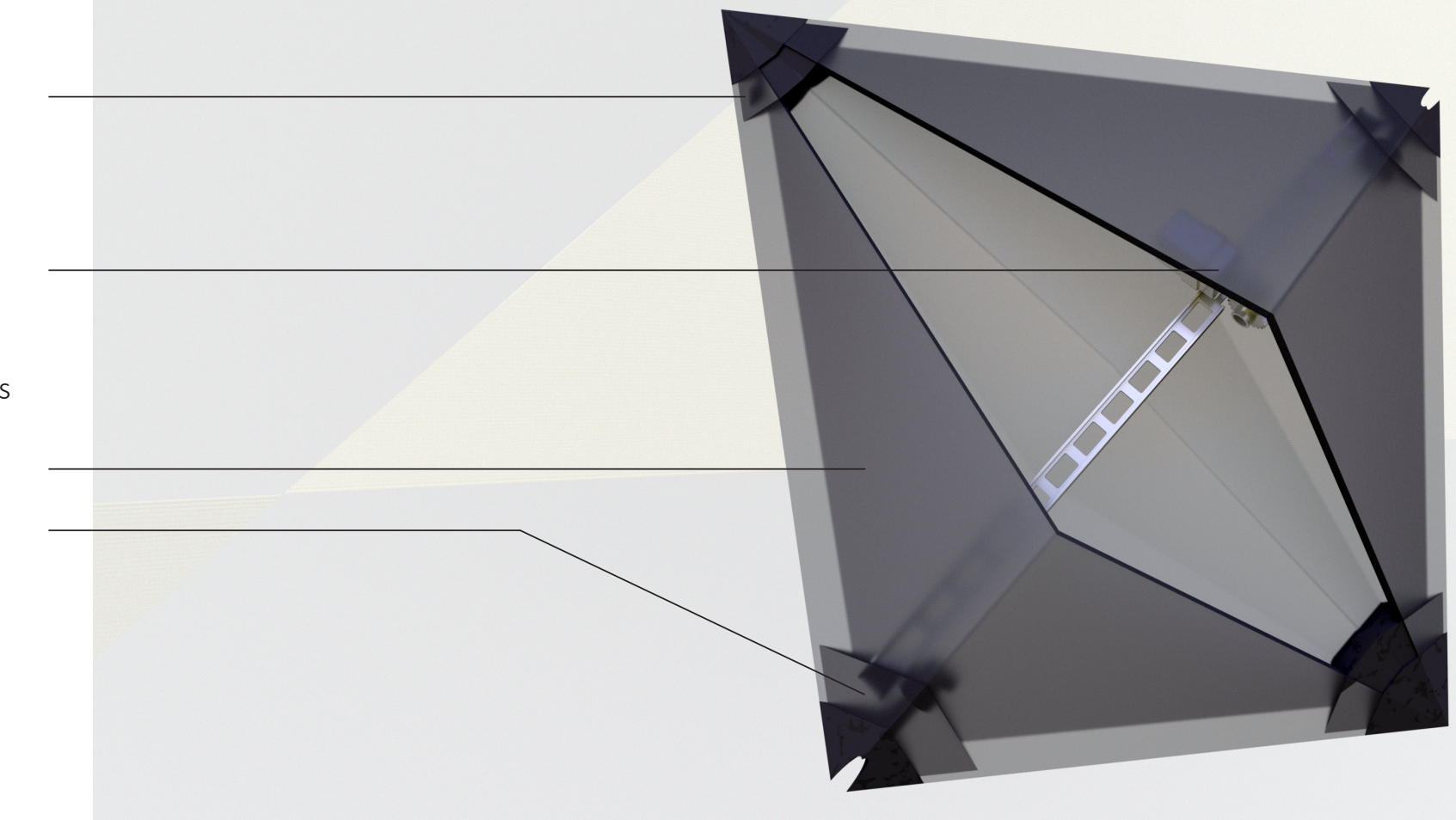

Fig. 3.2. Kinetic

polycarbonate skin. 


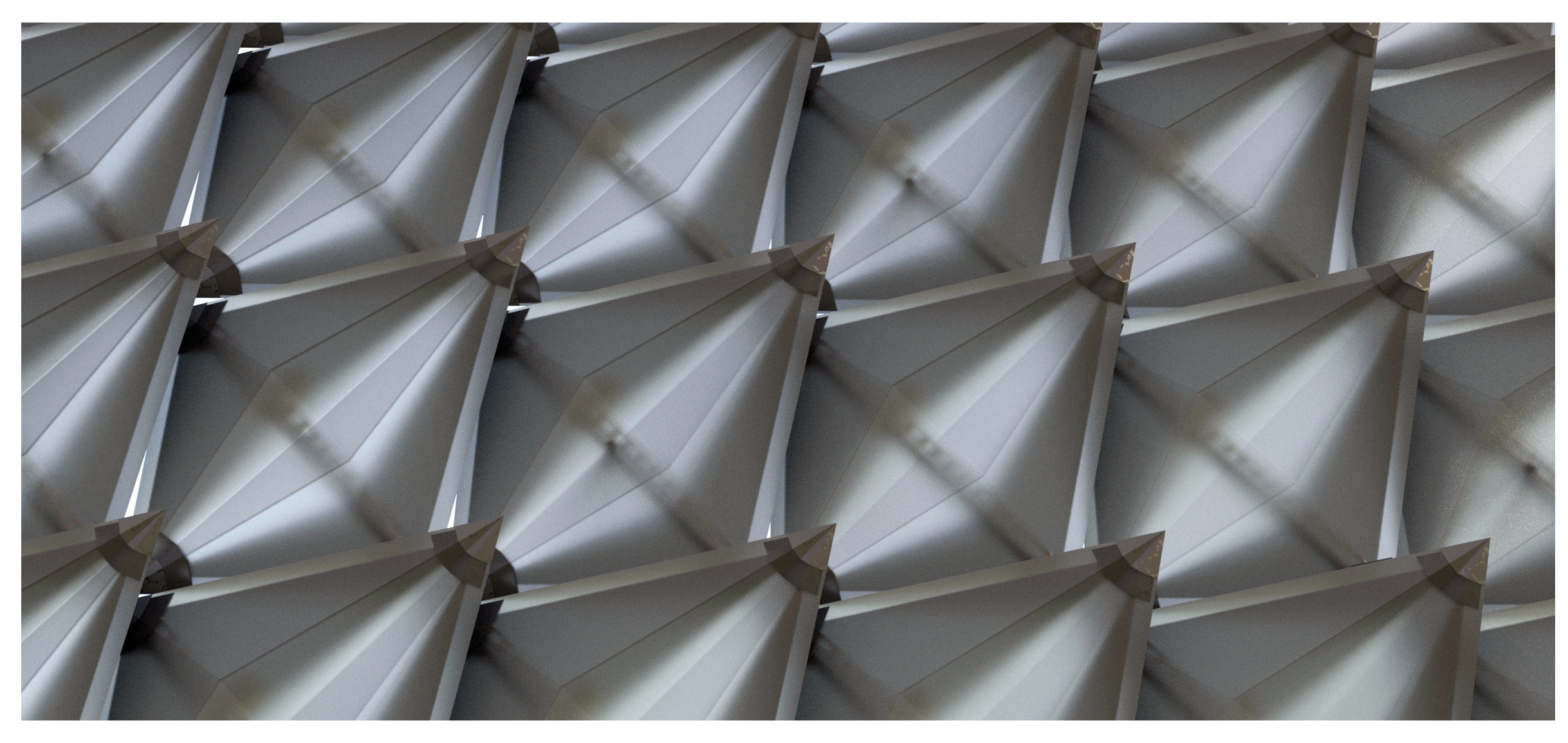

Fif. 3. . Final skin design,
showing all panels art est. 


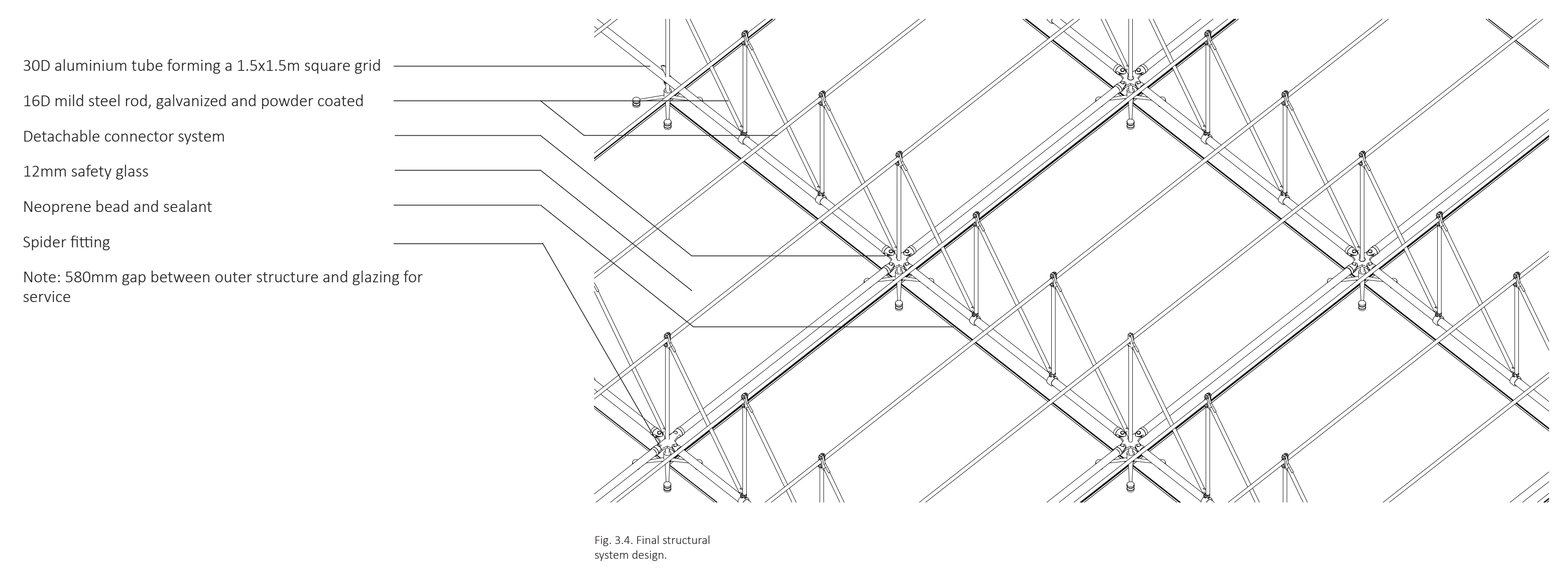




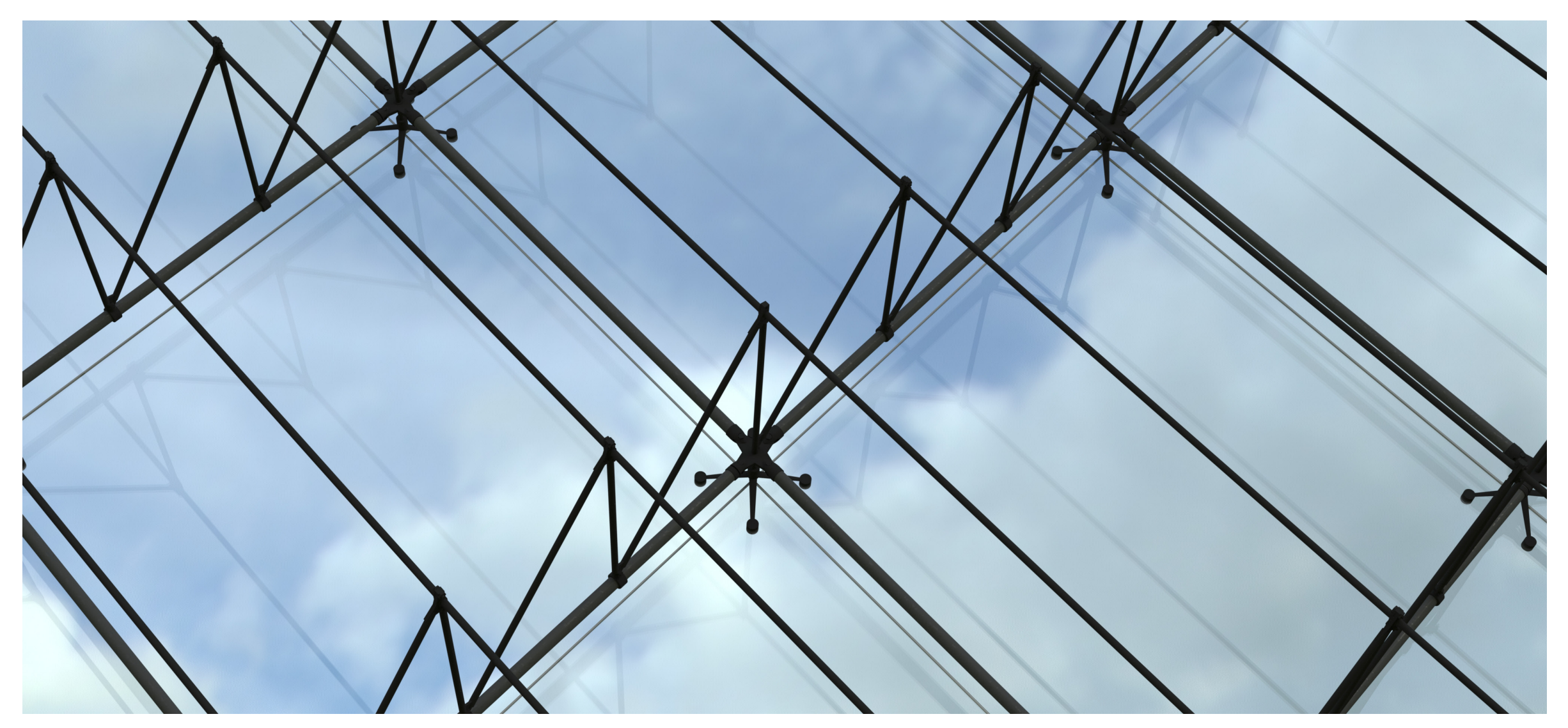




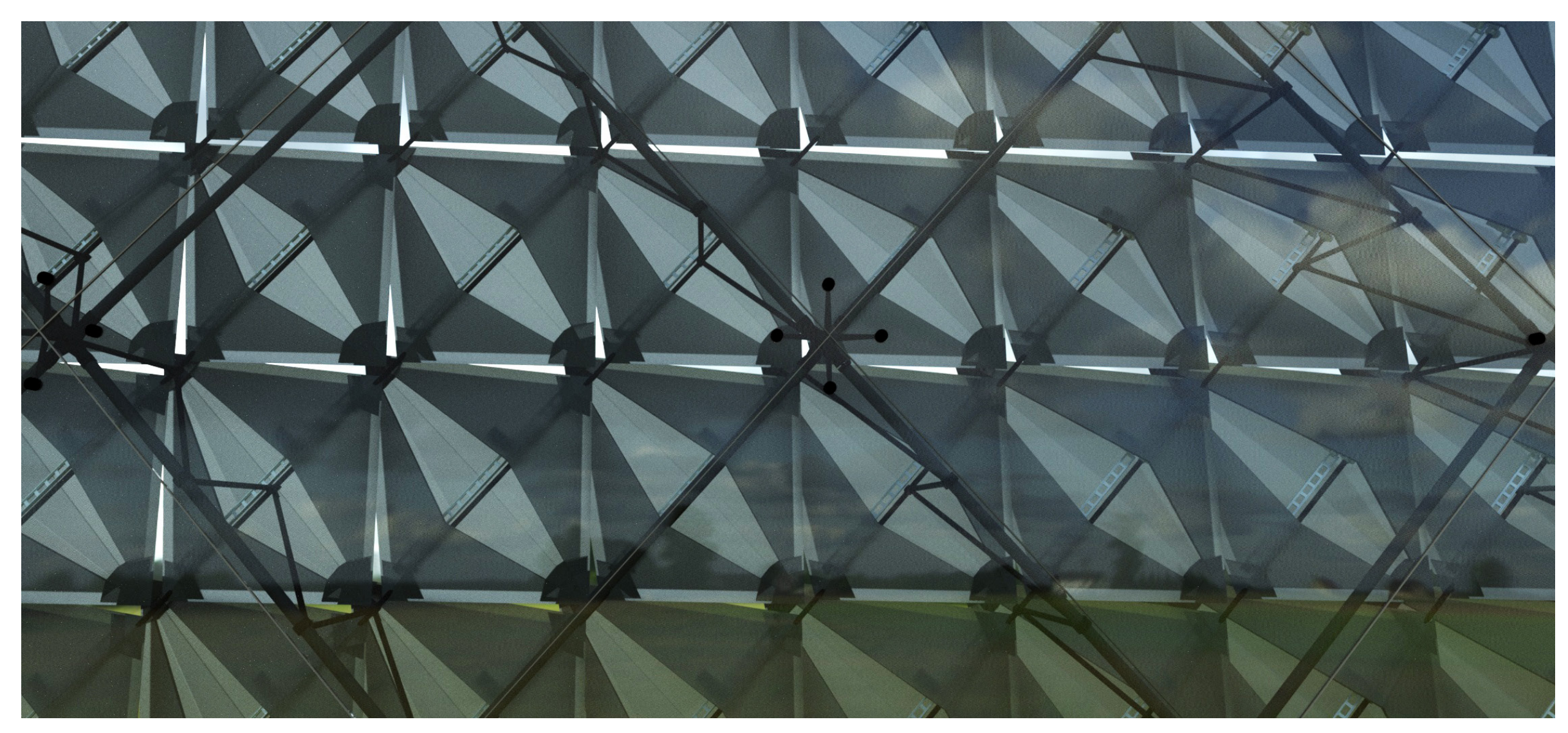

Fig. 3.6. Final skin design
viewed from the internal

face (actuation components
omitted from render) 


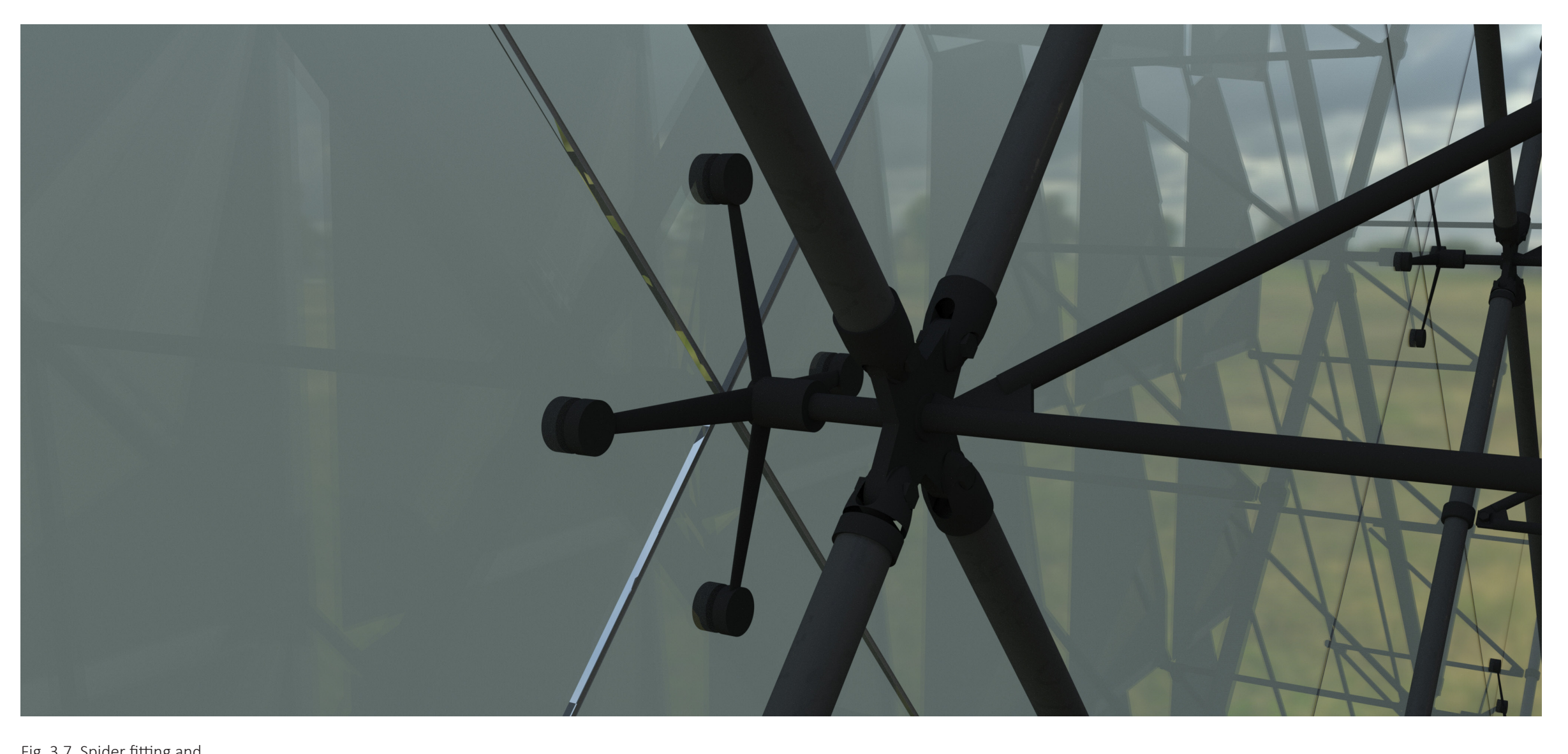

Fig. 3.7. Spider fititing and

joint system 


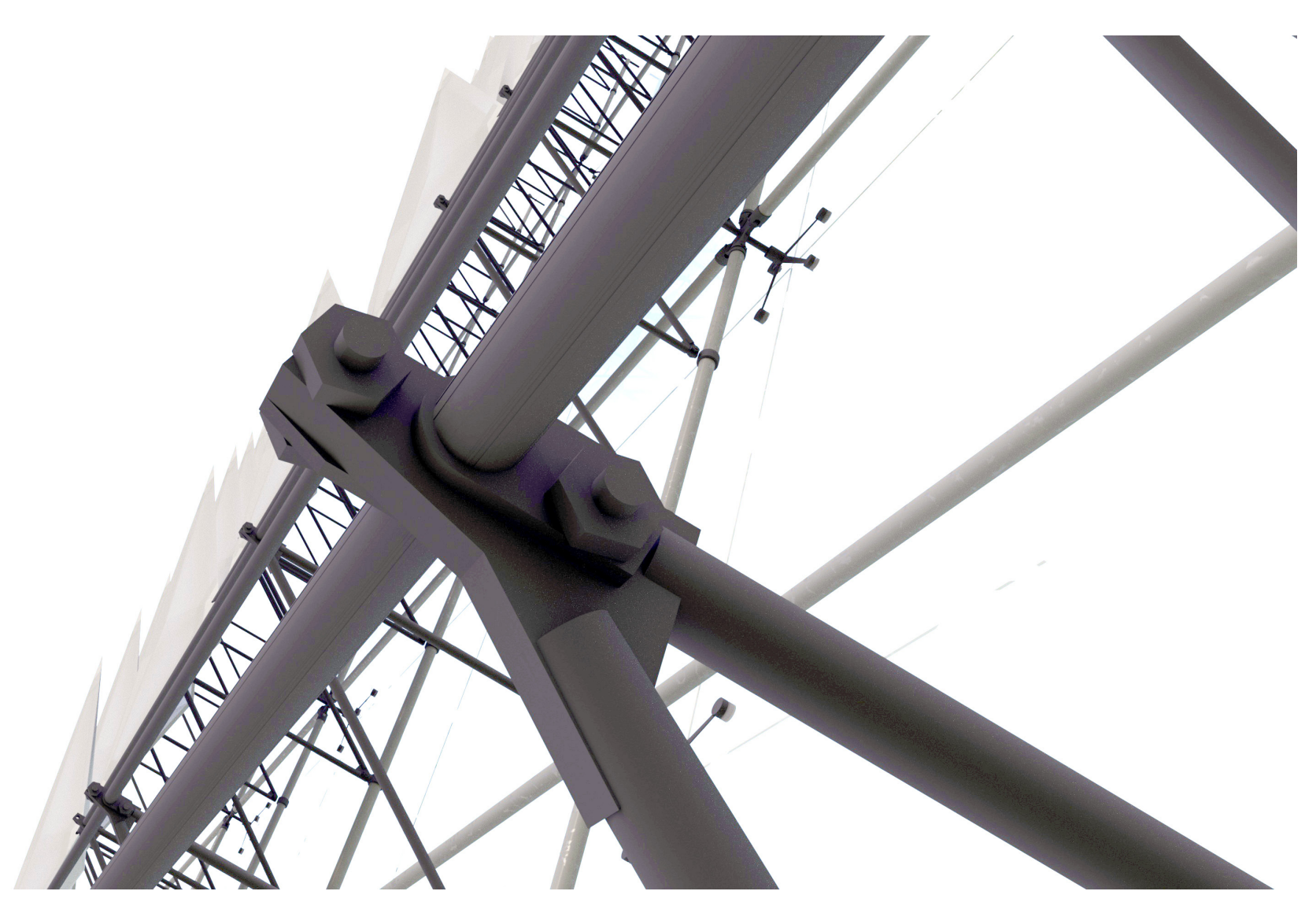

Fig. 3.8. Secondary joint
system. Joint allows outer

rods to be removed to

allow for maintenance
of Kinetic Units and
structure. 


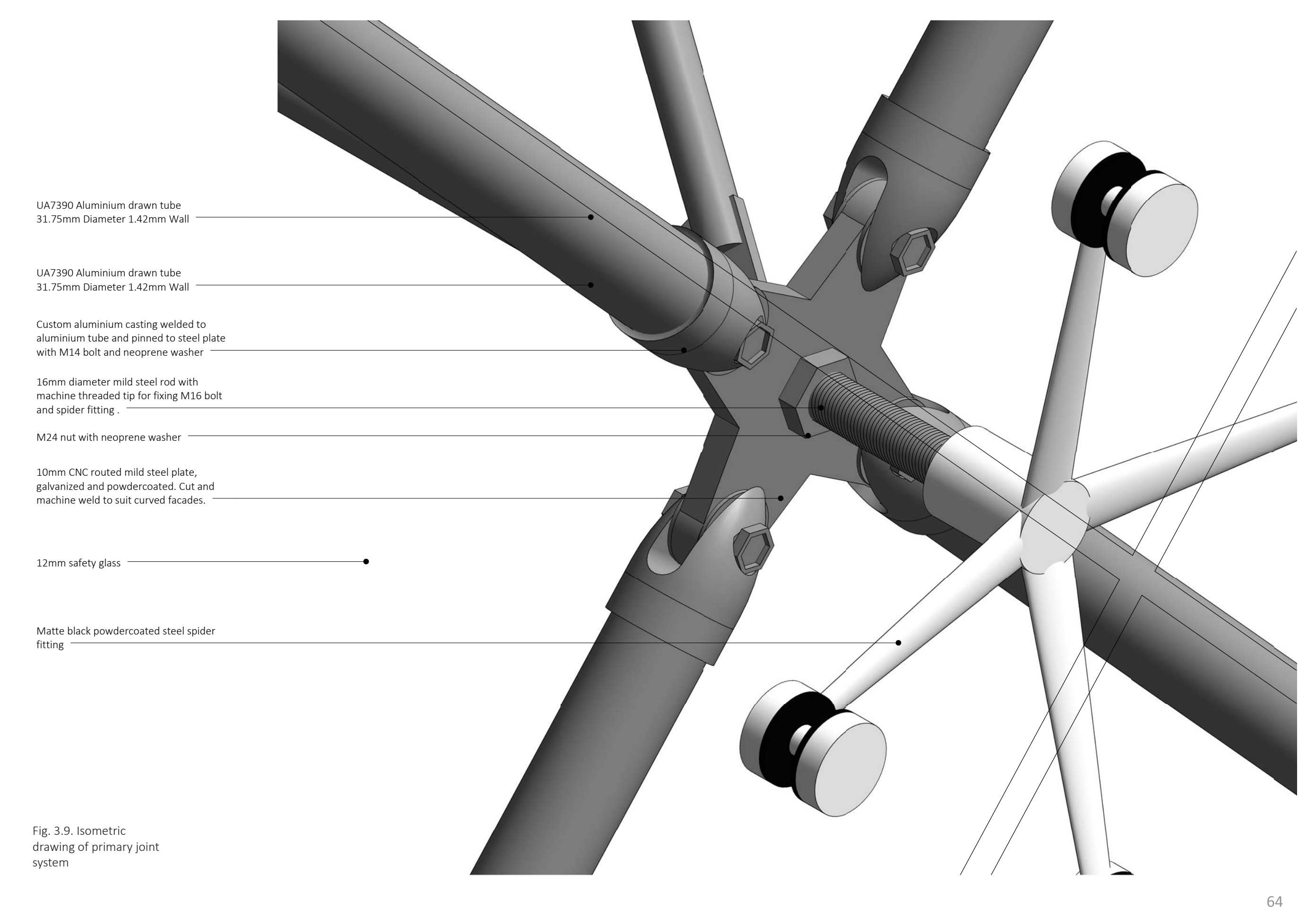




\subsection{Kumototo}

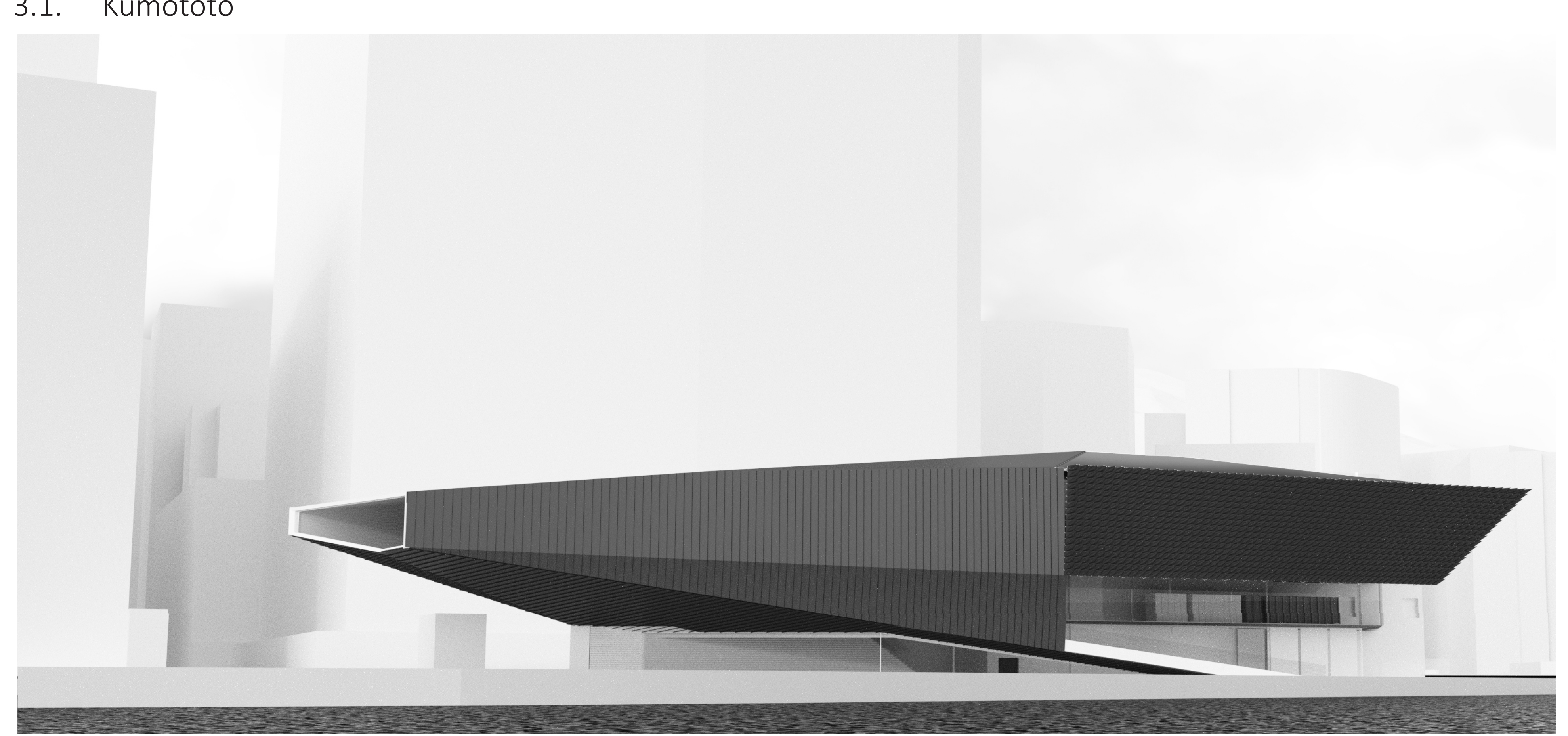




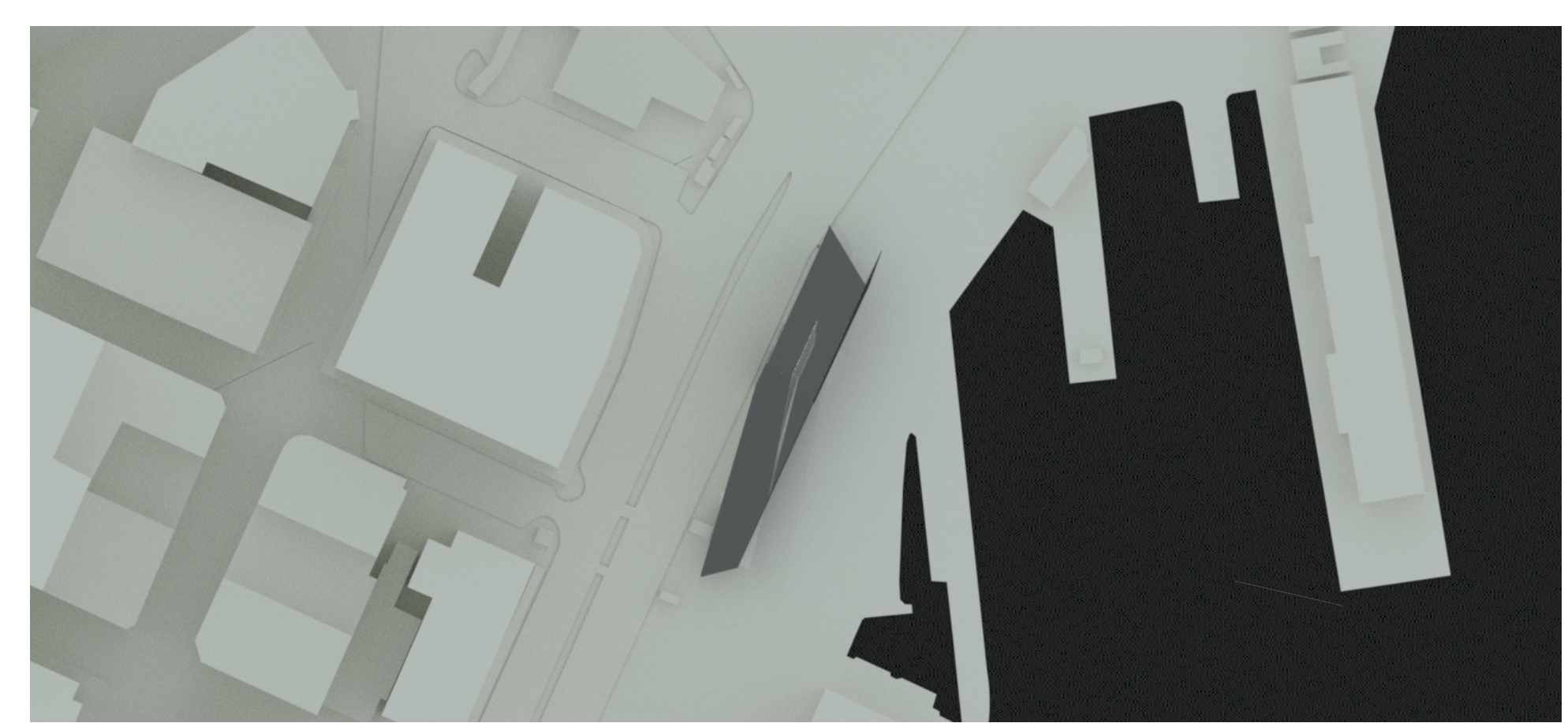

$\Delta \mathrm{N} 50 \mathrm{~m}$

Fig. 3.11. Site Plan.
Sections 3.1 and 3.2 introduce the kinetic skin system in the context of two proposals for NIWA's High Performance Computing Facility. The responsive skin definition has been applied to these designs in order to describe potential design applications, and to evaluate the performance of the skin

The first design proposal is sited in the Kumototo precinct of Wellington's waterfront. The site divides Waterloo Quay (an arterial road), and an

increasingly busy public waterfront space. The building presents an opportunity to test responsive architectural elements which need to angapporthe public, while also providing some environmental control to the interior spaces of the building.

The sculptural form of the building is the product of a long and narrow site a desire to lift the edges of the building upwar access, and meteorological fro

The building is publicly accessible at ground level, with exhibition and dis-

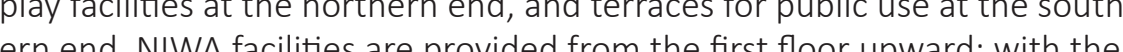
super computer occupying the entire first floor, and offices and lab spaces 


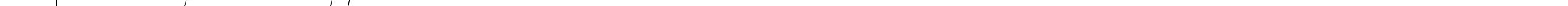




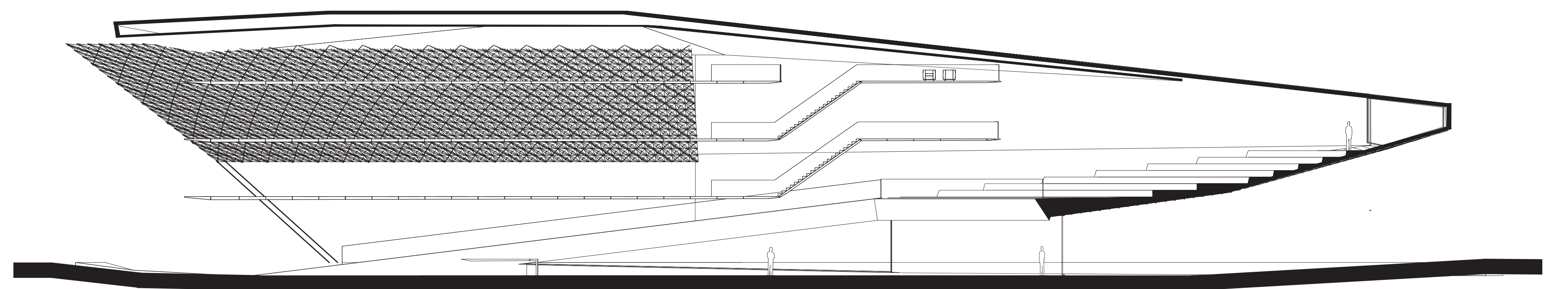




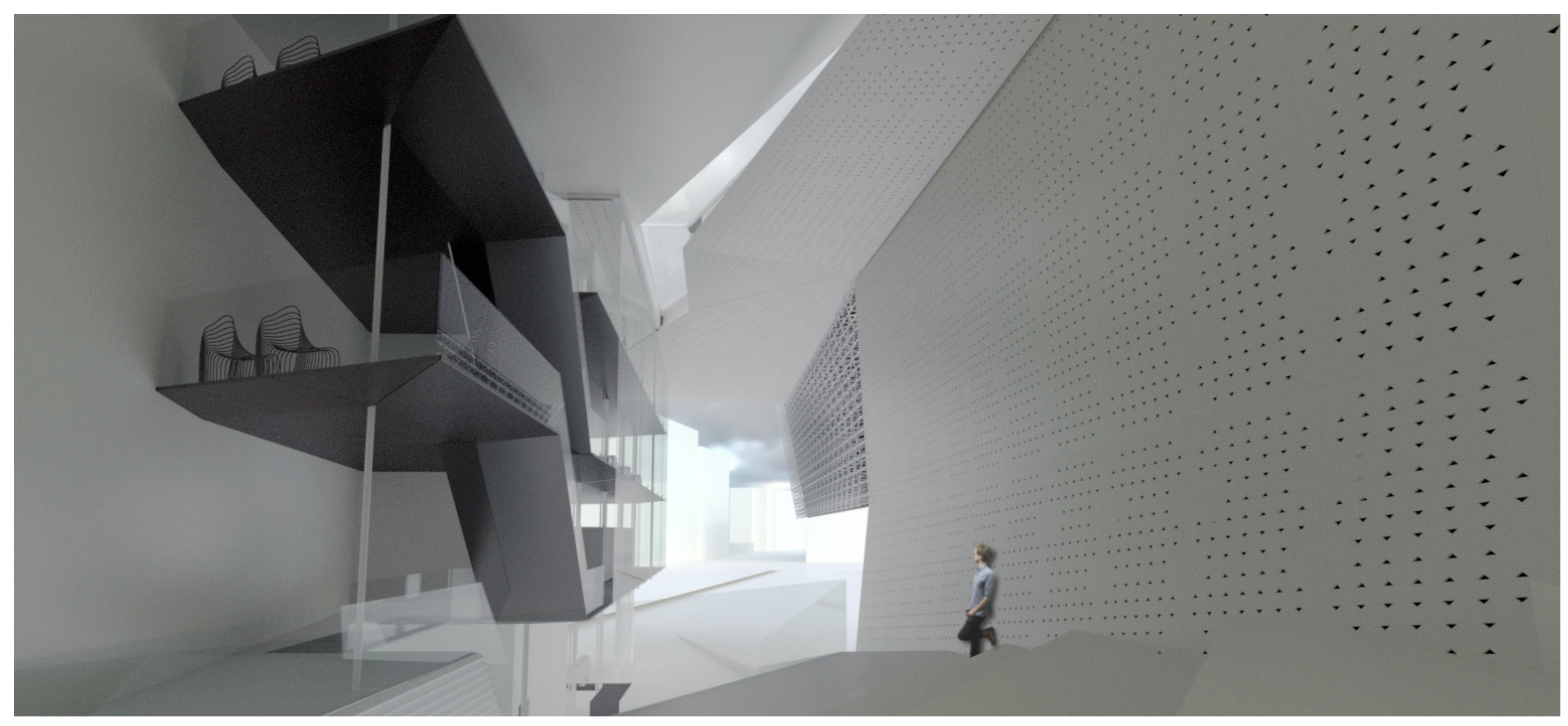




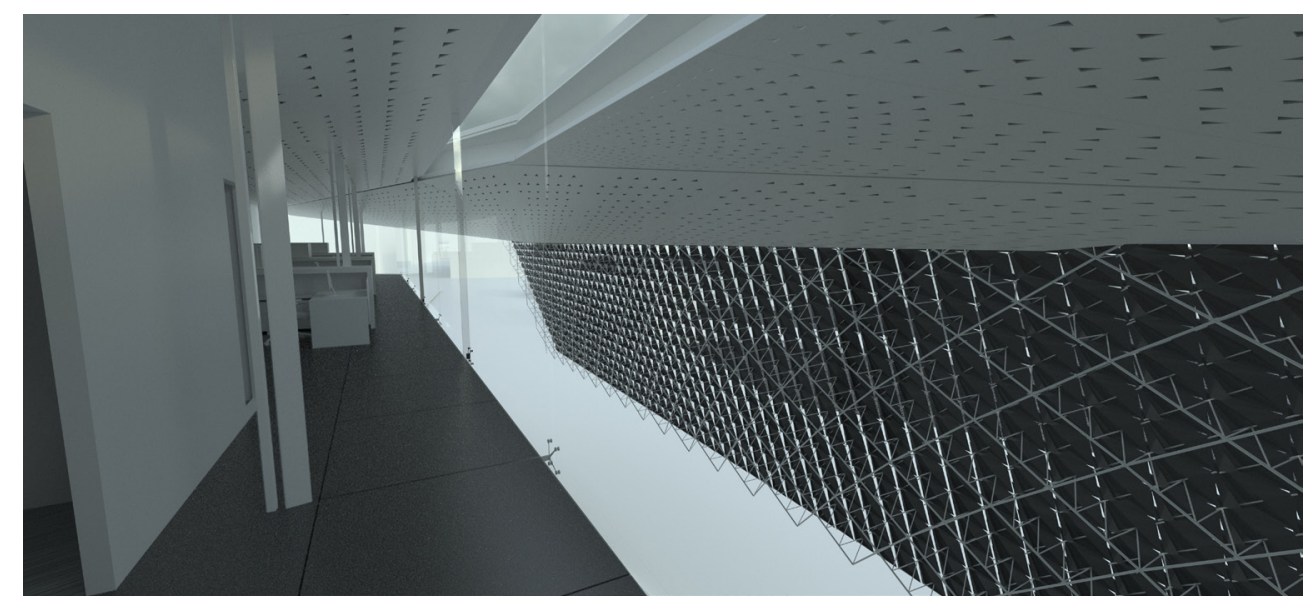

The design criteria used to establish good con-

ceptual responsive skin systems in Section 2 will

be used here to discuss developed responsive

skin outcomes and their applications. (Refer to

Section 2 for these criteria).

The parametric model has been used to gener-

ate panels at rest, and panels rotated through to

30 and 90 degrees. The rotation function of the

parametric model could be linked to weather

data and set to optimise internal lighting

ties; however in this instance, the panels hali-

been rotated with values specified directly in

Grasshopper. The interior lighting quality in

Grashopper. The values specified diectly in

not change significantly between panelitera-

tions; but the quality of the space is significantly

altered by different patterning in the skin, and

the ability to see through the skin at 30 and 90

degree angles of rotation. User interaction with

the skin would be made possible by allowing

occupants to manually control the angle of the

panels. Due to the height of the skin, a close up

experience of the skin is not possible; but given

the fine detailing of the panel, a close up experi-

ence of the skin should be explored in a future

design. 

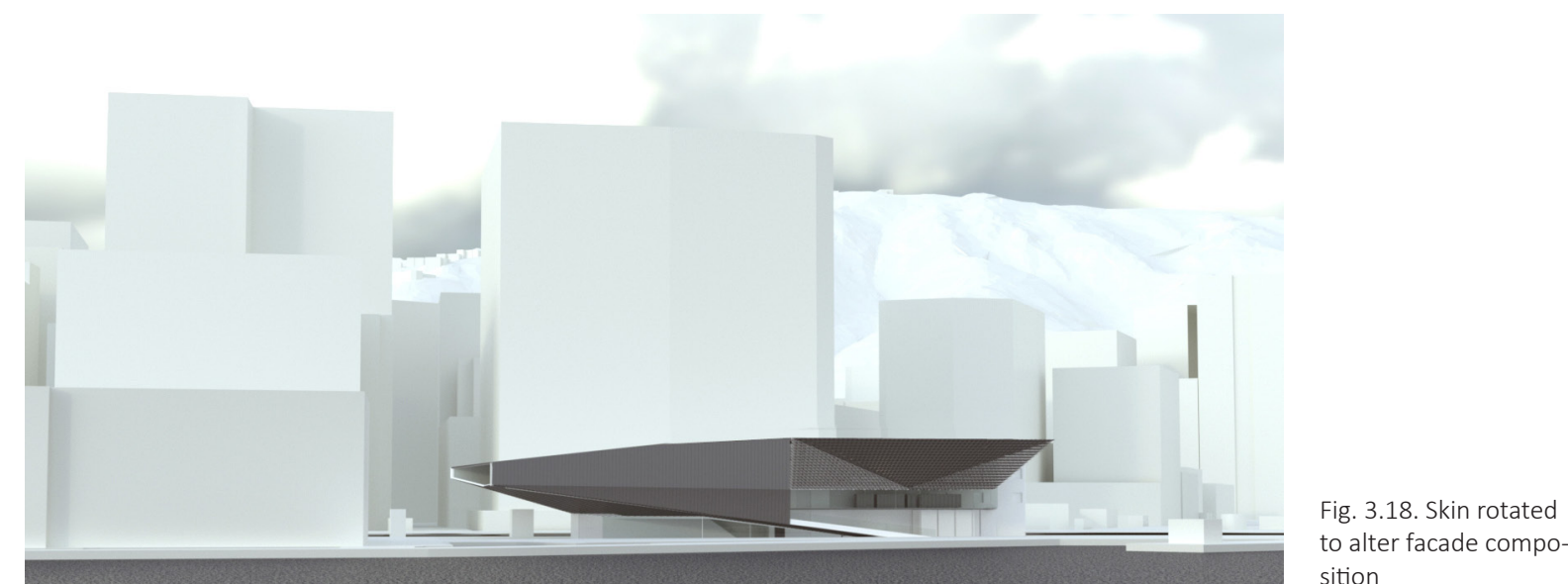

to alter facade compo-

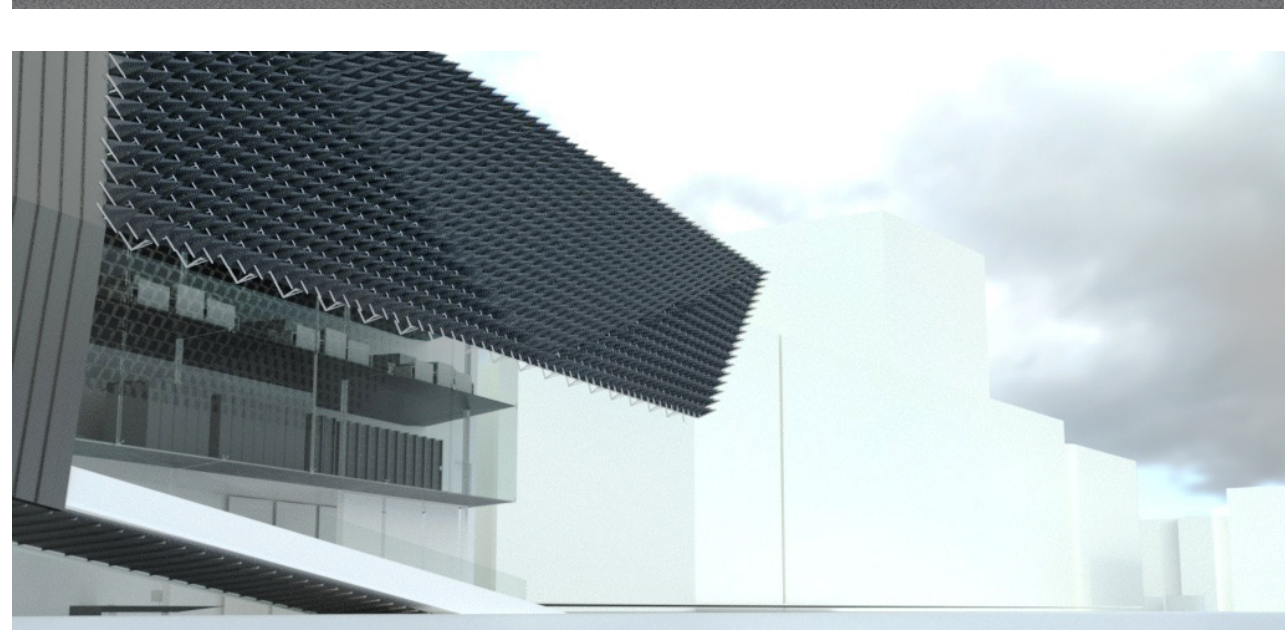

The skins effectiveness at displaying images is exam-

ined here. Images have been integrated into the skin

by parametrically controlling panel rotation values

with an image sampler inside Grasshopper. In this

sense parameters have not influenced architectura

kinetics, but have still impacted on the skins commu-

nicative ability Figures 3.18 and 3.19 show the skins

display abilities being used to alter compositional

display ab thes being used to aler compositional ele-

ments of the architecture. Extra triangular patterning

has been achieved, which is visible both close up and

from a long distance. Figure 3.20 shows NWA's logo

context outlined in Section 2.1 .

ig. 3.19. Skin rotated

sition

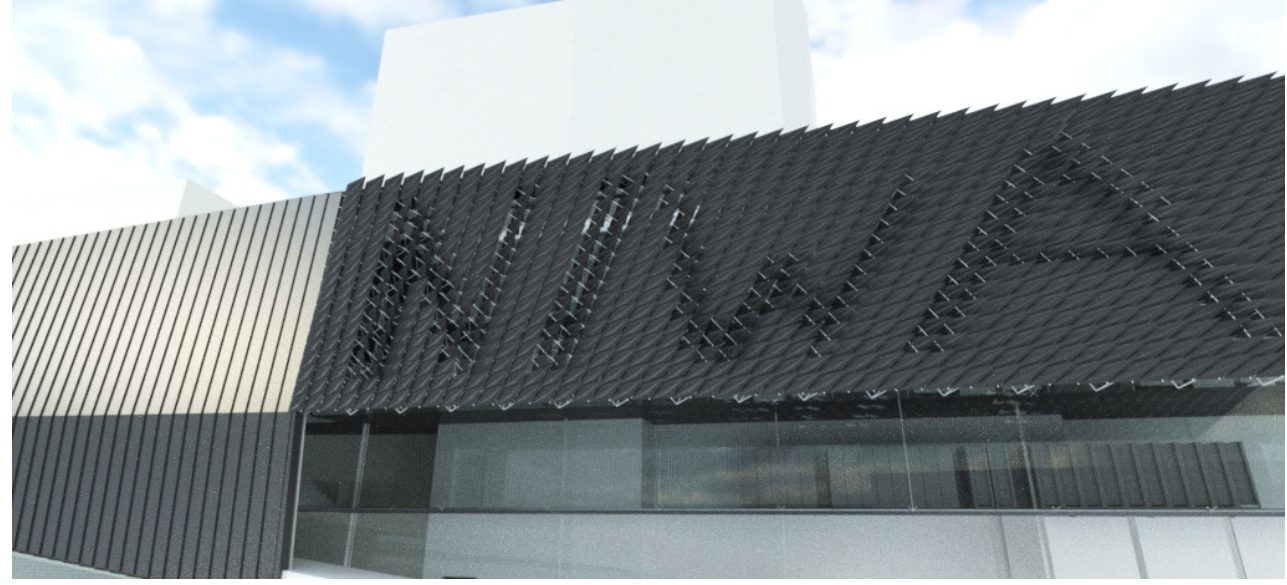




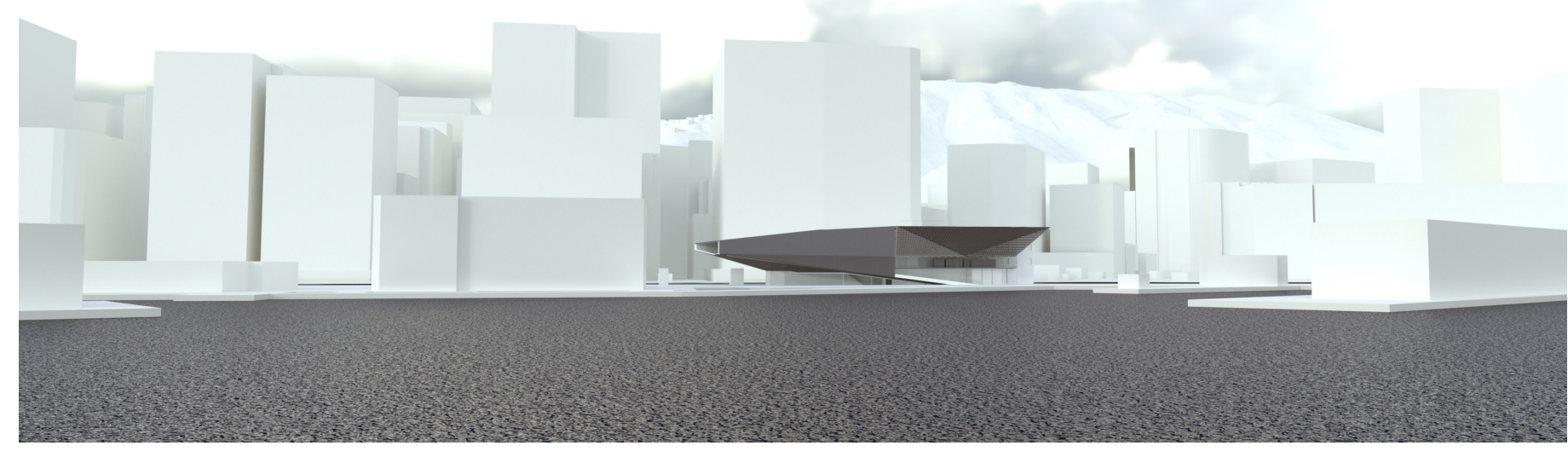

Fig. 3.21. Long distance
view of facade compo-

view of facad
sition test.

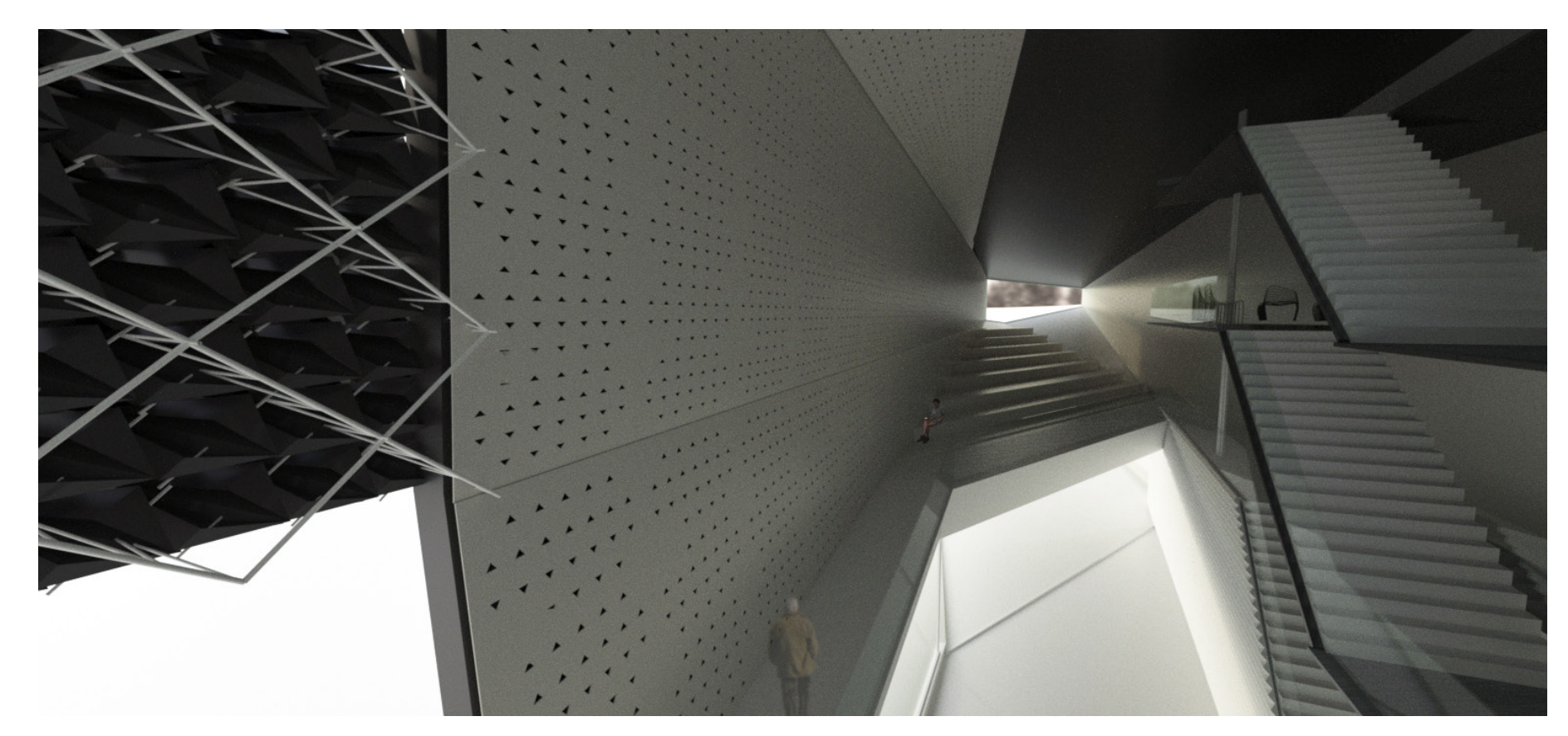

Fig. 3.22. Interior view

looking south. 


\subsection{Te Aro}
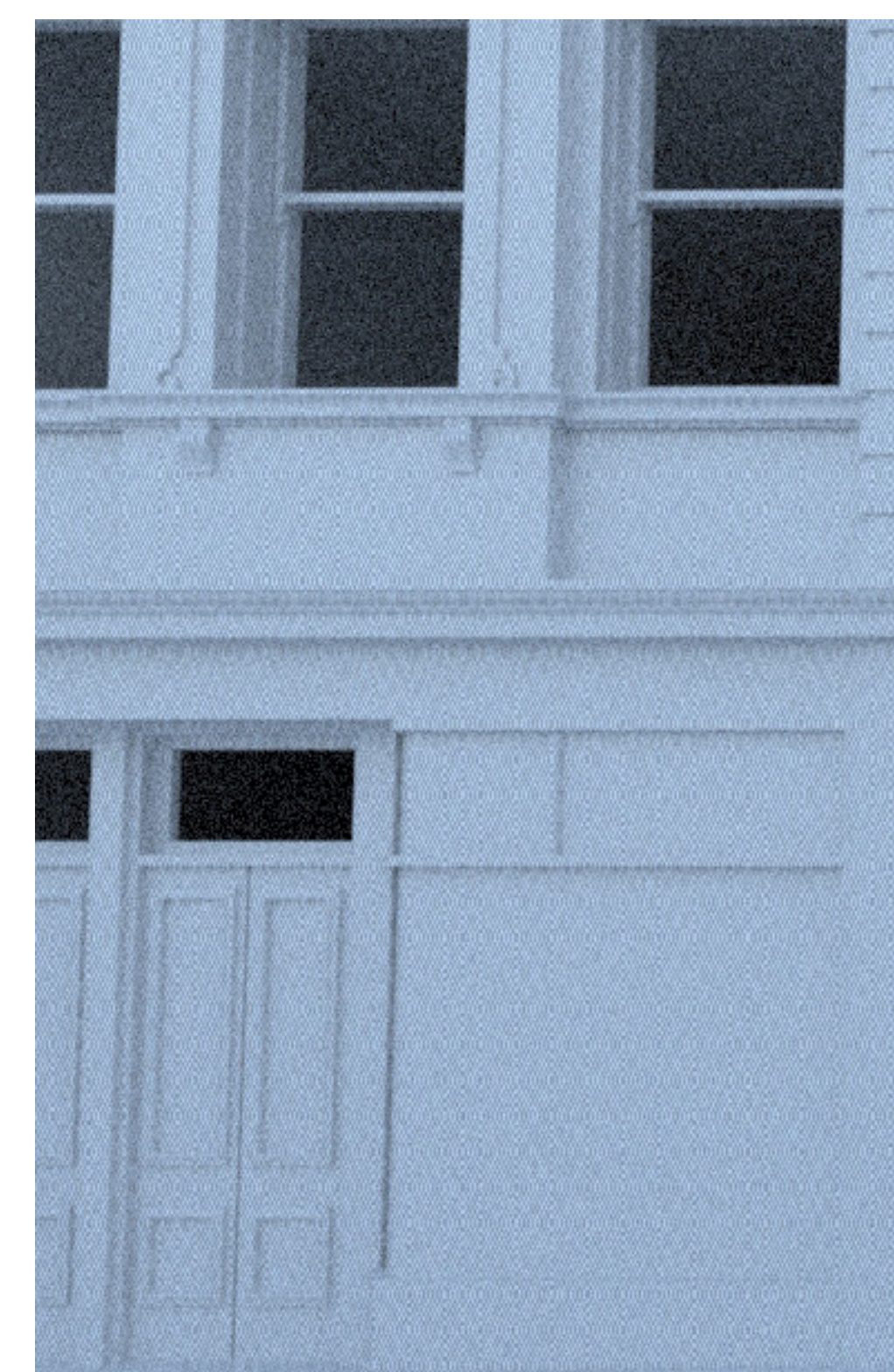

7ininininn.
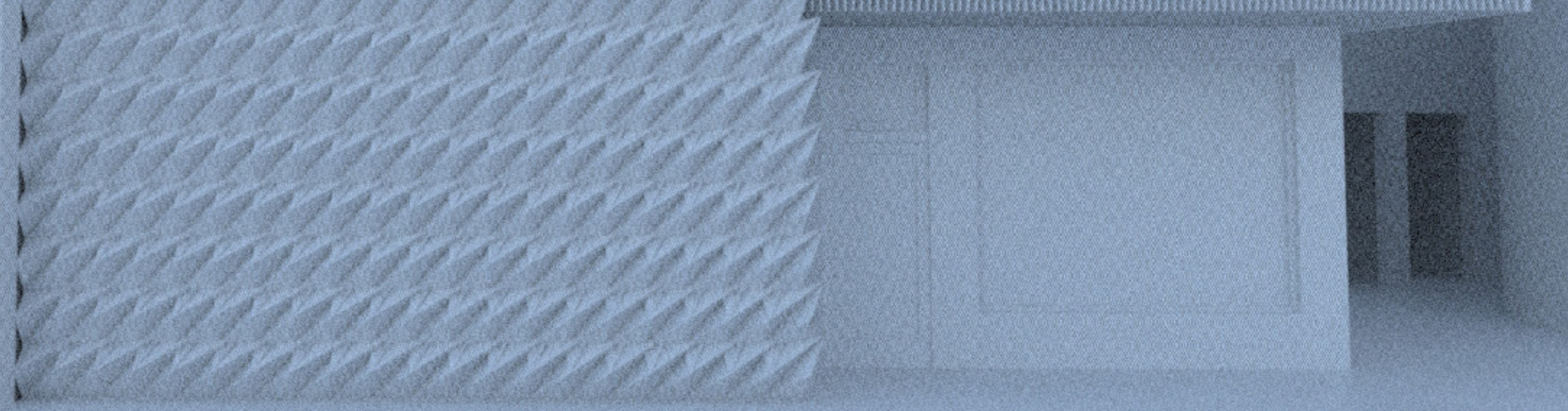


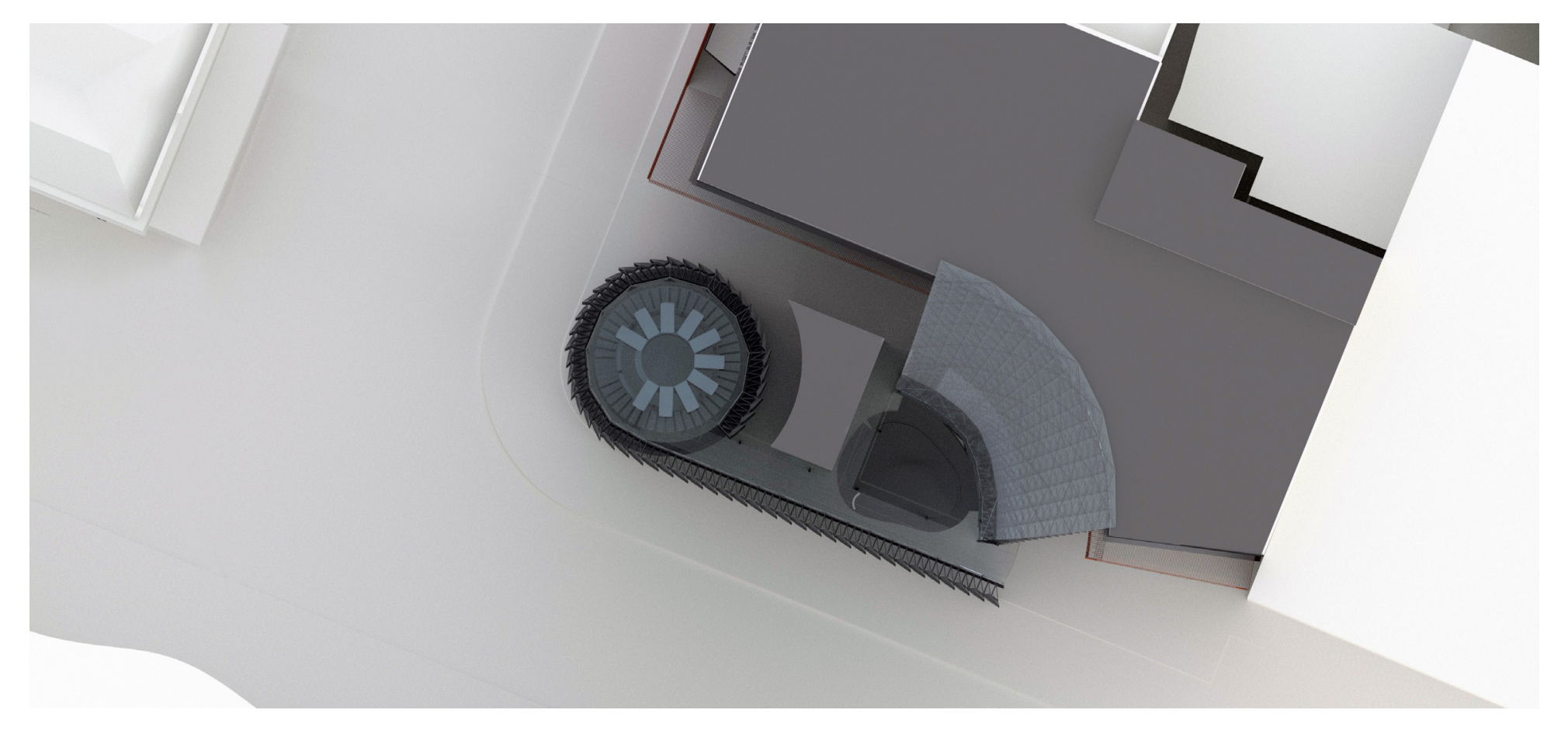

The Te Aro proposal is located at the southern end of Cuba Street, on a small and currently vacant corner site. A desire to use the skin system as a dominant

architectural feature in this design lead to its application along the Webb Street edge of the site, to form a large billboard inspired screen. The skin system has

also been used internally, as a continuous roof and

wall structure, which defines a public arcade, and

acts to draw activity into and throughout the build-

$$
\triangle N 10 \mathrm{~m}
$$

Fig. 3.24. Site plan. 


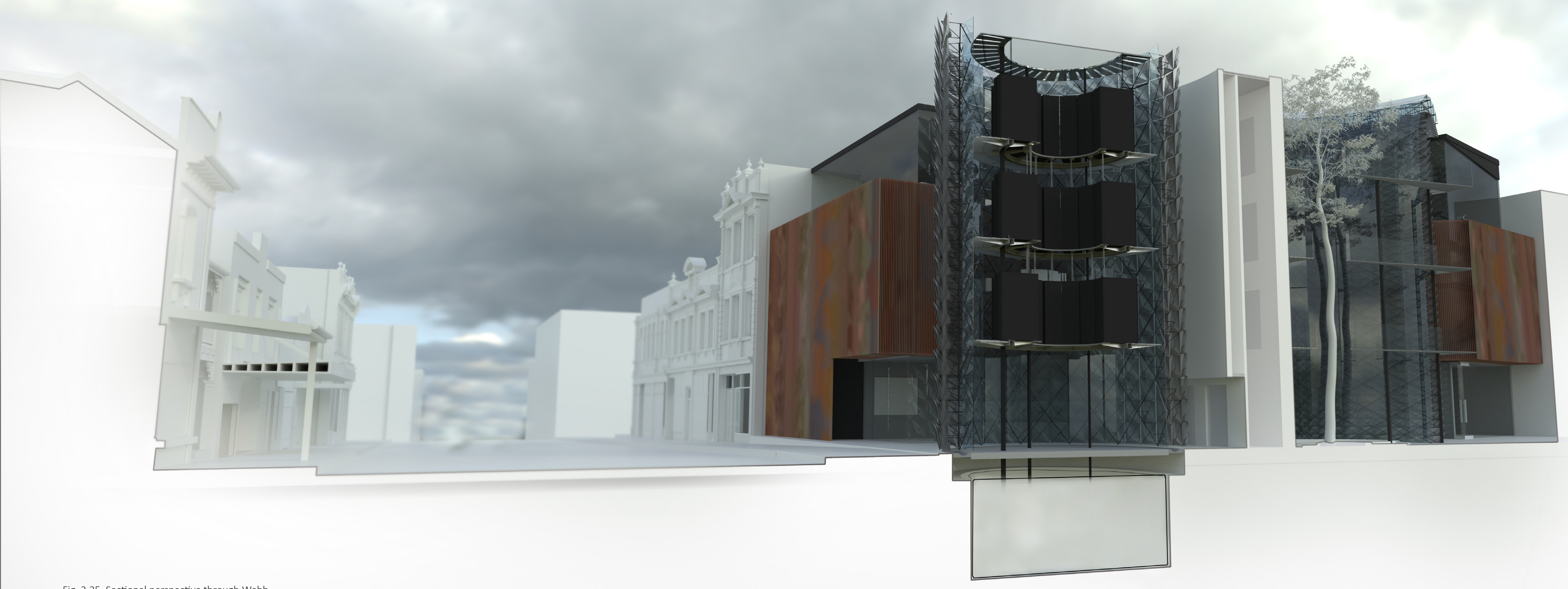




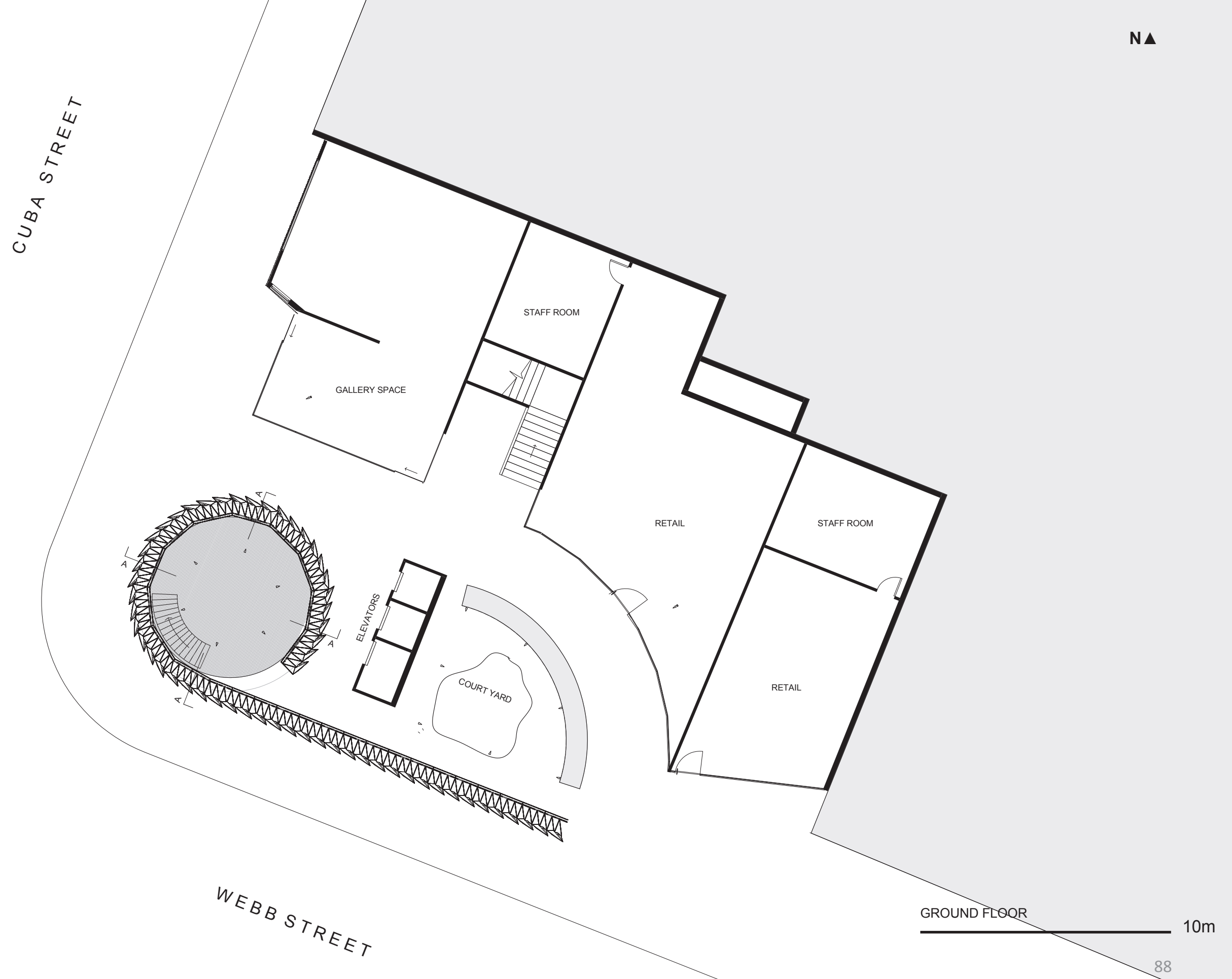




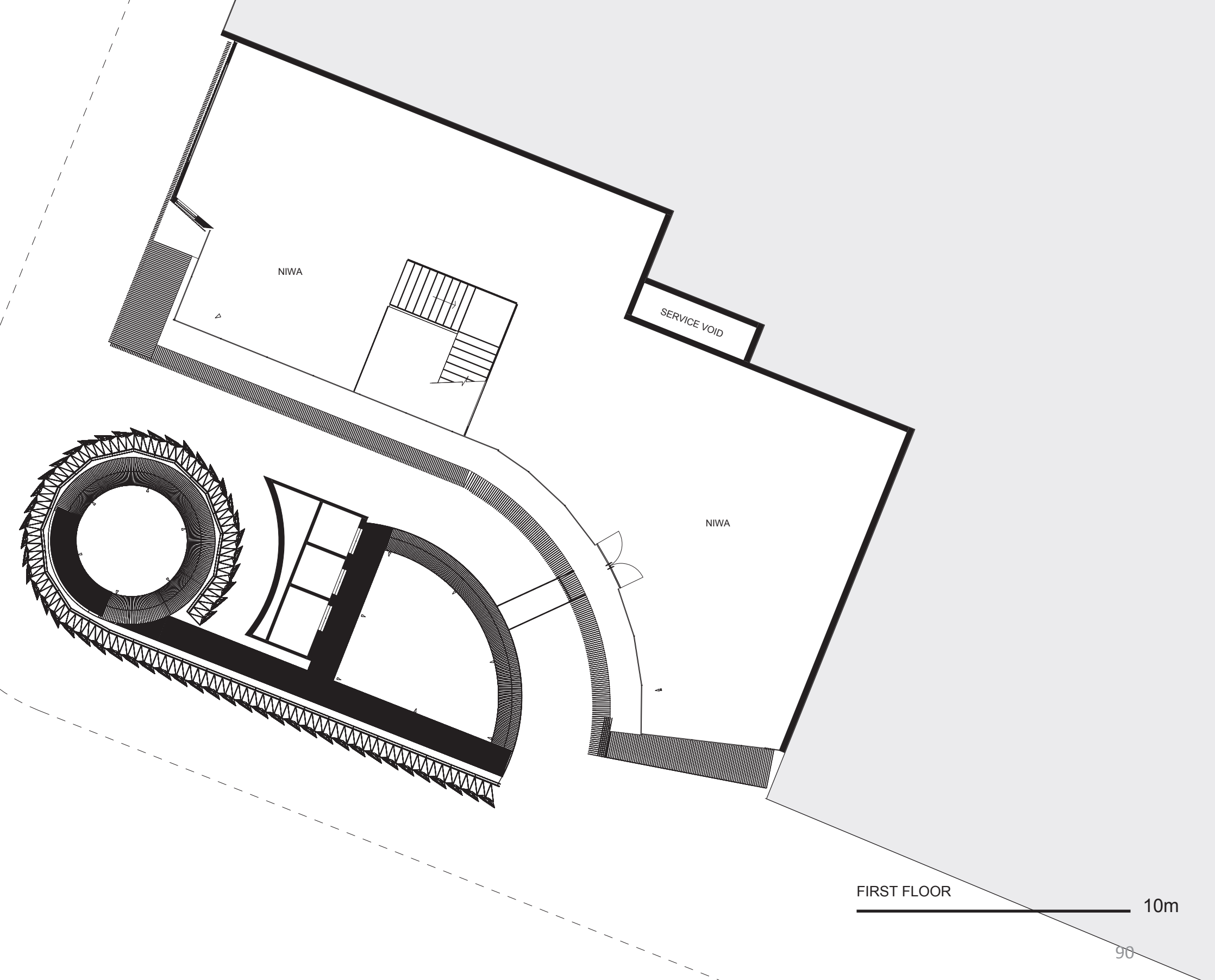




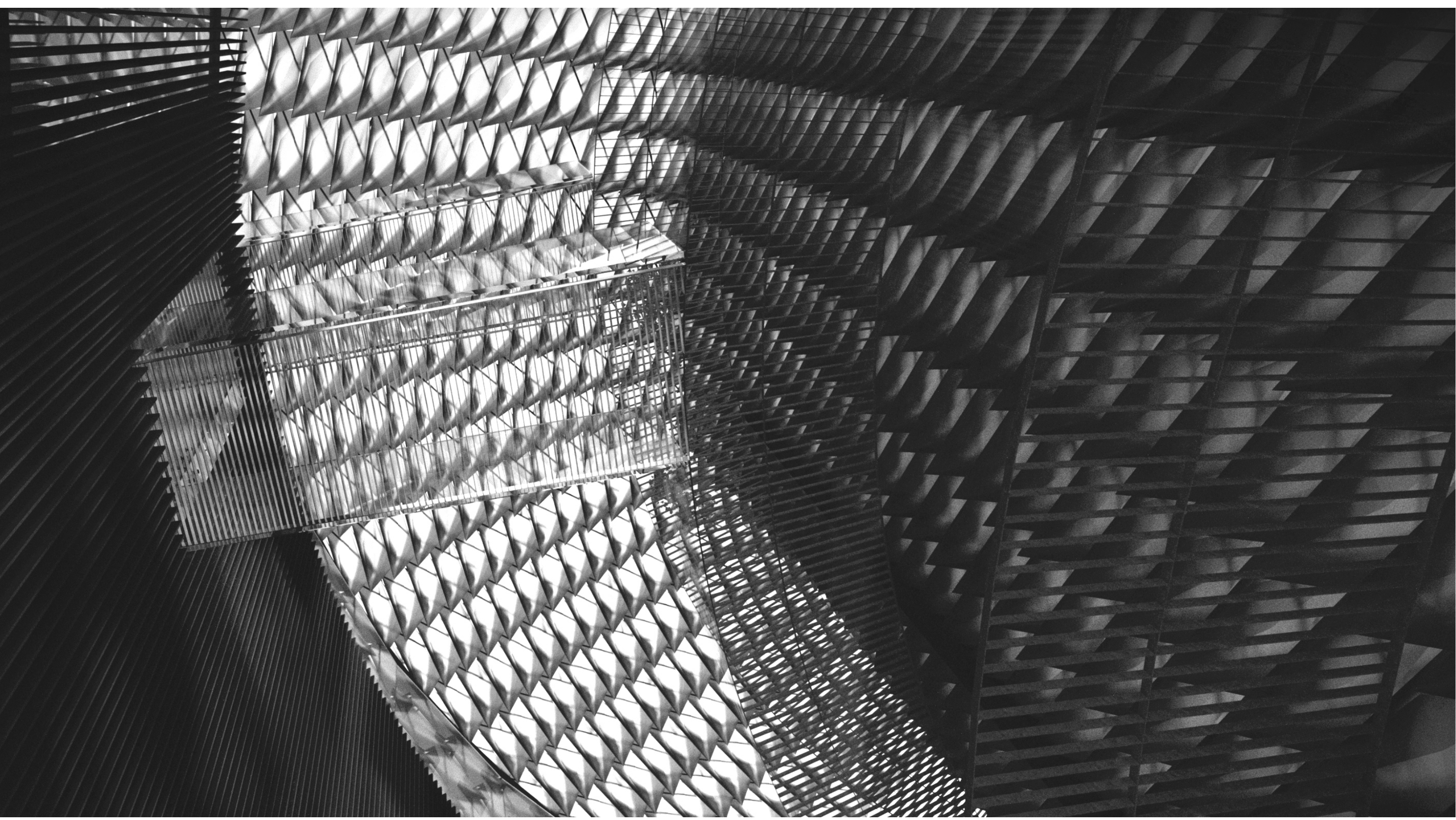




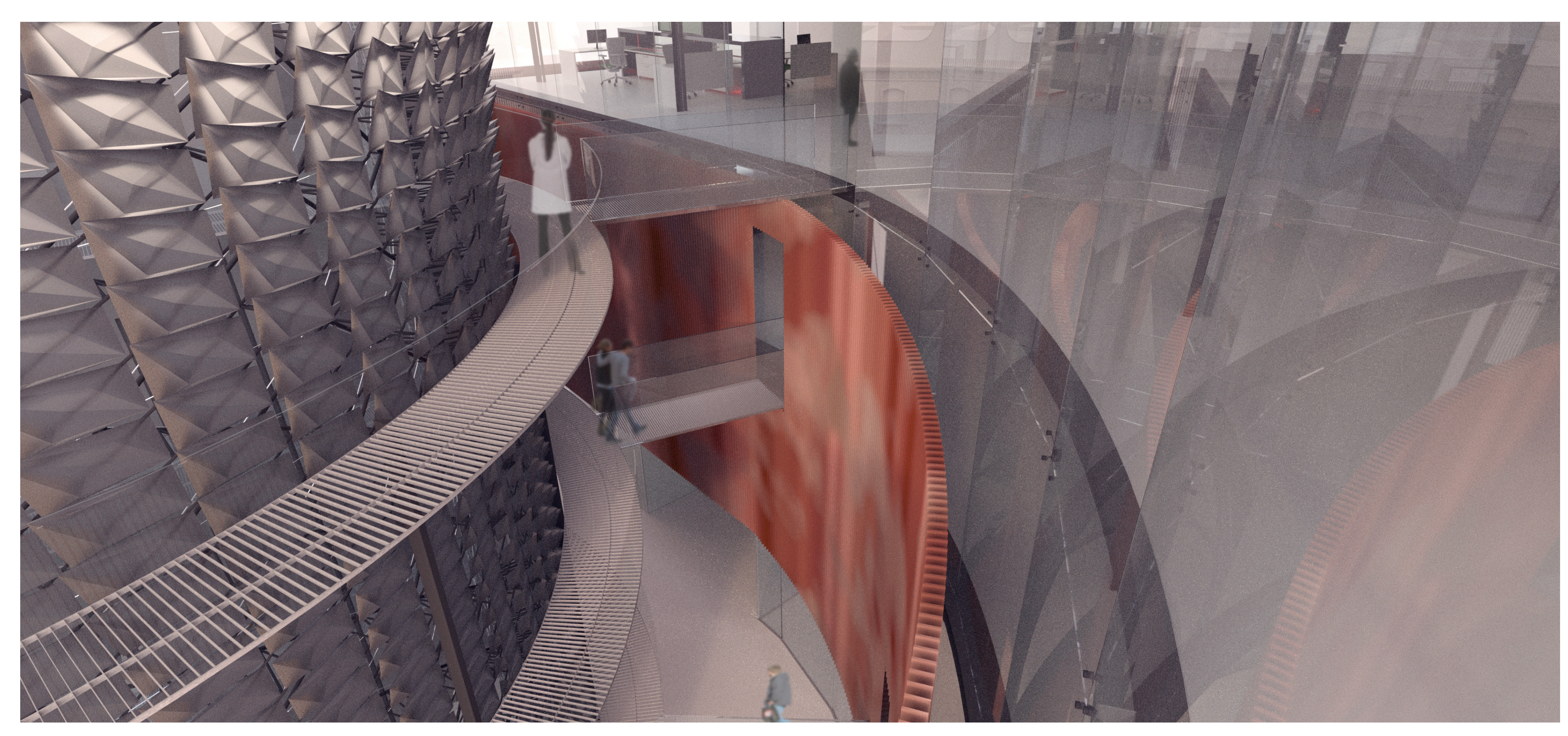




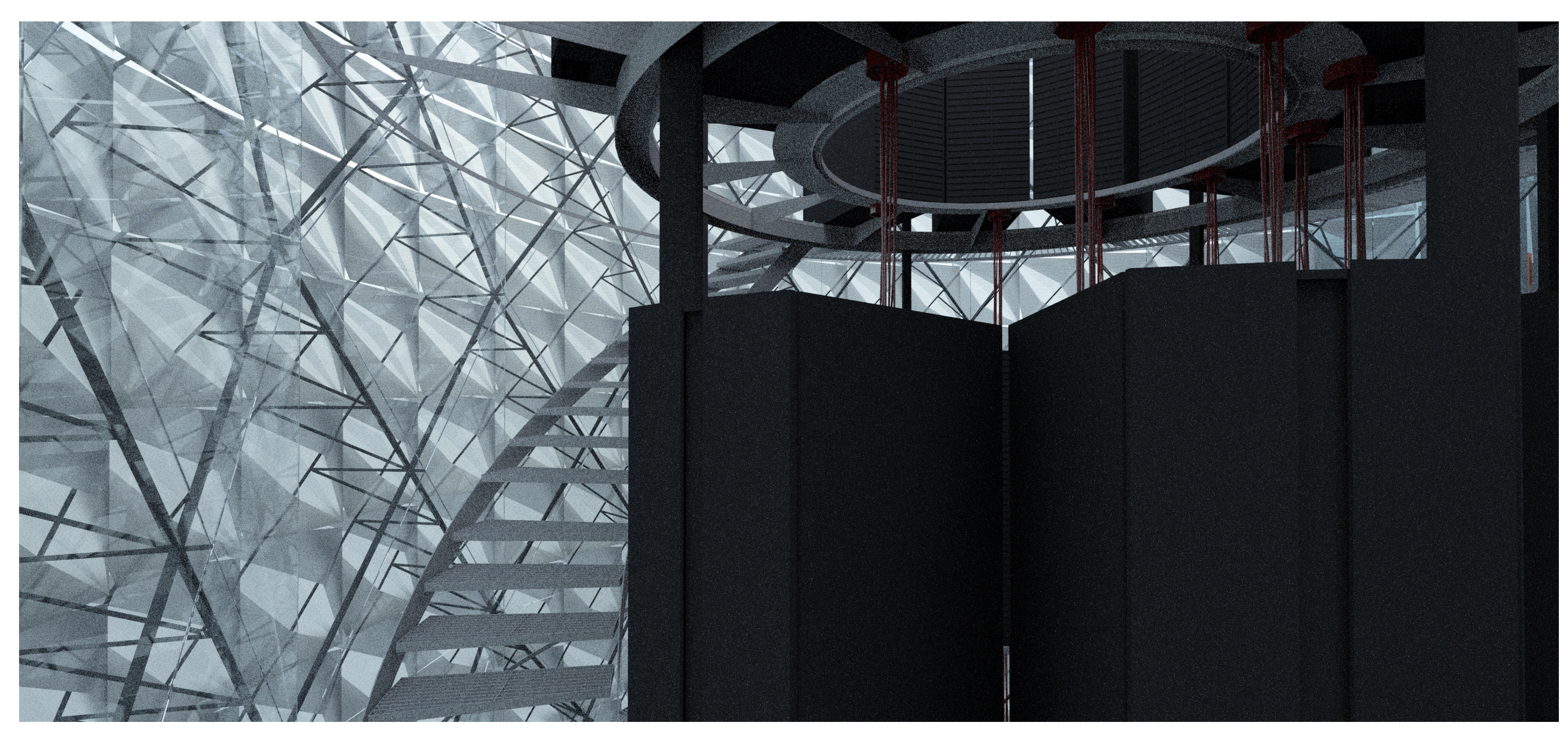




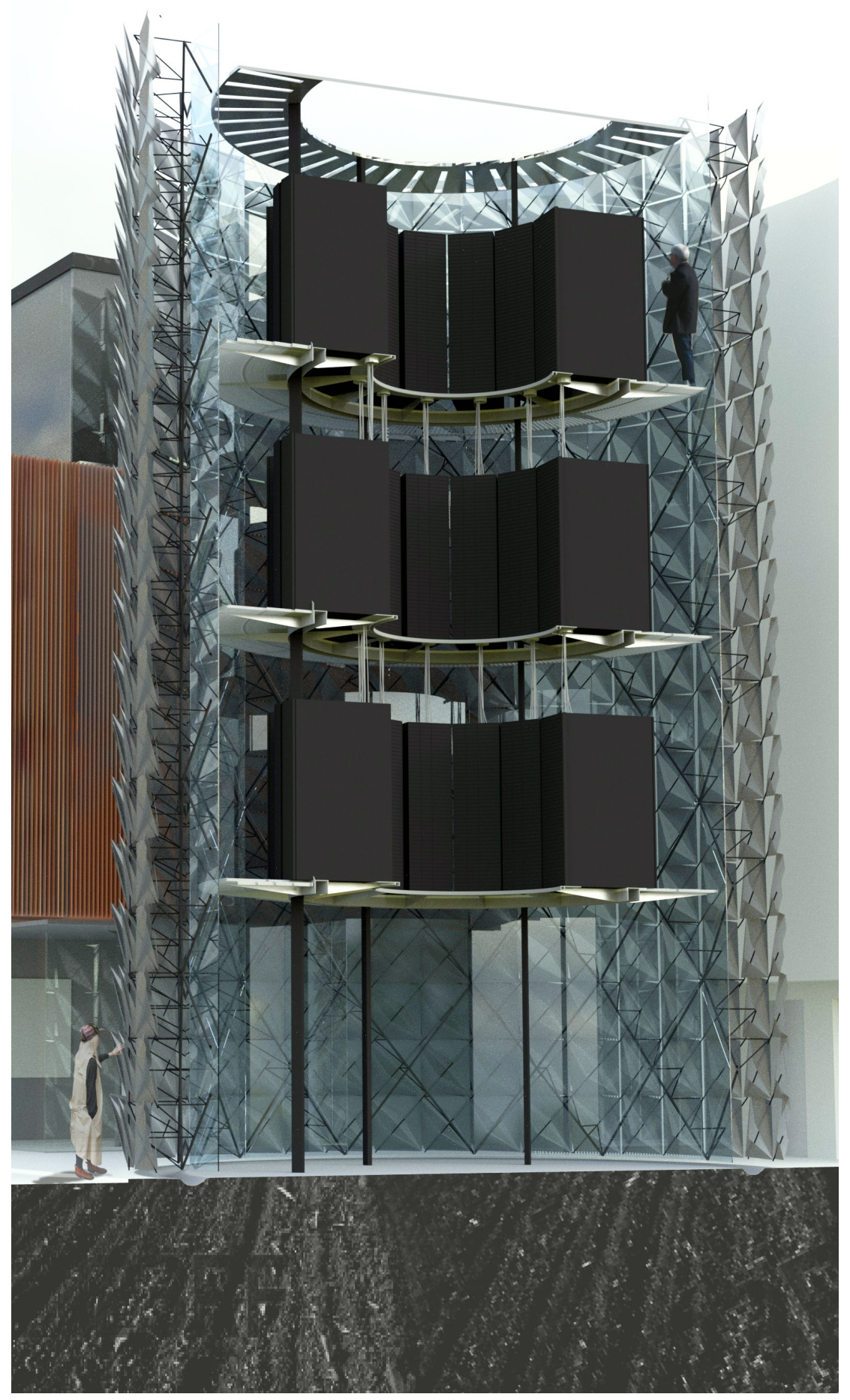

The super computer is arranged vertically in a

tower, suspended by a steel structure and accessi-

ble via a Webforge spiral staircase. The envelope of

the tower is formed by the responsive skin system.

to process environmental data for the purposes of

to process environ rontal data forthe purposes of

is usually distributed by NIWA In this instance, the

skin forms a close relationship with the computer

skin forms a close dations (hy

as environmentaldata (hypothetically processed

by the computer) can be relayed into the skin to

In another application of the skin, controllable

levels of transparency between the super computer and the public is achieved, as the panels can open to reveal the inner workings of the tower. The level of transparency between the interior of the tower and the public could be randomly actuated or

driven by levels of pedestrian activity. This applica-

tion would enhance the relationship between NIWA and the public by providing an engaging and novel architectural installation.

The temperatures of the tower and super computer are regulated by a mechanical services system which is not shown. However, the skin system acts to reduce the cooling load of the tower by providing shading and air flow through the outer layer of the skin when necessary. 


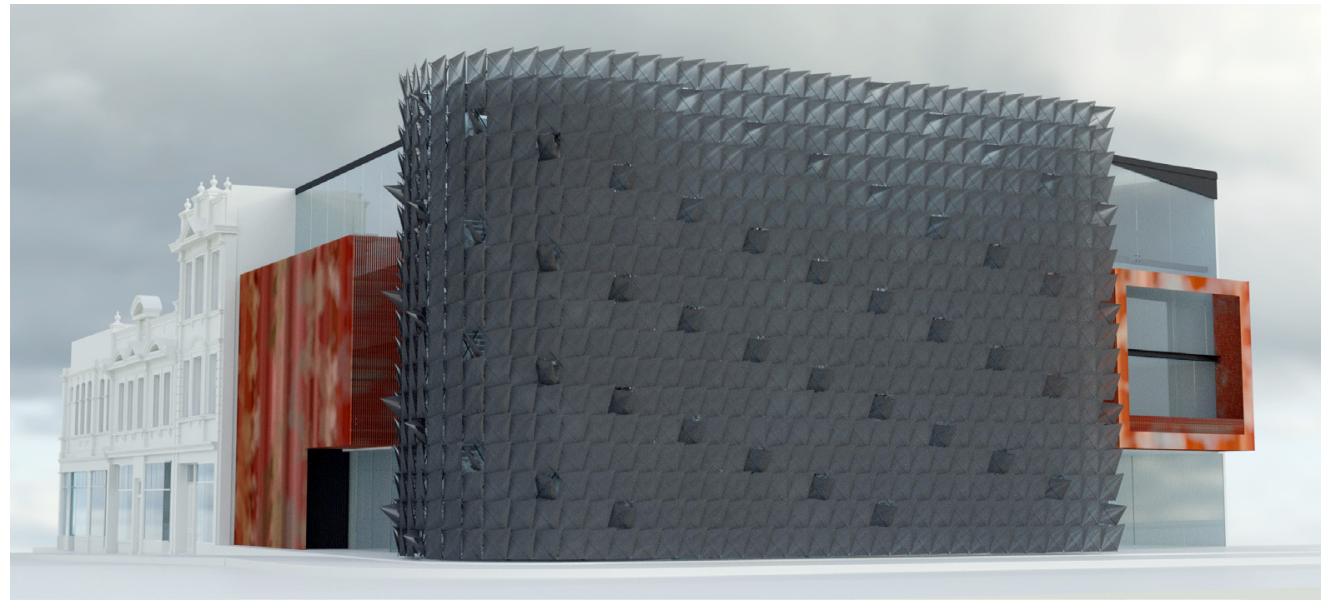

Fig. 3.32. Wind

generated pattern

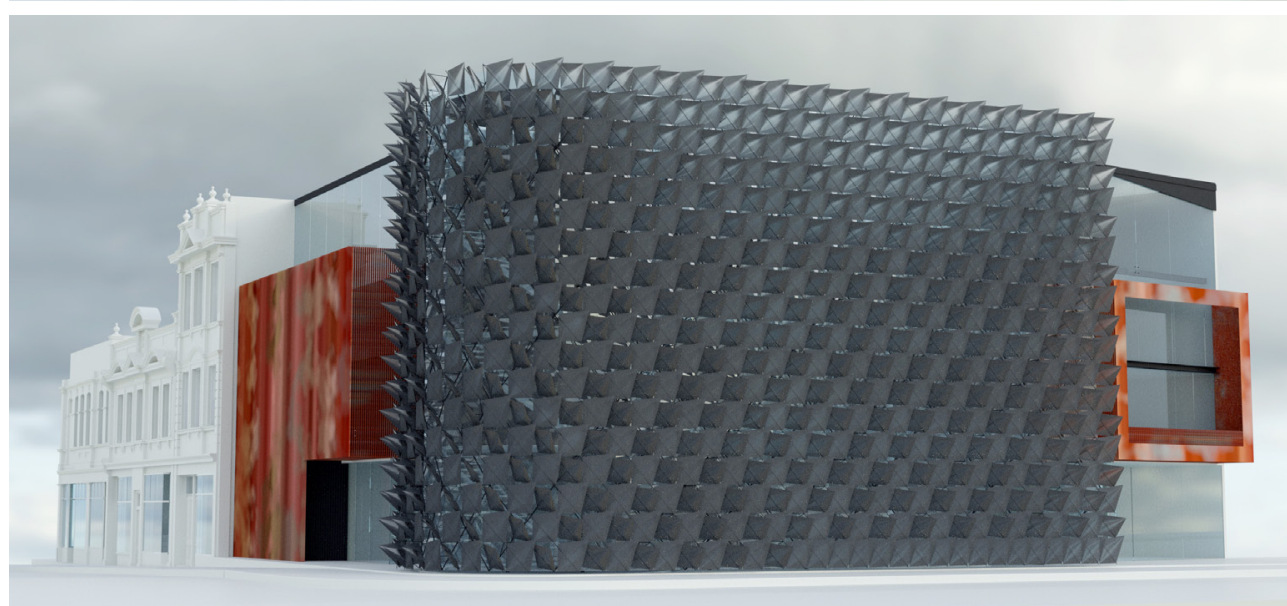

Fig. 3.33. Wind

generated pattern
in facade.

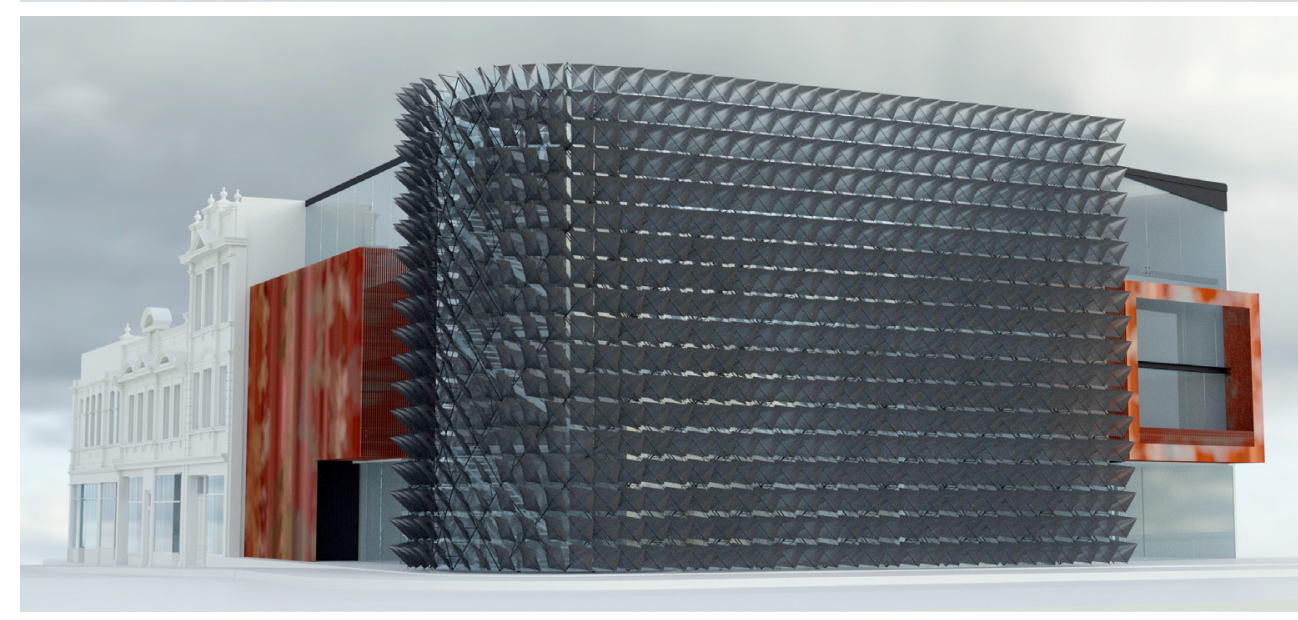

Fig. 3.34. Panels

rotated to
degrees.

In figures 3.32 and 3.33 , the responsive skin has been

linked to a weather data sampler in Grasshopper.

Using weather data as a parametric variable, panels

are rotated according to a mathematically defined

algorithm which is able to generate significantly dif-

ferent patterns in the skin over time. Similar to some

test outcomes in Section 2.0, there is a relationship

between weather data and kinetic response; how-

ever, it is relatively generic, and information about

the weather is not communicated through the skin.

The conceptual and aesthetic value of this response

however would generate strong user engagement,

given the novelty that live weather data is driving $\mathrm{ki}$ -

netic architectural form. Testing in Section 2.0 did not

reveal the potential strength of an arbitrary weather

kinetic relationship, although seeing it in a resolved

architecture proves this initial notion was incorrect.

The interior spatial quality of this skin patterning

application is significant, as the shadows created by

the skin would constantly change and be relatively unpredictable.

Figure 3.34 shows the responsive skin rotated to an angle of 45 degrees. This has been done manually in Grasshopper, but could represent a parametric response to a need for cooling the tower, or for increased transparency between the public and the computer. The aesthetic and spatial qualities of this outcome are interesting, given that the response is intended for functional purposes. The skin appears to grow in size and is more coarsely textured than in figures 3.32 and 3.33 , which are generated for primarily aesthetic purposes. 


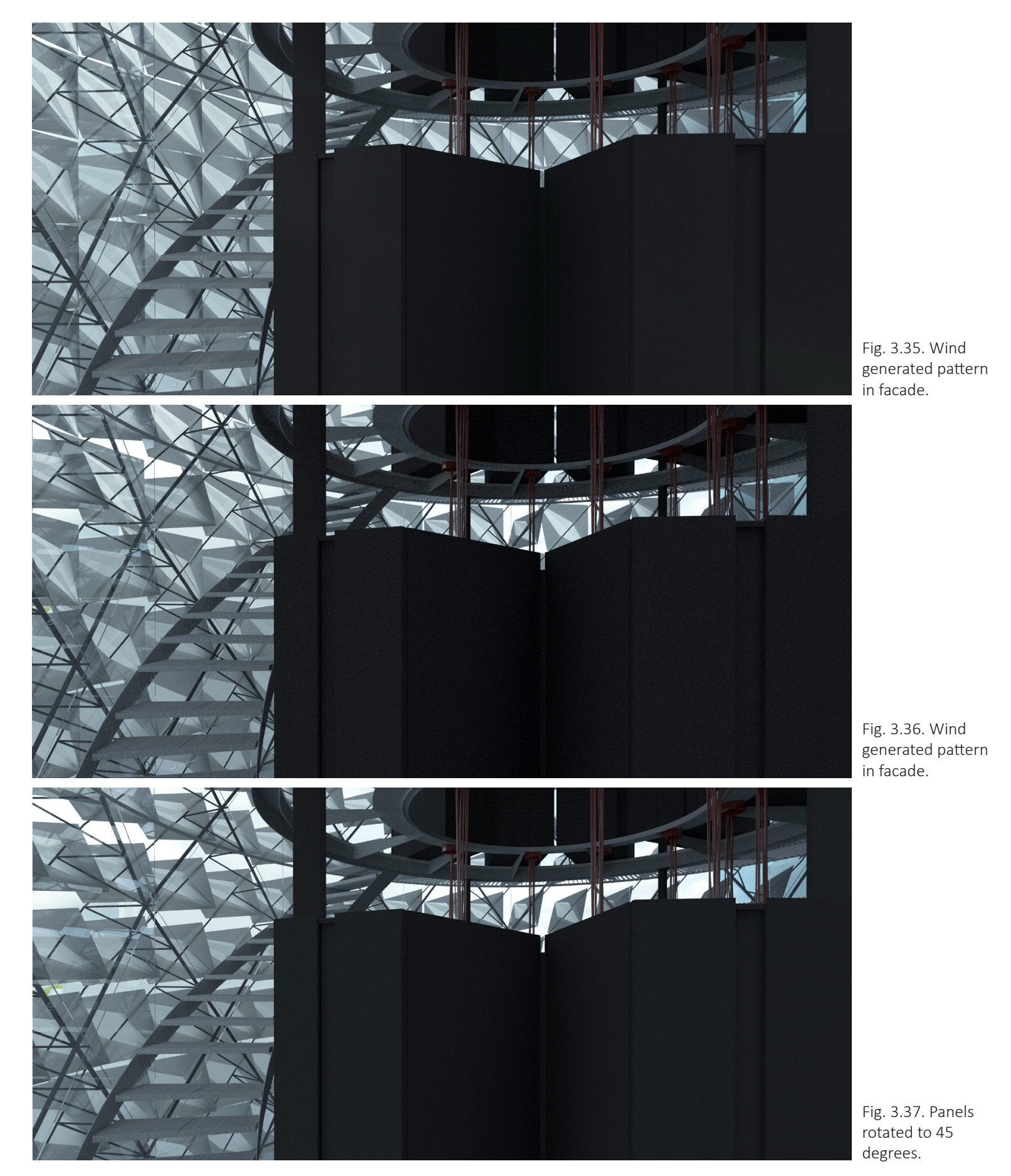

Figures 3.35 and 3.36 show the same response to

sampled weather data as figures 3.32 and 3.33 on

page 99 , in identical lighting conditions. It is apparent

that from a close distance, there is not a significant

change in aesthetics, lighting or interior spatial qual-

ity between the two patterning outcomes. Figure

3.37, where panels have been rotated to 45 degrees,

shows greater change in interior spatial, lighting and shows greater change in inteir spatiol, light aest cic qualites; although the is stil no signifiin the rubber option, it is likely the panels were clad greater change in interior lighting quality.

Figures 3.35 and 3.36 show the skin responding to weather data though surface pattern, and figure 3.37 shows panels uniformly rotated to 45 degrees. Some of the steel structure is visible through the skin with the panels rotated to 45 degrees. If the panels were rotated to 90 degrees, it is likely that the super computer would be visible from Cuba Street, which would create a strong visual connection between the programme of the tower, and the public. 


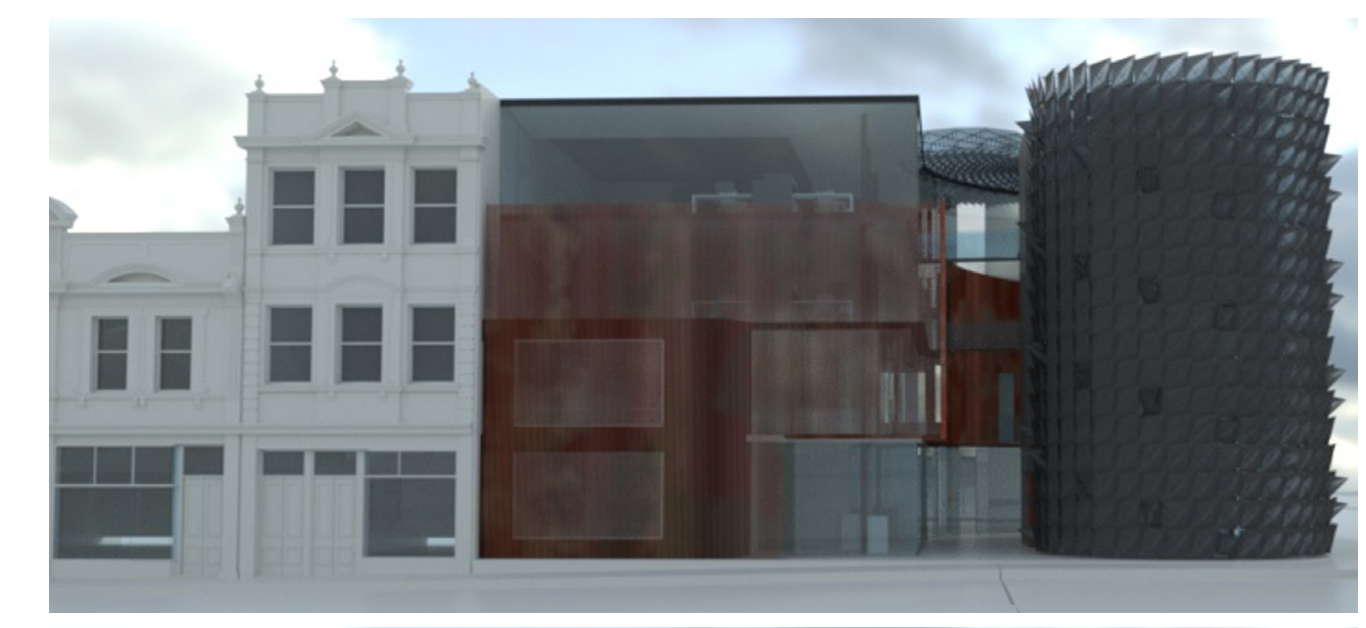

Sampling wind speed data over time, the parametric

definition has been altered to communicate wind

speed values by displaying a bar which rises and falls.

This application of the system effectively turns the

façade into a weather communication device. The

building communicates weather events in a The

and engaging way. Test results from Section 2, where

and engaging way Test resuls from Section 2, where

respansive archictic

artistic outcome, has re-emerged in this application

Fig. 3.38. Wind

generated pattern

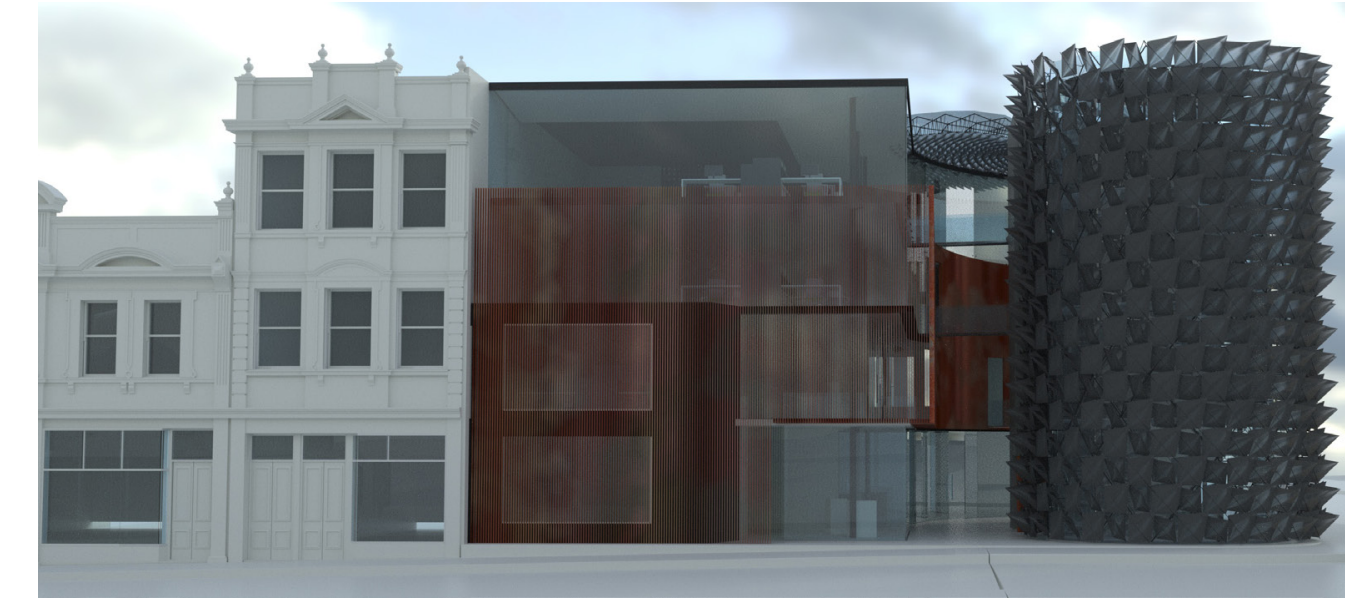

ig. 3.39. Wind

generated pattern
in facade.

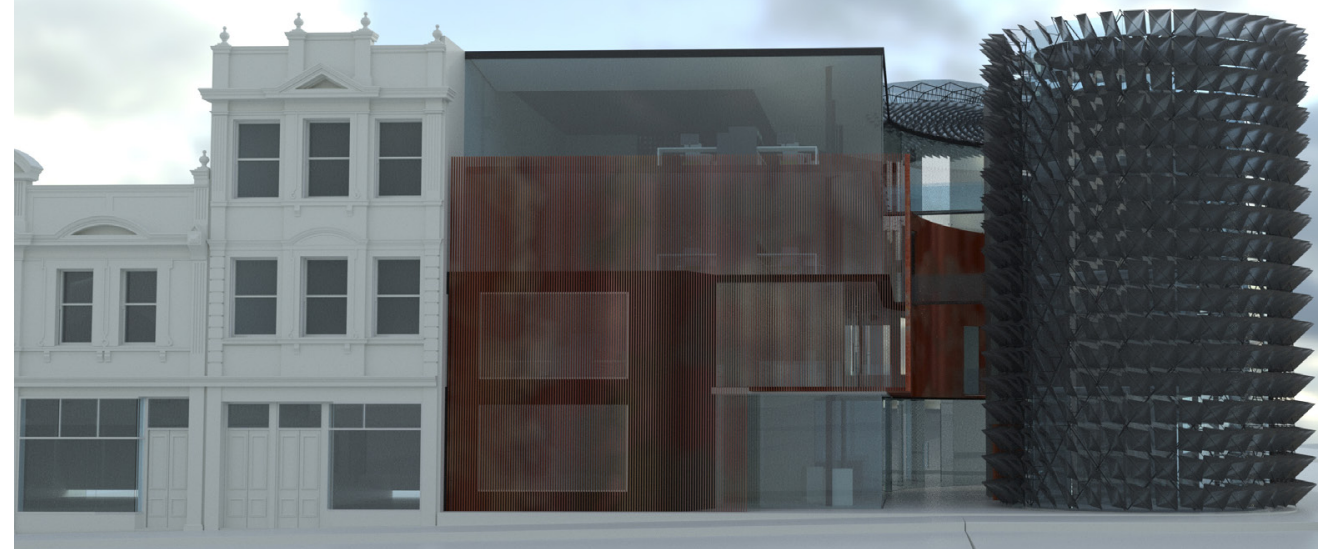

Fig. 3.40. Pane

ontated to 45 


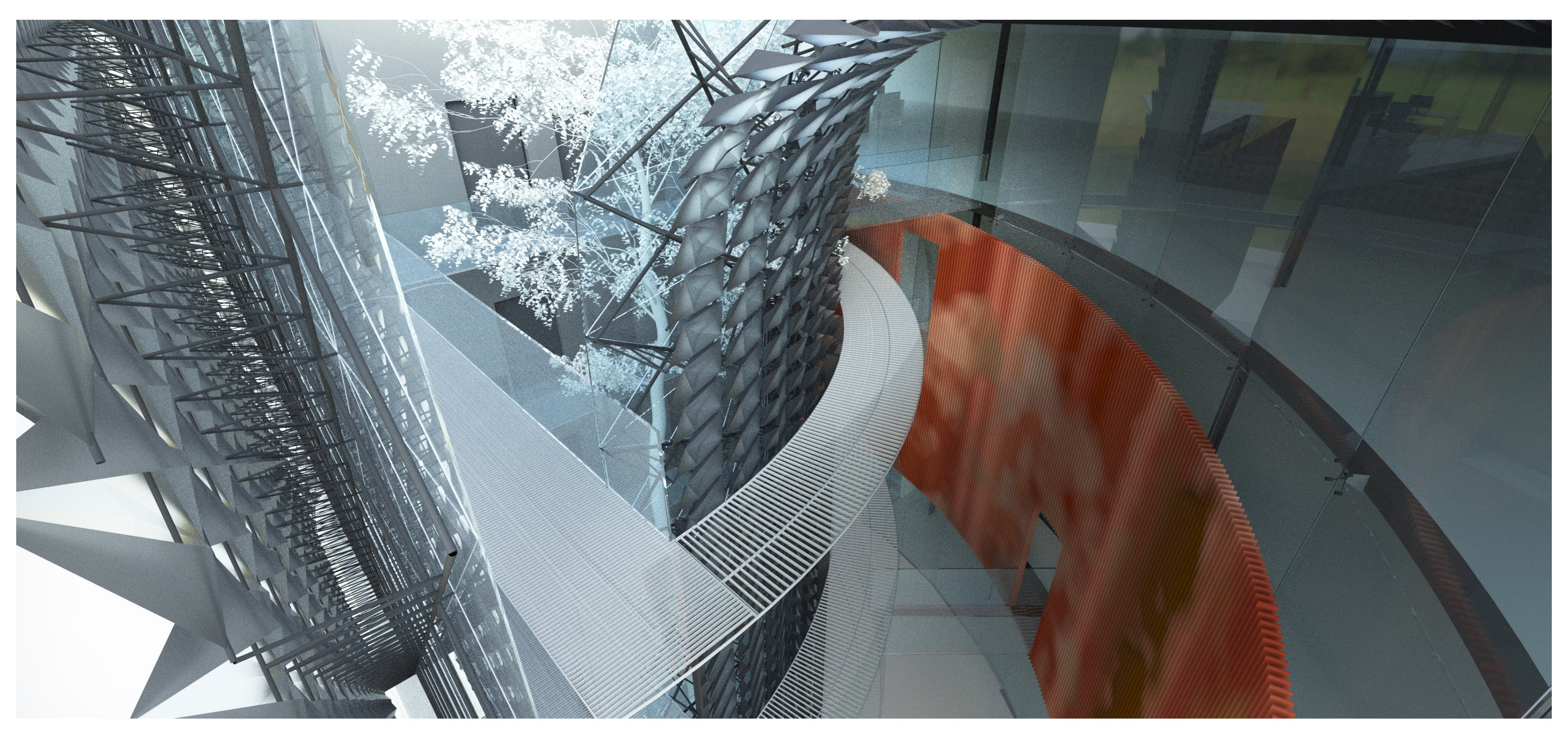




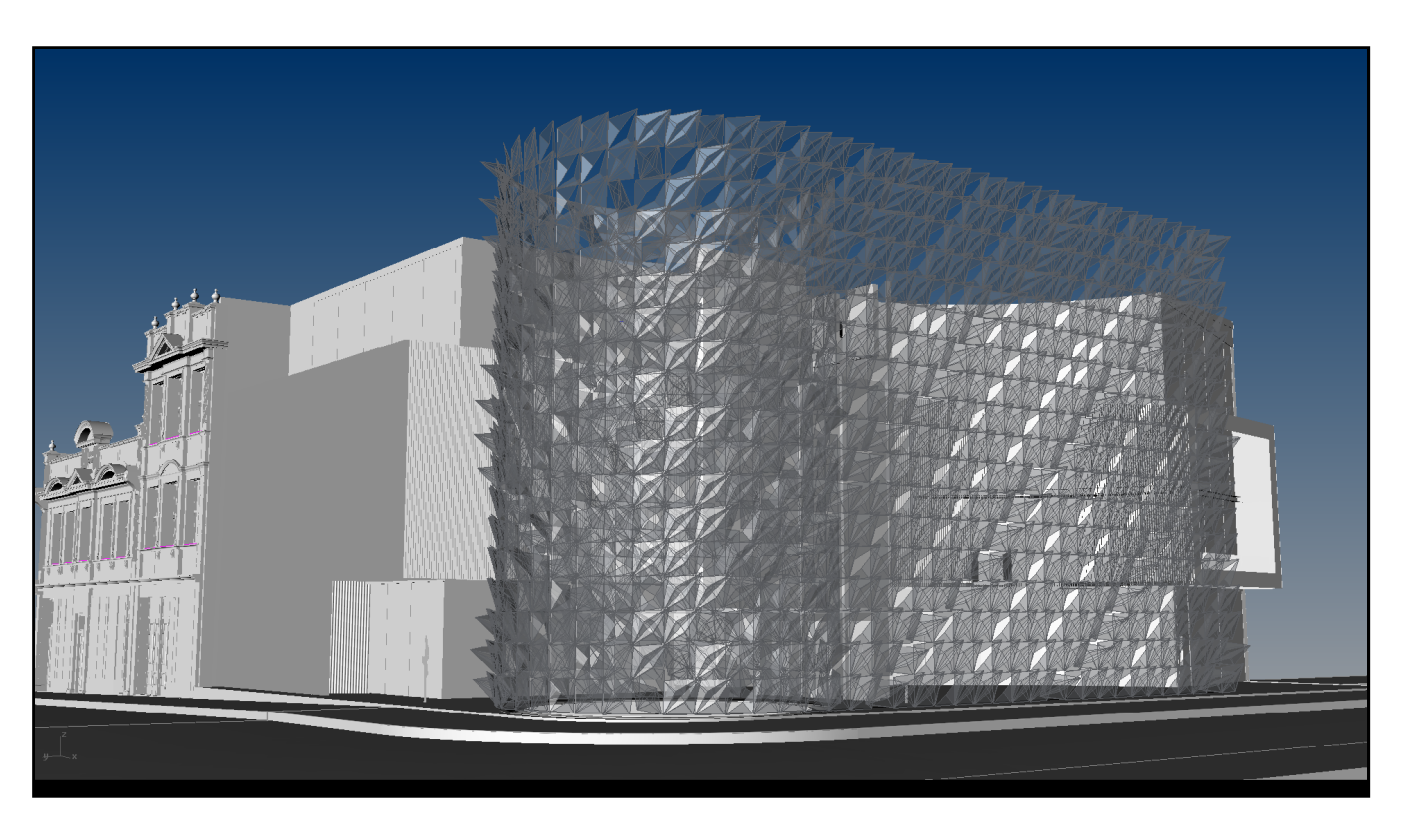

Fig. 3.42. Animation of

wind seede
facade. 0

http://www.youtube.com/watch?v=9WowXWbDvls

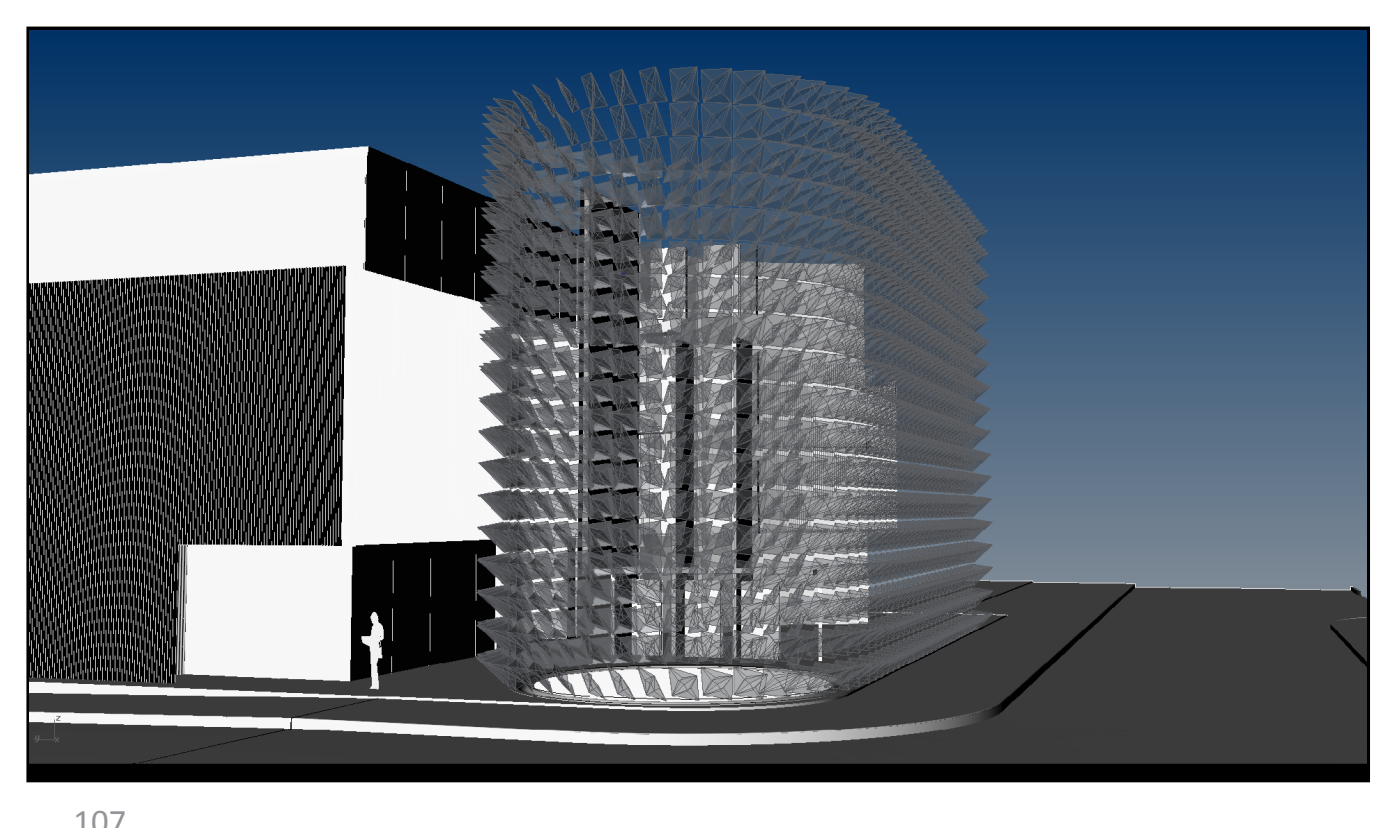




\section{Reflection}

The aim of this thesis has been to develop an understanding of how parametric modelling can aid in the design process of a responsive skin system. An initial background study in kinetic, responsive and digital architecture was undertaken in order to and digital position and methodology to facilitate design lead search. It was established that with the use of scriptsearch. It was established that with the use of scripting, a parametric model could enable morphological control of an architectural model, and that this process could be utilsed to enable both static and dynamic iterative design development. From this, a design methodology which focused on iterative testing against design criteria was used to develop a responsive skin solution.

Initially, parametric modelling was used to create a range of concept designs for a responsive skin. Environmental data was sampled for use as parame ric input, and an experimental approach was taken toward the development of parametric definitions. This allowed for the production of dynamic and responsive form which was used to develop a range of potential designs. The analysis of these designs acted to broaden the understanding of the potential manifestations and applications responsive skins enabled by a parametric process. While there was potential for augmented reality systems to provide a relatively seamless transition between kinetic digital models and onsite manifestations of architecture, it was found that more value was gained by providing an architectural outcome which could physically modulate environmental conditions as well as provide the potential for novel application.

From the initial conceptual work, it was established that an intelligent skin system consisting of rotatable panels would form the focus of continuing design development within this thesis. It was proposed that this skin system could embed images in its surface via panel rotation and that it could also provide environmental modulation in response to externa weather conditions. However, as design development took place, the potential for other uses for the skin system were developed. The intended design outcomes were expressed as design criteria, and an iterative process of modelling, analysis and modification was undertaken in order to arrive at a developed outcome.

The analysis of animations, rendered images and 3D models provided a platform on which qualitative design decisions could be made. The criteria used to validate design decisions was developed to ensure that a feasible and well performing system was developed. This system introduced a high level of feedback into the design process, enabling the development of a gradually more and more resolved architectural model. Beginning with a basic concept, the parametric model was developed to a point where it represented a credible architectural system that has an iterative developmental history as proof of its success. The success of the developed responsive skin in terms of its performance against the specified criteria is evidence that this methodolog is a credible design tool.

However, limitations to this methodology are evident when a more developed level of design detail is required in a parametric model. As explained at the quired in a parametric model. As explained at the beginning of Section 3 , the construction detail required to describe a fully functional panel system would require significantly more scripting than has been done in this thesis. The amount of processing power panel system would be extremely high. As scripting processes become more efficient, and as computers become more powerful, the potential to create highly resolved parametric architectural systems will emerge.

Despite limitations to the level of detail which can be incorporated into a parametric model through be incorporated into a parametric model through the scripting techniques used in this thesis, enough detail has been provided to describe the fundamenta components of the skin system, and to produce relatively convincing descriptions to aid development and visualisation. Optimisation using iterative procedures resulted in a design that included a thoroughly developed panel unit, integrated structural system, an internal skin of glazing. While parametric alteration and subsequent testing of architectural components consumed a significant portion of development time in this work, a large amount of time was spent developing the parametric script. The parametric scripting process involved a significant amount of trial and erro itself, and provided the greatest technical challenge within this work.

The final skin system has been developed to deliver a range of kinetic and responsive functions which have been articulated in section 3 . The first function of the system is its ability to respond dynamically to light and wind. This response takes the form of panels which can open and close to modulate internal light and air flow through the skin. While this thesis has provided a way to describe this responsive action, ways to accurately analyse its performance for iterative development have not been thoroughly explored. Although renders can aid in lighting analysis, air fow has not been considered. Future wo rysis, air flow thesis would involve the analysis of the skin system in thesis would involve the analysis of the skin system in envionmental modelling sotware to aid in a further has been presented with and without an internal layer of glazing, providing the option of weathertightness, to give a greater scope to potential future applications of the system.

The second function of the skin system is its ability to display images. The analysis of this function has been effectively facilitated by the production of renders and animations. This process, evident in Sections 2 and 3, demonstrates the system's ability to provide this function.

Other applications of the skin system have included environmental data being used for communicative purposes. Theses have been presented in section 3.2, where abstract pattern has been generated in the skin, and also where a vertical band in the skin has been used to communicate actual wind speeds.

In Section 3, the final skin system has been presented both as a planar façade and as a system which conforms to a surface with a single curvature Planar and regularly curved façades are comprised of a limited range of regular construction components, which would make the manufacturing and assembly process relatively straight forward and efficient. However, the parametric definition gives provision for the system to be applied to complex double curved surfaces. The developed panel design allows for the construction of a non-standard system by utilising digital manufacturing techniques. The primary joint system can connect structural members at nonstandard angles because of a stee plate which can be bent or cut and re-welded using CNC machinery. Although this design detail was not scripted into the parametric model, its inclusion in this thesis substantiates the fact that the skin system could conform to nonstandard curved surfaces. 
Future work could include developing a highly re-

solved parametric joint for use in this system. In-

cluded in this future work would be research into the

process of transfer

process of transferring the 3D modelled skin system

to the manufacturers. The foundation for this con-

systems have been designed to besis, as the joint

partially assembled offsite. 


\section{Works cited}

Anderson, Jonathan, and Tang Ming. 'Form Follows Parameters'. Circuit Bending, Breaking and Mending: Proceedings of the 16th International Conference on Computer-Aided Architectural Design Research in Asia. 2011, Hong Kong. CUMINCAD. Web. 14 Sept. 2013.

Bohnacker, Hartmut et al. Generative Gestaltung: Entwerfen, Programmieren, Visualisieren. New York: Priceton Architectural Press, 2012. Print.

Burry, Mark. Scripting Cultures. Sussex: John Wiley and Sons Ltd, 2011. Print.

Fox, Michael A. 'Sustainable Applications of Intelligent Kinetic Systems'. Transportable Environments 2001: Proceedings of the 2nd Conference on Portable Architecture. National University of Singapore. CUMINCAD. Web. 8 Nov. 2013

Hansen, Paul. Responsive Kinetics. MA thesis. Victoria University of Wellington, 2013. VUW

Restricted online archive. Web. 12 June, 2013.

Lynn, Greg. Animate Form. New York: Princeton Architectural Press, 1999. Print.

Jaskiewicz, Tomasz. Towards a Methodology for Complex Adaptive Interactive Architecture. Diss. Delft University of Technology, 2013. Google Scholar. Web. 11 Aug. 2013.

Moloney, Jules. A Morphology of Pattern for Kinetic Falccades. University of Melbourne, Melbourne School of design, 2009. Google Scholar. Web. 13 Aug. 2013.
Ottchen, Cynthia 'The Future of Information Modelling and the End of Theory: Less Is Limited, More Is Different'. Architectural Design 79.2 (2009): 22-27. Wiley Online Library. Web. 11 Feb. 2014.

Schumacher, Patrik. 'Parametricism: A New Global Style for Architecture and Urban Design" Architectural Design 79.4 (2009): 14-23. Wiley Online Library. Web. 15 Nov. 2013.

Sterk, Tristan. 'Using Actuated Tensegrity Structures to Produce a Responsive Architecture'. ACADIA22. 2003, Indianapolis. Google Scholar. Web. 8 Nov. 2013

Sterk, Tristan. 'Shape Control in Responsive Architectural Structures-Current Reasons \& Challenges'. 4 World Conference on Structural Control and Monitoring. San Diego, 2006. Google Scholar. Web. 8 Nov. 2013.

Sterk, Tristan et al., eds. 'Building a Better Tomorrow : Proceedings of the 29th Annual Conference

of the Association for Computer Aided Design in Architecture'. Association for Computer-Aided Design in Architecture. 2009, Chicago. CUMINCAD. Web. 8 Nov 2013 


\section{Appendix}

A selection of the animations made for this thesis can be found at the following URL: http://www.youtube.com/channel/UCBTTCRROgqtorLzxcU6_BpA

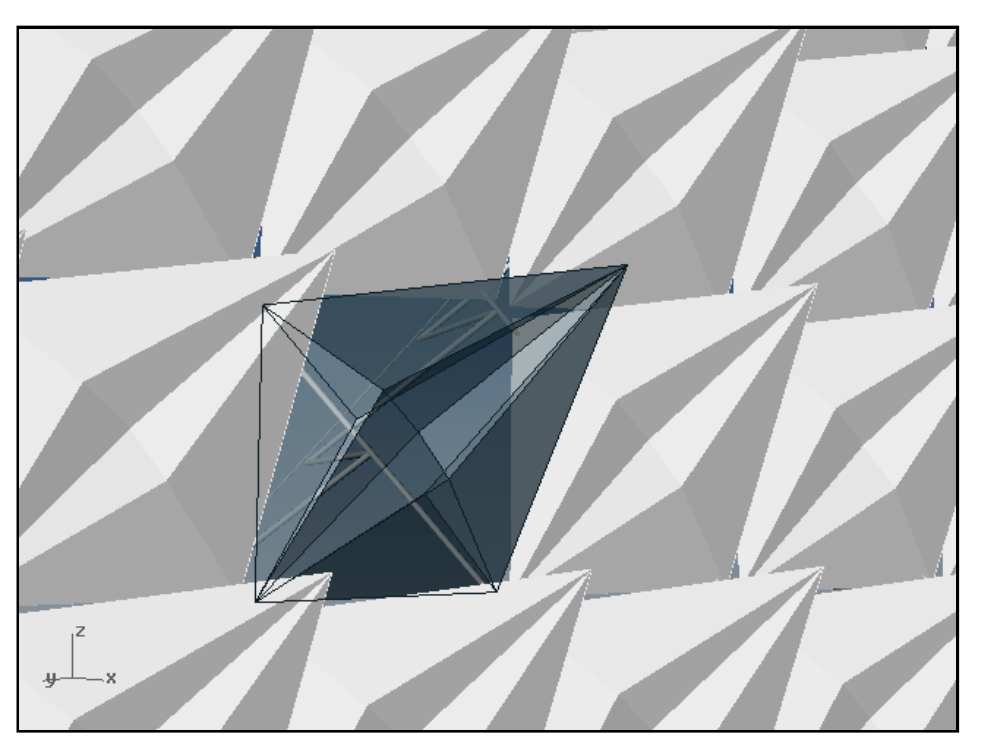

Panel being modified in grasshopper. The top left point of the panel is being translated $200 \mathrm{~mm}$ to the left.

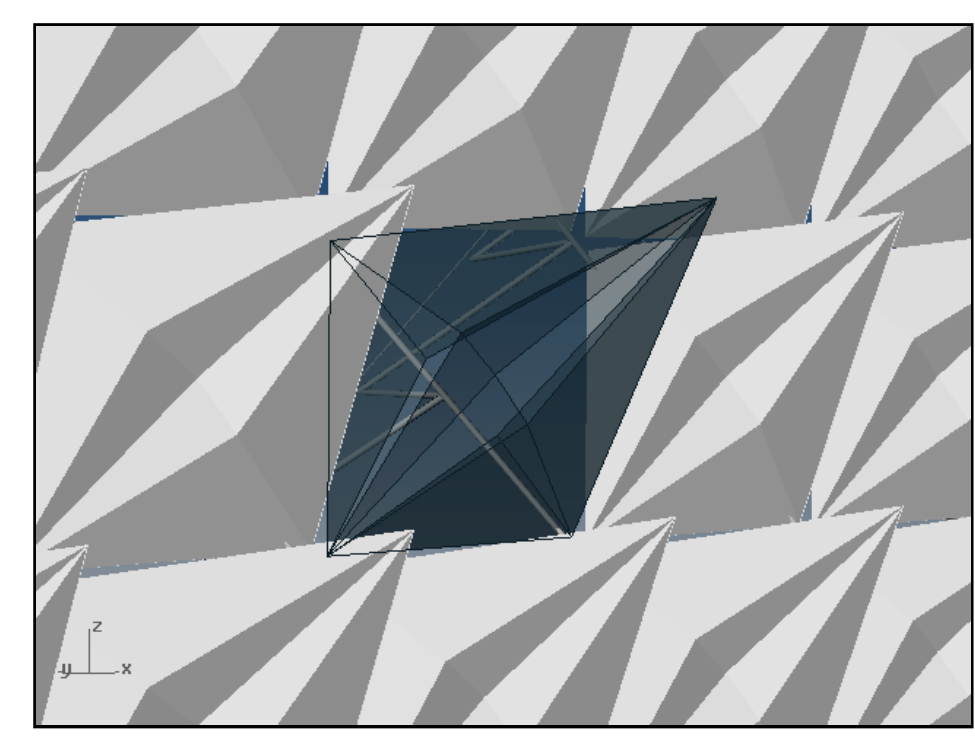

Panel being rotated in Grasshopper. This was being done to test the clearances between panels.

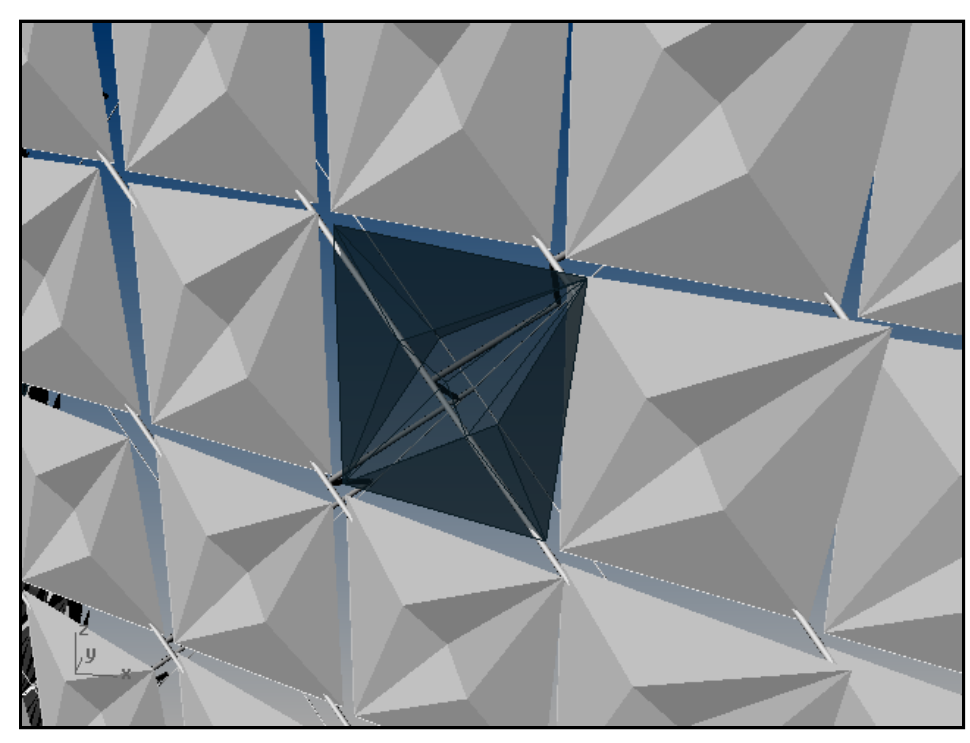

Panel being rotated in Grasshopper 2 . 


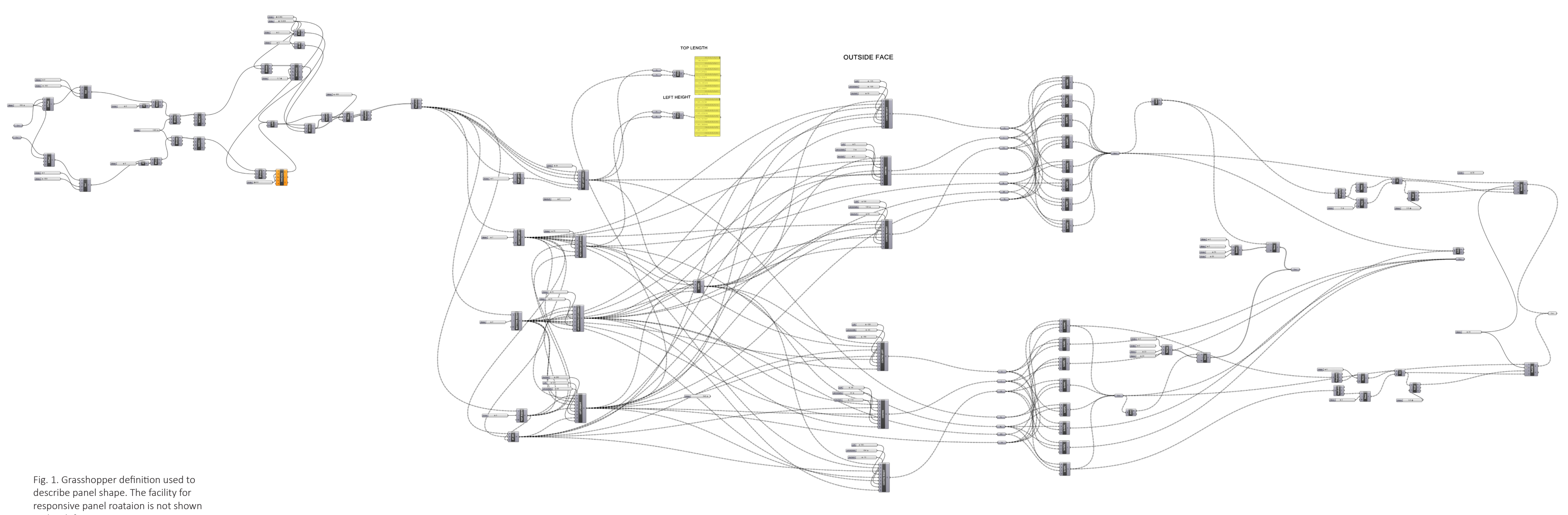




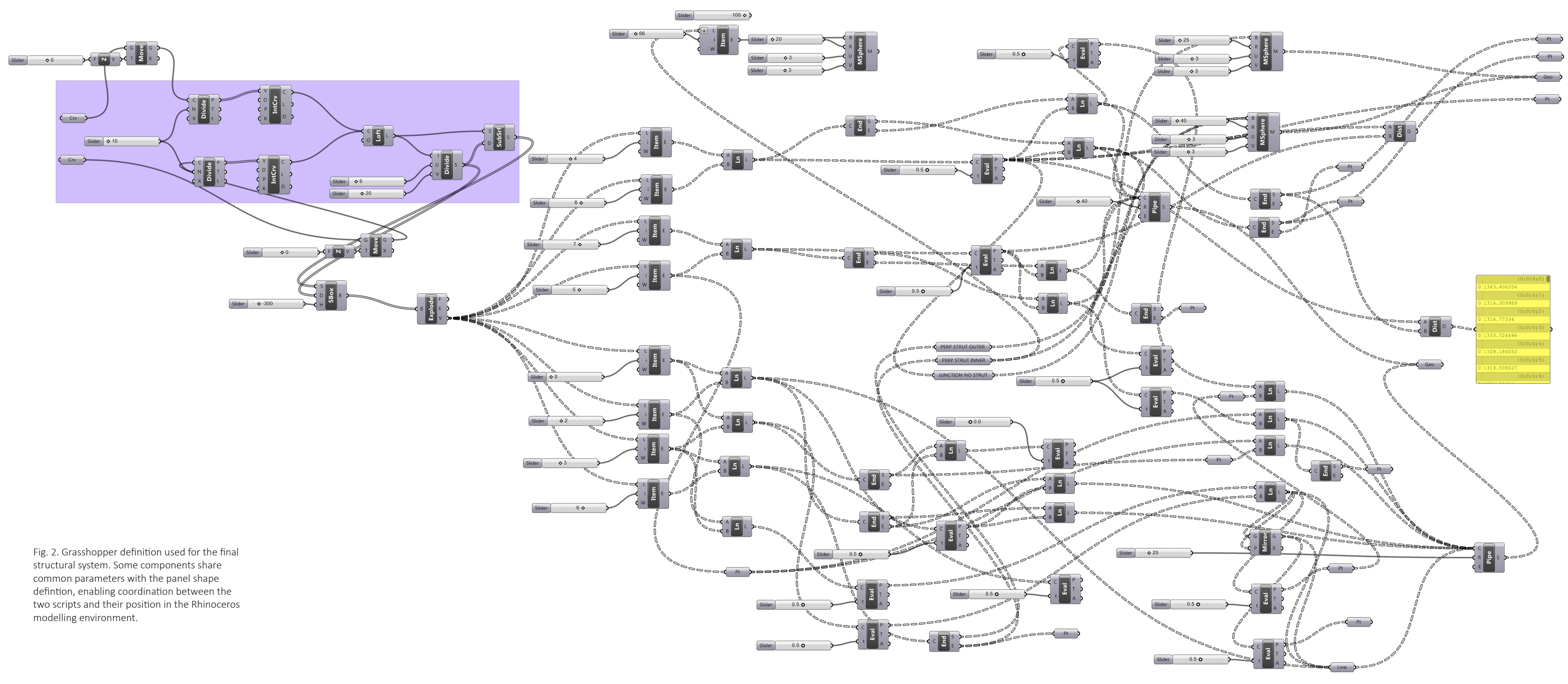




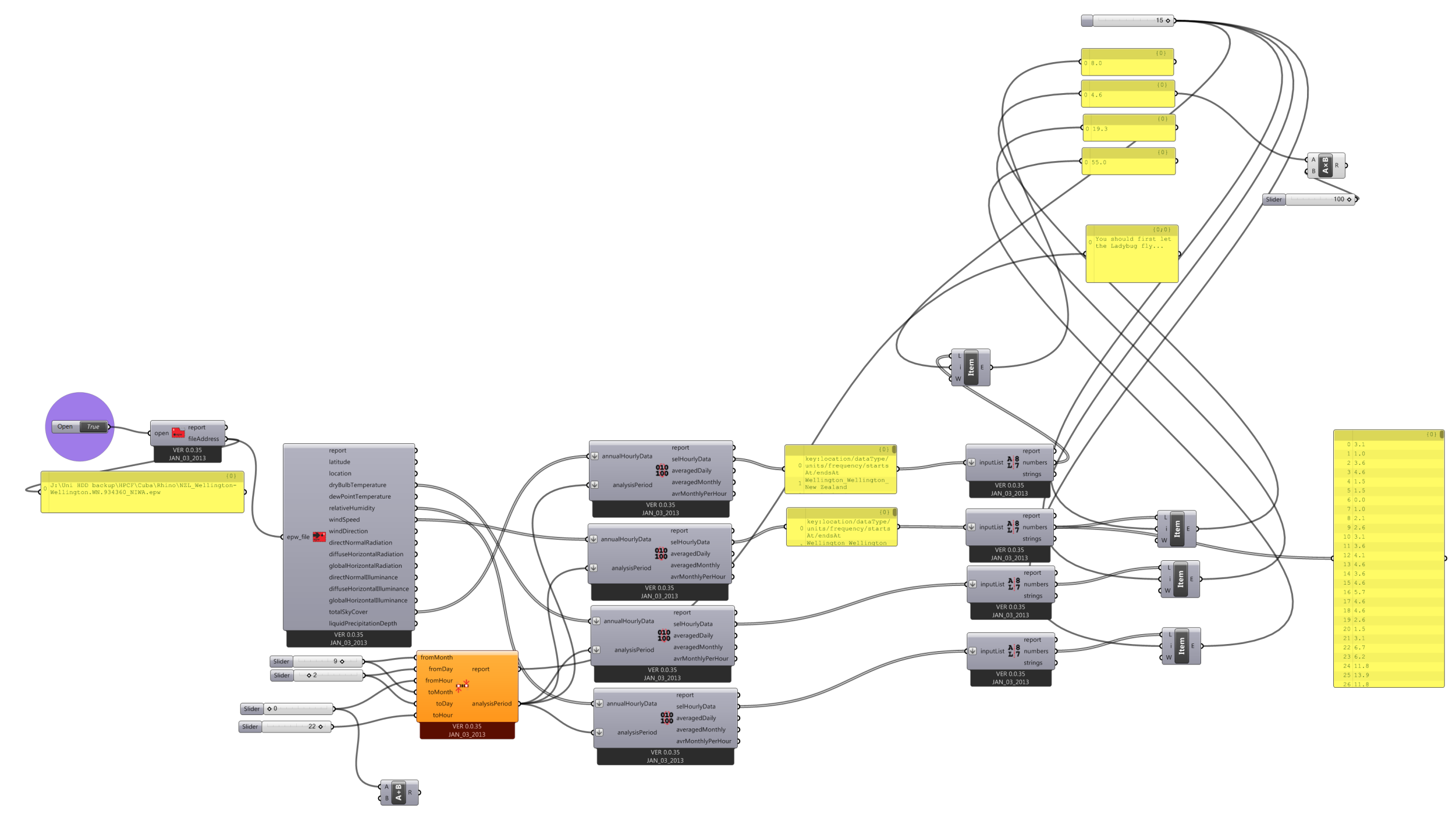



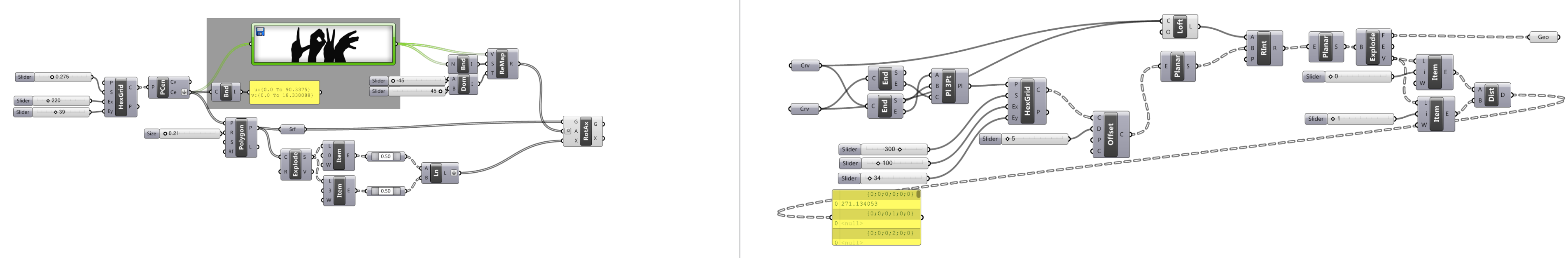


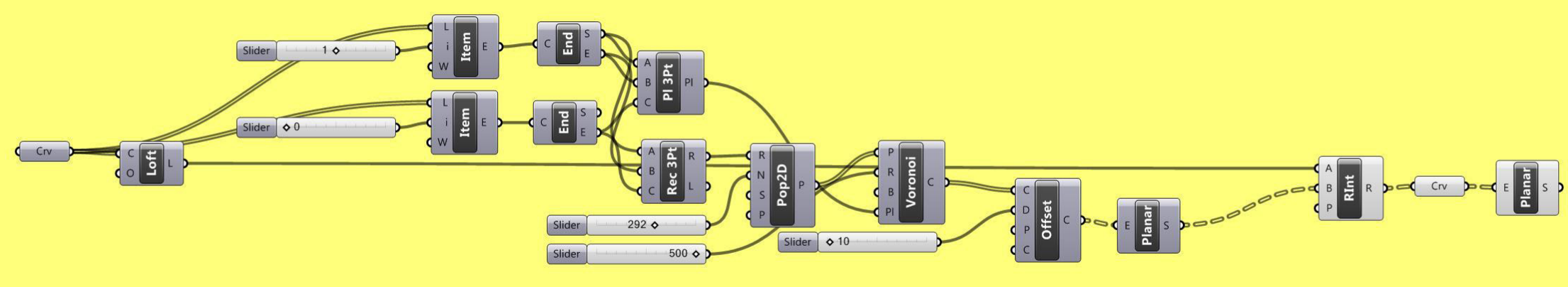

